\title{
The New York Botanical Garden BRONX PARK
}

\author{
A GUIDE \\ to \\ The PINETUM
}

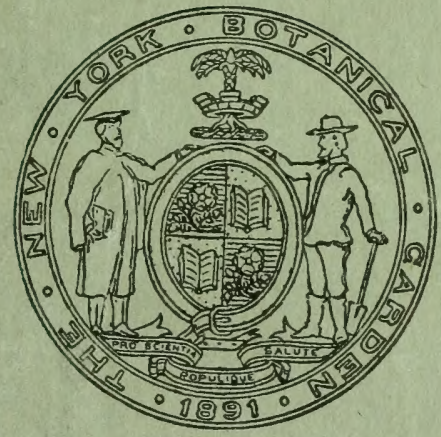

NEW YORK

SEPTEMBER

1929

Price 50 Cents 


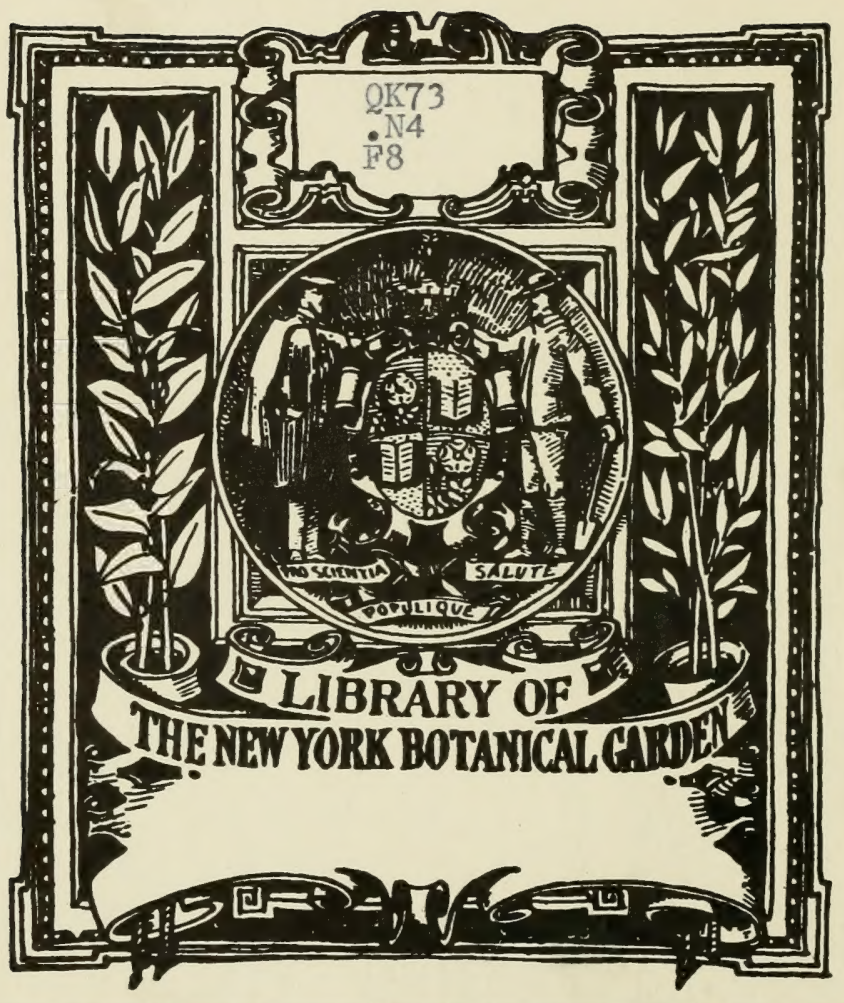






\title{
The New York Botanical Garden BRONX PARK
}

\section{A Guide to The Pinetum By EDMund H. FULling}

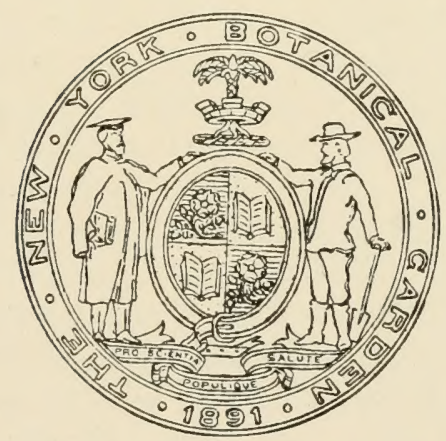

\section{A Separate Issue of}

Bulletin of The New York Botanical Garden, No. 51

\author{
NEW YORK \\ SEPTEMBER \\ 1929
}

PRICE 50 CENTS 


$$
\begin{aligned}
& Q \times 73 \\
& . N 4 \\
& F 8
\end{aligned}
$$




\title{
BULLETIN
}

$\mathrm{OF}$

\section{The New York Botanical Garden}

\begin{tabular}{lc}
\hline \hline Vol- 14 & No. 51 \\
\hline \hline
\end{tabular}

A GUIDE TO THE PINETUM

By Eduund H. Fulling

\author{
INTRODUCTION \\ I.-TO THE USE OF THE GUIDE
}

This Guide has been prepared for the purpose of supplying to students and others concerned some of the most interesting and important information regarding all the kinds of coniferous trees growing in the Garden. About 3,000 of these trees, consisting of approximately 225 different kinds, have gradually been collected. They are planted according to two schemes.

In the one, they are in groups botanically known as genera, such as the Pines, the Spruces, and the Hemlocks. Each genus, in turn, consists of one or more species as Red and White Pine, Norway and Tiger-tail Spruce, and Canada and Japanese Hemlock. All of these coniferous trees put together constitute the section of the Garden known as the Pinetum. This is the area treated in the Guide.

In the second scheme, the trees have been mixed in various places to form decorative plantings in which two or more genera may occur. These plantings are to be described elsewhere.

In the Pinetum there are eighteen different genera of trees and the Guide is divided into as many parts. The location of these genera will be determined from short descriptions and by maps. The latter indicate a starting point and a suggested route of progress through each group of trees. They also bear the names of some of the trees on the various areas. Obviously, the size of these maps does not permit mention of all the trees. Consequently, those that are indicated should serve as guides to others associated with them and mentioned in the text. 
A few other points should become well fixed in mind:

1. Since the entire Pinetum lies south of the Museum, the direction "north" always means generally toward the Museum from any point where it may be given. Correspondingly, "south" will always be in the oposite direction, "west" to the left and "east" to the right, if one faces north.

2. The term "ahead" means in the general direction of travel as indicated on the maps.

3. The Guide endeavors to mention every individual needleleaved tree that lies in the course of travel, but disregards all the broad-leaved trees, except one, that may be encountered. That one is the very first in the Guide, Ginkgo. Consequently, the Guide must be followed carefully that no trees are missed. If confusion does occur (which may happen through changes that time will bring), one may go ahead until he meets the next unquestionable tree and then work backwards.

4. Every tree in the Garden has been provided with a copper tag, $3 \mathrm{r} / 2$ inches long, which bears the tree's name. These tags hang on some branch at convenient height and always serve as a check.

5. If one wishes to see a particular kind of tree he must consult the index and find the page on which that tree is described. Then by turning back he will find the Section containing the tree and reference to a map locating it. The name of the tree may appear on the map and if not, he can find the tree by tracing through the section until he arrives at it.

Each group or genus of trees is considered in this Guide, first, by a specific consideration of the trees as they stand in the Garden. Then follows a general discussion of the genus as a whole.

Certain limitations must be appreciated in using this Guide:

1. It is obviously impossible to furnish all the information that every class of reader may desire. The trees are treated from the viewpoint of their popular identification, their economic and ornamental use and other interesting relationships. This information may prove sufficient for some and should serve as a stimulus for further investigation on the part of others. The Garden maintains a very large botanical library and a collection of many thou- 
sand dried plants. Both may be freely consulted by anyone interested.

2. The names of plants in many cases have not become sufficiently standardized to give any one name precedence over others. All nomenclature and systems of classification are merely very painstaking attempts on the part of botanists to systematize our knowledge of over 160,000 different kinds of known plants. This figure does not include possibly 150,000 different kinds of "flowerless" plants, such as ferns, fungi, and algae. In the great majority of cases the scientific name of a particular kind of plant is sufficiently well established to carry no ambiguity as to what plant it covers. Common names, on the other hand, are very frequently misleading. It is a common thing for a tree to have a dozen different popular names and for the same name to be applied to several distinctly different trees. Scientific names have greater precision. But even they, too, once in a while, are confusing. Standard books on plants, however, usually list most of the scientific names by which a plant has ever been known and this assists in applying names correctly.

The greatest confusion of names occurs, probably, in the many horticultural varieties of Arbor-Vitae and "Retinospora." This will be mentioned again in the descriptions of these plants. The names given in this Guide have been selected more or less arbitrarily as best suited for the occasion. Ninety percent of them will cause no confusion at all.

A few definitions are in order here. The expression "species," as generally understood and used in this Guide, means a particular kind of plant found wild somewhere on the earth. Since the application of the term is purely man-made and since no two plants, however similar, are exactly alike, there sometimes arise questions as to whether or not two plants are sufficiently similar to receive the same name. If, in the opinions of experts, and they may differ, the differences are insignificant, then the two trees are regarded as one. If the difference is somewhat greater, one tree may be regarded as a variety of the other, and if their differences are great they are considered as two entirely different species. 
In this Guide the term "variety" is applied to two different types of trees. The concealed distinction should, however, be borne in mind. In the one case it refers to natural variations that occur in the wild and which may be found in any batch of seedlings. An example is the well-known Colorado Blue-Spruce. Seeds from this tree will yield a mixture of green, "blue," and intermediately colored trees. This is the only strictly correct application of the term "variety."

Most of the so-called varieties in the Garden, however, are not true varieties. They do not occur in the wild from seedlings but have originated in another way. At various times and at various places, an individual plant of a wild species has produced an odd type of foliage, often on only one or two branches. When this occurred under the observation of gardeners, those odd twigs were usually removed and rooted in sand. By careful culture those cuttings grew into large plants whose entire foliage showed the character of the original odd twig. Once established in this way, thousands of plants have since been produced from the one original without the intervention of seeds. Such plants may be continuously either male or female or may have both sexes of flowers on them. Taken collectively, they are properly known as a "clon" rather than a "variety." The big majority of horticultural "varieties" among the evergreens are really clonal variations. The distinction, however, is not made in each case in this Guide.

3. Inaccuracies may occur in the Guide where trees mentioned are not to be found and, conversely, where trees found are not mentioned. This cannot be avoided, for occasionally a tree dies and must be removed; or, new trees are planted. Obviously, all these changes cannot be accounted for. However, they are not frequent and the liability of confusion from them is rather small. Newly planted trees are usually young and small. Some large old tree will generally serve to indicate approximately where the text may have become inaccurate.

II.-TO THE TREES DESCRIBED IN THE GUIDE

The trees described in this Guide are those which are commonly spoken of as evergreens, e.g., Pines, Spruces, Hemlocks, and 
Cypress. They are characterized, as a whole, by having needlelike or scaly leaves. There are other totally different evergreen plants, such as the Rhododendrons and Live Oaks whose leaves are broad and blade-like. Furthermore, the evergreens under consideration here are commonly known as conifers, for their fruit is a cone, which harbors the seeds. Coniferous evergreens, then, are, in general, the trees we shall consider.

But just as some evergreens are not conifers, so, some conifers are not evergreens. We shall meet three different kinds of conebearing trees which lose their leaves in autumn, the Bald-Cypress, Larch, and Golden Larch. And we shall see a tree which has broad leaves that are not evergreen and which does not bear its seeds in cones, the Ginkgo.

What, then, is the feature that justifies considering all these trees as a group? It is this. They all have true seeds and so have long been known by botanists as Spermatophytes or Seed-bearing Plants. Ferns, Mosses, Fungi, and Algae have no "seeds." But apple trees, peas, and pansies, among thousands of other plants, also have seeds, but we do not consider them here. The difference is that among approximately three hundred thousand different kinds of known seed-bearing plants all but about five hundred have their seeds imbedded in a pulp, capsule, or other container. The apple seed, for example, is inside the apple and a pea grows within a pod. All such plants are known as Angiosperms. The remaining five hundred do not, as a rule, have their seeds enclosed and these are known as Gymnosperms. The pine seed, for example, grows at the base of a cone scale, but is not enclosed in anything when ripe. This is the group to which all the plants described in this Guide belong.

The cone-bearing trees, which constitute almost all the Gymnosperms, are widely distributed throughout the world. Many are ('ssentially tropical or so dependent upon local conditions that they cannot be grown outdoors here. The conifers of the north temperate zone, particularly the pines and spruces, supply the bulk of the world's lumber. In this country alone two-thirds of the lumber production is coniferous, or "soft-wood," as the trade refers to these trees. 
During recent years coniferous evergreens have greatly increased in value as ornamental plants and this is the phase of their use considered primarily in this Guide.

Among the Gymnosperms or naked-seed-plants, the Ginkgo is the only non-cone bearing tree hardy enough to be of ornamental value here. Other coneless Gymnosperms, together with tender coniferous evergreens, may be seen in the greenhouses. 


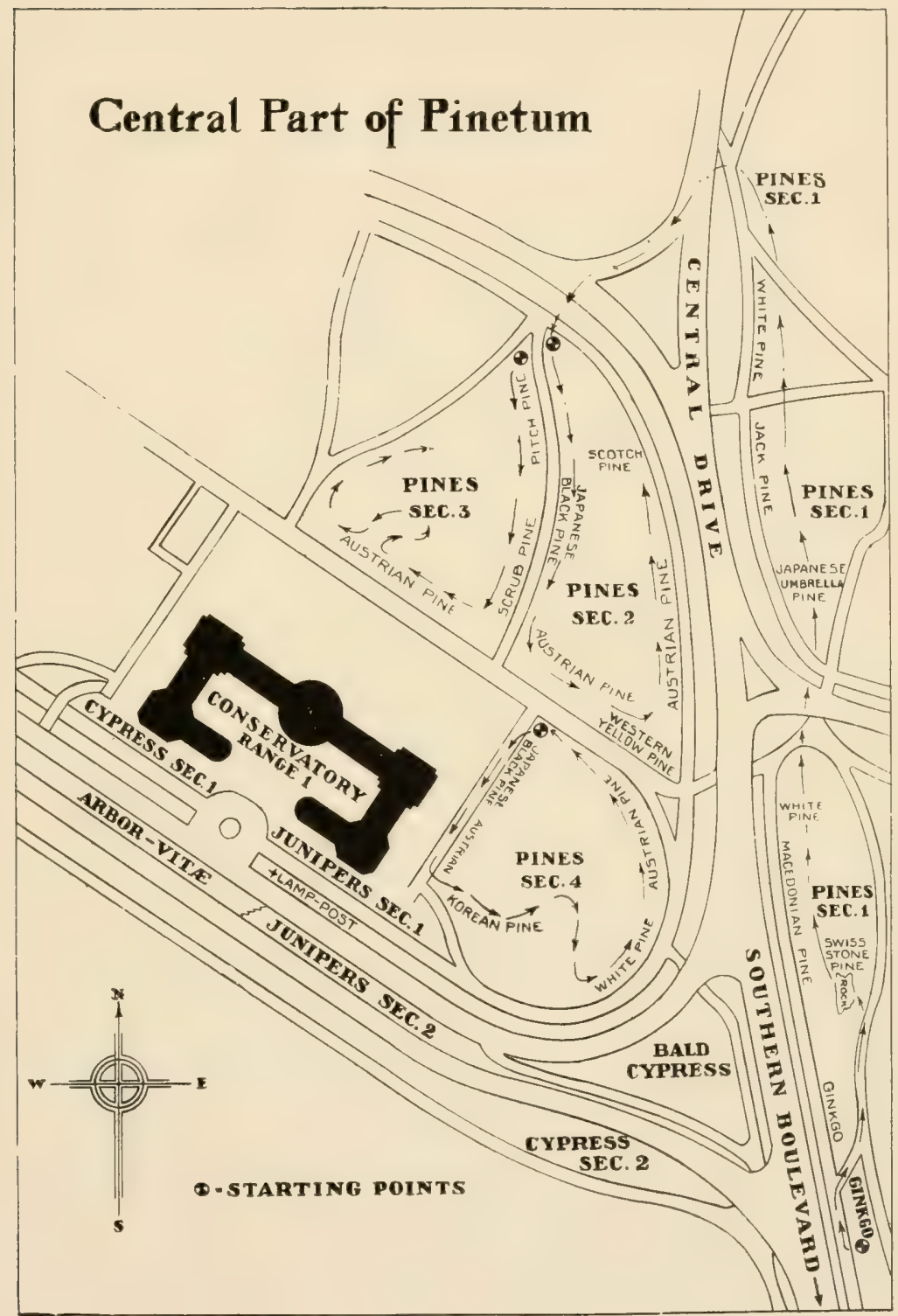




\section{PART I-GINKGO}

\section{A "LIVING FOSSIL" FROM PREHISTORIC TIMES}

\section{AN INSECT- AND FUNGUS-lREE ORNAMENTAL TREE}

Starting on the eastern side of the Central Drive as it enters the Garden from Southern Boulevard and on the inside of the foot path along that sicle of the drive, we come to the first trees that we shall consider in following this Guide. (Map p. 7).

Three trees stand in a row just inside the low railing along the path. Behind them, scattered over the higher ground, are five more, similar trees. In winter their light-colored bark and few but widely projecting limbs are their outstanding characteristics. The numerous short spurs on these limbs bear wedge-shaped leaves in summer that distinguish the trees from others about. The trees themselves do not look at all like conifers. In fact, they are not true conifers, though in books one sometimes finds them described under Coniferae. They bear no cones, neither are they evergreen. They are trees that stand by themselves in the entire plant world and are known as

\section{Ginkgo biloba, the Maidenhair Tree}

The drive on the west side of the Musetum is partially lined on buth sides by these trees. Some of them are considerably larger than the ones before us now.

The Ginkgo is one of the most interesting of trees, for it is the sole survivor of a once great family that thrived in prehistoric times. Is one writer has very appropriately pointed out, there is probably no other existing tree to which Darwin's term of "living fossil" may be so truly applied as the Maidenhair Tree. It is regarded as the oldest living type of tree, that is, in terms of plant evolution. It is closely related to no other living plants and is the only survivor from a type of vegetation that flourished during what is known as the Mesozoic Era. Its range extended then from what to-day is Australia, Cape Colony, and South America to northern Europe and Greenland. To-day it is nowhere known in the wild state. 


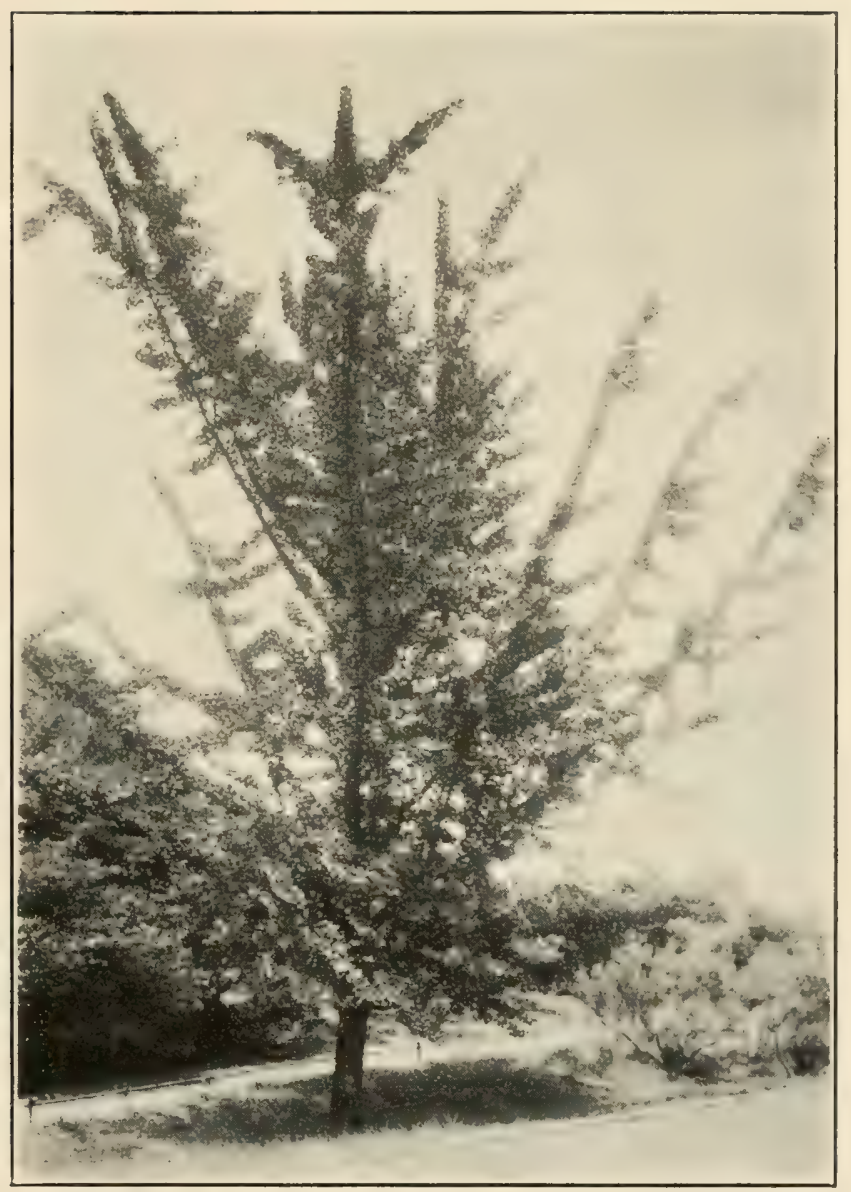

Figure 1. Maidenhair Tree Ginkyo biloba 
Two very interesting questions naturally arise here: "What became of the relatives associated with the Ginkgo in prehistoric times?" "Why has the Ginkgo alone survived?" Any answer would be necessarily speculative and would be too involved for discussion here. The only thing that we know with reasonable assurance is that the Ginkgo, which we regard as a native of China, was preserved for us by the timely intervention of the Buddhist and Taouist priests. For long ages it has been cultivated about temples and shrines, court gardens of palaces and great mansions throughout China as well as in Japan, where it was probably introduced. It has been sought for by botanists in China but there is no authentic record of its existence outside of cultivation. We must then give thanks to the priests of ancient times who snatched this splendid tree from extinction at some remote date and preserved it for us.

From the Orient the Ginkgo was introduced into Europe and then brought to this country, probably sometime during the late eighteenth or early nineteenth century. To-day it is very widely planted as an ornamental tree and has proved well worthy of great use. In addition to its striking shape and attractive form, its principal asset is its possession of an unusual combination of characters scarcely to be found in any other tree. It is, so far as we know, free from both insect and fungous attack. Moreover, it is apparently unaffected by the poisonous gases and smoke common about cities and so fatal to many native trees. Finally, it is quite hardy as far north as Massachusetts, lower Canada, and southern Minnesota and thrives on a variety of soils.

The only objection that is sometimes raised against the Ginkgo has its basis in the disagreeable odor emitted by the fallen fruit. The fruit (really a seed) resembles a small yellow plum and its fleshy covering is rich in butyric acid, which gives an odor of rancid butter. This bad feature is apparent, however, only when the seeds have fallen and is scarcely noticeable while they are still on the trees. Furthermore, seeds as a rule are not borne until the trees are from 25 to 40 years of age. In addition, the fruit has been found to be poisonous to some, causing a very severe skin irritation similar to ivy poisoning in many respects. The 
poison is in the outer fleshy layer. These two objections, however. may easily be avoided. Since the Ginkgo has the male and female flowers on different trees, the selection of male trees for planting eliminates the fruit. Notwithstanding statements to the contrary, it is practically impossible to distinguish between male and female trees by habit or foliage. The appearance of the flowers or fruit alone separates them. Though propagation hy seed kept over winter and planted in the spring is quite successful, the percentage of male and female trees that will result cannot be foretold. Grafting or budding of known male stock is the recognized method of securing desirable material.

This same fruit, however, contains a sweet kernel which in China is roasted or eaten raw and highly esteemed as a dessert nut, supposedly having digestive properties. It is sold in China as pa kwo. In Washington, D. C., where many of these trees have been planted, the Chinese laundry men gather the fallen fruit for food.

The soft, straight-grained, light-brownish wood with a silky sheen is used for making abacus beads, seals, and other small fancy articles in China. In Japan it is extensively used for the ground work of lacquer ware and in the manufacture of chess hoards and chess men. The Japanese use the leaves for fertilizer. especially in rice fields under water. Moreover, they ascribe to the leaves an insecticidal power and the leaf of the Ginkgo used as a bookmark, it is claimed, keeps away insects that attack books. Generally, however, the Ginkgo in the Orient has been associated with sentimental tradition and consequently it is not much used commercially.

Botanically, the tree is unique among living plants, ${ }^{*}$ for it bears affinities with the conifers on the one side and with the ferns on

\footnotetext{
* In all seedless plants, such as ferns, mosses, and algae, fertilization of an egg cell. when it occurs, is usually accomplished by means of motile sperm cells. Moisture is required at some point for these sperm cells to swim in by means of their moving lairs. This is a very dominant feature in these lower and less highly organized plants. In the seed plants, in general, however, the sperm cells are not motile but are produced in pollen tubes that assist the mechanics of fertilization. That is the process in perhaps ninety-nine per cent of the plants that ordinarily come to our attention. But there are two kinds of trees out of all the one hundred and sixty thousand kinds of seed plants known that show the primitive way of fertilization by motile sperm cells. One is the Cycad group and the other is the Ginkgo. The singular occurrence of this mode of fertilization in the Ginkgo is the most interesting feature of the tree to the botanist. The details of it cannot be discussed here.
} 
the other. The Ginkgo obrionsly is a woody tree in every sense but one strange feature about it is the renation of the fan-shaped leaves. The veins extend in radiating lines to the upper border of the fan, as can easily be observed. Such venation, generally absent in other gymnosperms, may be indicative of some affinity with the ferns. It is, therefore, regarded as a transitional stage in the process of plant evolution from the lower more primitive and seedless plants to the more highly developed seed plants. The same applies to the matter of fertilization mentioned in the footnote.

The Ginkgo may attain a height of 100 feet and an age of 1000 years. Its name has come from the original Chinese term for this tree, while the common name, Maidenhair Tree, arises from the resemblance of the wedge-shaped leaves to the pinnules of the Maidenhair Fern, Adiantum. The flowers appear in April or the beginning of May and fertilization occurs in September.

Let us now follow the path that branches eastward from the main one we are on. It very soon meets another which we shall follow to the left. On our left now and extending a bit ahead we should notice five more Ginkgos of various heights. The first of these at the junction of the two paths is particularly narrow. It is one of the several horticultural varieties of this tree, and is known as the Columnar Maidenhair Tree, G. biloba var. pyramidalis.

We shall now go up the path we are on, which is parallel to the road and passes over the small ridge. The Ginkgos are on our left. The last of them is the smallest and quite undereloped. Just beyond we come to the first true conifers, the Pines. 


\section{PART 2-PINES}

THE WORLD'S GREAT TIMBER TREES

VALUABLE LARGE ORNAMENTAL EVERGREENS

\section{Section 1}

Section 1 of the Pines is that portion of the Pinetum, not including the Maidenhair Trees, that borders the Central Drive on its eastern side from the Southern Boulevard entrance to a point opposite the Museum. It hegins with the first evergreens near the last of the Ginkgos. (Map p. 7).

In order to view these first pines, let us stand on the highest point of the rocky formation that lies at the north end of the Ginkgos and at the beginning of the Pines.

The three similarly shaped trees to the extreme left are

Pinus Cembra, the Swiss Stone-Pine

Omitting the next taller tree to the right, the seven similar compact trees nearest the foot of the rocks more to the right are also Swiss Stone-Pines. Most prominently we notice the very compact, symmetrical, and rounded-pyramidal contour of these trees, a very pleasing feature that makes them highly desirable for ornamental use. It is a youthful shape assumed in cultivation, whereas, naturally, older trees are of taller and less compact habit. They are exceedingly hardy and slow of growth.

The Swiss Stone-Pine or, as it is sometimes called, the Arolla or Alpine Pine, has a very extended natural range. It is found in the central European Alps from Savoy to the Carpathians, and in northeastern Russia and northern Asia. In the valleys of the higher Alps it is the only tree capable of withstanding the elevation and intense cold. Herdsmen, as a result, have destroyed whole forests of these trees for firewood and today they no longer are so abundant as formerly. However, they still cover immense tracts of country in Siberia, Tartary, Italy, and Switzerland, reaching to an altitude of 6,000 feet in the Alps. In Siberia they become a dwarfed variety, pumila, and extend as far east as northern Nippon and Kamschatka. 
The seeds of the Swiss Stone-Pine are nearly as large as hazel nuts, edible, and are much relished in Russia and Siberia. In that country the gathering of them constitutes quite an industry. From the shells, an oil is sometimes expressed that is used for fuel in lamps. Squirrels, too, are fond of these seeds. For these reasons the cones seldom remain long enough to yield mature seeds. One record, nearly a hundred years old, states that the kernels of the seeds furnished an important part of a Swiss dessert, and that an essential oil was obtained by distillation from the young shoots of this tree after they had been macerated and steeped in water for $\mathrm{z}$ month. The liquid whitish oil thus obtained was known as Carpathian Balsam and in Germany was believed to possess extraordinary health-giving qualities.

The wood of this tree is of considerable economic value in alpine regions where it is native. It is white, soft, and finegrained, with an agreeable odor that is obnoxious to insects. It is consequently used for lining clothes-closets in addition to its use for wainscotting, upholstery, cahinet making, and turnery work; it takes paint and polish well.

The cones, which at first are purplish violet, later becoming brown, never open but fall when mature. The scales must rot away or he removed by man or beast to liberate the seeds. The needles are in groups of fives and the whole foliage is characteristically tufted. It is the only five-needle pine found wild in the Alps. Most distinctive of this tree is the prominent dense yellowish-brown hairiness on the young branchlets. The only other fiveneedle pine with which this one may be confused is the Korean Pine, $P$. koraiensis ( $\mathrm{p} .42)$. In the latter the shoots are similarly hairy but the leaves are stouter and the teeth on their margins are more numerous and extend to the tip. The cones, moreover, are distinctly longer. The hairiness on the current-year shoots serves to distinguish the Swiss Stone-Pine from the next species,

Pinus Peuce, the Macedonian Pine

The remaining seven pyramidal trees in the group are of this kind. The first of them is just to the right of the first three Swiss Stone-Pines. These Macedonian Pines, too, are very fine, 
but have a less rigid foliage, not so tufted and bushy, and the young branchlets usually show a smooth yellowish surface.

This tree has a very much more restricted range than the Swiss Stone-Pine. It is a native of southeastern Europe, being confined to three small areas in Macedonia, Bulgaria, and Montenegro, at elevations ranging from 2,500 to 6,000 feet.

From the contrast displayed in the planting it might be supposed that the Swiss Stone-Pine is normally smaller than the Macedonian. Both, however, may attain to a height of 100 feet in their native ranges. The Macedonian Pine, too, is a five-needle pine and together with the Stone Pine and the native Eastern White-Pine that we shall soon meet is regarded as one of the best five-needle pines for northern regions as far as Ontario, Canada.

The wood of this tree, though straight-grained and easy to work, has little commercial value outside its native country, and even there the difficulty of its extraction limits its usefulness. In this country the tree has only ornamental value.

One more pine tree in this group remains unmentioned. It stands farthest to the right and is of a very different shape from all the others in having spreading branches and a less compact habit. It is

Pinus parviflora var. pentaphylla, the Japanese White-Pine

We shall meet other specimens of this tree and gradually notice certain distinguishing features about the leaves-their short tufted habit at the ends of the branches, a certain delicateness about them and their glaucous hue. Their shortness and whitish lining serve to distinguish this one from other five-needle pines. Moreover. the flat-topped head is characteristic of mature trees. It is one of six different pines native to Japan and is the Japanese representative of our Eastern White-Pine.

The Japanese White-Pine is not normally a tall tree, averaging from 40 to 60 feet in height, though occasionally it may attain 90 feet in the forests of Japan. In cultivation, however, it seldom is over 20 feet high. To the Japanese it is known as Goyo-matsu and Hime-komatsu. Its wood is used for general 
construction purposes in Japan, and the trees themselves are extensirely cultivated for ornamental purposes. They are the favorites of the Japanese gardeners for pot culture and are dwarfed and trained into many kinds of fanciful shapes. These gardeners graft this pine and others on the stock of the Japanese Black-Pine, $P . T h u m b e r g i i$ (p. 28), which tree we shall see later. This operation of grafting a soft on a hard pine is, as a rule, unsuccessful. But in the hands of those skilled workers the natural incompatability is partially overcome and the stunting results in the odd forms we recognize as Japanese.

This species, though it grows wild in Japan, seems to have been named a variety, var. pentaphylla, of the tree which is much cultivated in Japan, $P$. parififora. This apparent departure from the usual practice in horticulture according to which varieties are generally named as forms of the wild type probably arose from the fact that the cultivated form might have been known and studied before its wild form was described.

Leaving, now, our position on the rocks, we shall walk through the group toward the evergreens farther ahead. Just beyond the last Macedonian Pine we pass a splendid black gum tree, leafless in winter, which in its beautiful autumnal coloration is one of the choicest sights in the Garden. To the left are a few elm trees. Just beyond and to the right of the black gum stands our next evergreen, one of open formation and very different habit from the close growth of the Stone Pines and Macedonian Pines. Its leaves are slender, quite long, grayish or bluish green and droop pronouncedly. Right ahead of us in a diagonal line with it are two others. These trees are

\section{Pinus nepalensis, or $\mathbf{P}$. excelsa, the Himalayan White-Pine}

This tree is native to the temperate Himalayan region at elevations ranging from 6,000 to 12,500 feet between Nepal on the east and Afghanistan on the west. In its native habitat it attains a height of 50 to 150 feet and is one of the important timber trees, furnishing lumber for a great variety of purposes. Its fairly hard and durable wood works and finishes well. First class rosin and turpentine are obtained by distillation of the resin secured by 
tapping. In fact, next to Cedrus l) codara, the Deodar, this Bhutan Pine, as it is sometimes called, is the most important coniferous tree of its region. The roots yield an oil used to anoint the arms and legs of natives as a protection against water insects while they work in the wet rice fields. During the dry winter seasons there is a copious sweet manna-like exudation from the leaves which is collected and eaten by the natives.

This species, with five needles in a cluster, is distinguished from all other pines of that class by its large horizontal lower branches and long drooping needles. These two features will become more apparent when we meet larger trees in Section 4. There we shall see that because of the persistence of the lower limbs that hany close to the ground and turn up at their tips this tree must be given plenty of room in ornamental planting. The pendent leaves that droop from the lower limbs of mature trees are especially attractive.

All the remaining eleven pine trees in this immediate area as far as the road ahead of us, including one that is separated from all the others by the diagonal row of three Himalayan WhitePines, are

\section{Pinus Strobus, the Eastern White-Pine}

This is the only five-needle pine native to the eastern United States, where since the advent of the Pilgrims it has been the most valuable forest tree. The vast forests of it that once covered the northeastern section of the country as well as a good part of the Lake States were the bulwarks of this country's early industries. But these vast forests no longer remain, for they have for the most part fallen before the axe. From 1620 to 1840 , white pine was the chief timber of New England, and during that periorl the reserve was reduced from 400 billion board feet to 10 billion feet, a reduction of $97 \mathrm{1} / 2 \%$. In 1892, after lumbering had shifted to the wonderful white pine forests of the Lake States, 10 billion feet were cut and since then the annual production has steadily decreased. This gives some idea of the inroads that have beeil made on a great natural resource. 


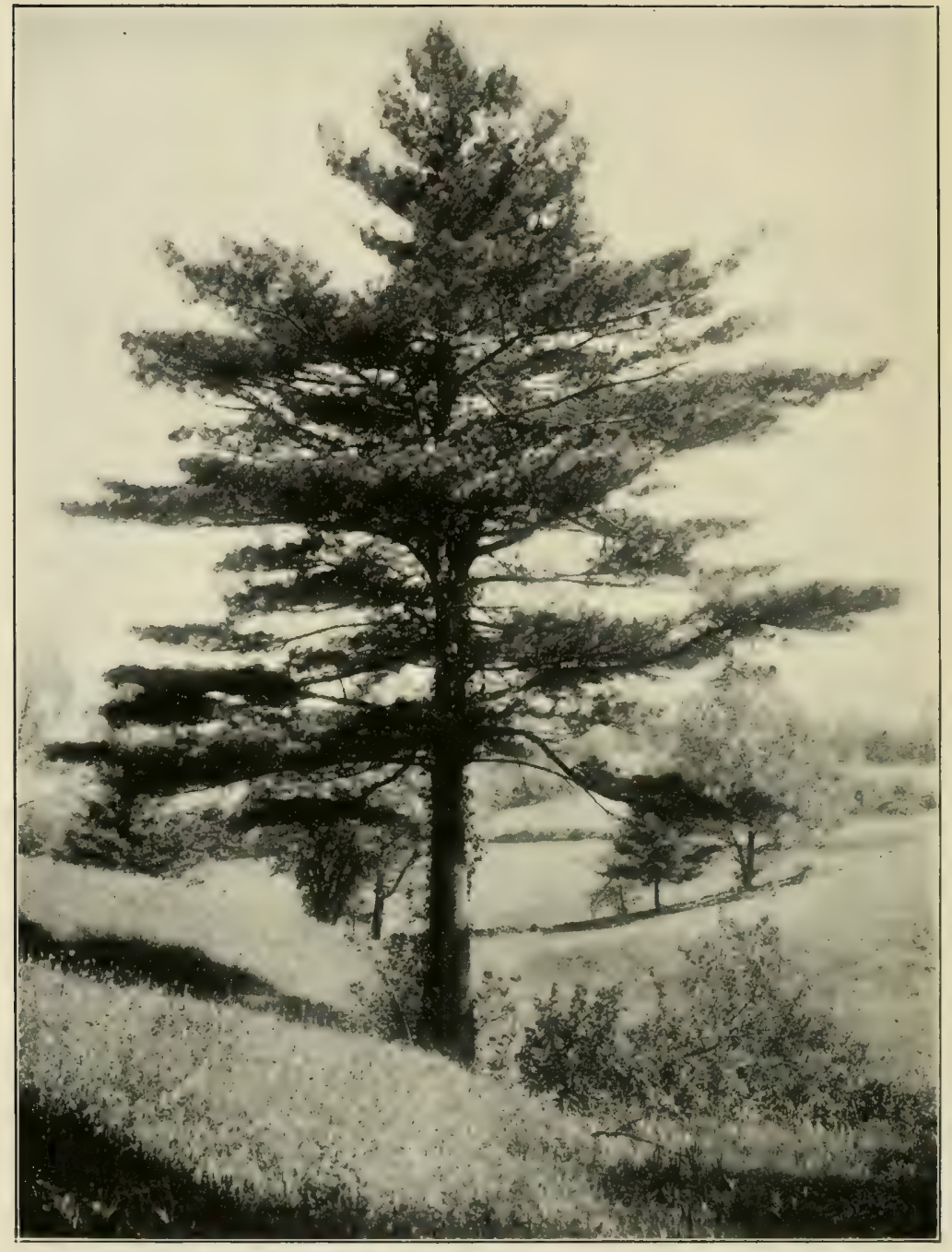

Figure 2. Eastern White-Pine Pinus Strobus 
Pimus Strobus is a native of eastern North America, extending from Newfoundland to Manitoba and throughout the Uniter States from Minnesota to the Atlantic and south along the Apralachians to northern Georgia. It is the tallest conifer east of the Rockies and records exist of trees up to 260 feet in height and 20 feet in girth. Today, however, trees 150 feet tall are uncommon. The wood has always been regarded as one of the finest and most valuable in this country. It is straight-grained, soft, easily worked and finishes well, with a fine even surface. It takes paint and polish well and when once it has been properly seasoned it rarely checks. Its widle uses include almost every wood-utilizing industry in the country, from indoor trim and cabinet work to aircraft and shipbuilding.

In addition to the intrinsic value of the wood, white pine is one of the best species for reforestation purposes in the northeastern United States. It is unquestionably the most important forest tree in eastern North America and, as one authority states, probably in the world. It is being much used for reclamation work and in Pennsylvania, where much attention is given to forestry, twenty million young white pines were planted during a recent period of eighteen years on the state forests. An additional ten million trees have probably been set out on private lands in that state. New York, Massachusetts, and Connecticut have done similar work. Nursery stock is used for this purpose and it is interesting to note here that the cones of white pine yield from 50 to 75 seeds each, that from 25,000 to 35,000 of these seeds are required to make a pound of clean seed sufficient to sow 100 square feet of nursery bed and that each bed can produce from 10,000 to 15,000 two-year-old seedlings.

The white pine has been extensively introduced into Europe with marked success. In 1705 it was brought to England by Lord Weymouth and in that country it is most commonly known as Weymouth Pine. In 1794, a Hessian forester who was visiting America returned to Germany with sufficient white pine seeds to reforest 15 acres of woodland near Trippstadt in Bavaria. Years after, when the forestry movement in the United States was in its infancy and nurseries could not yet supply the needs, white pine 


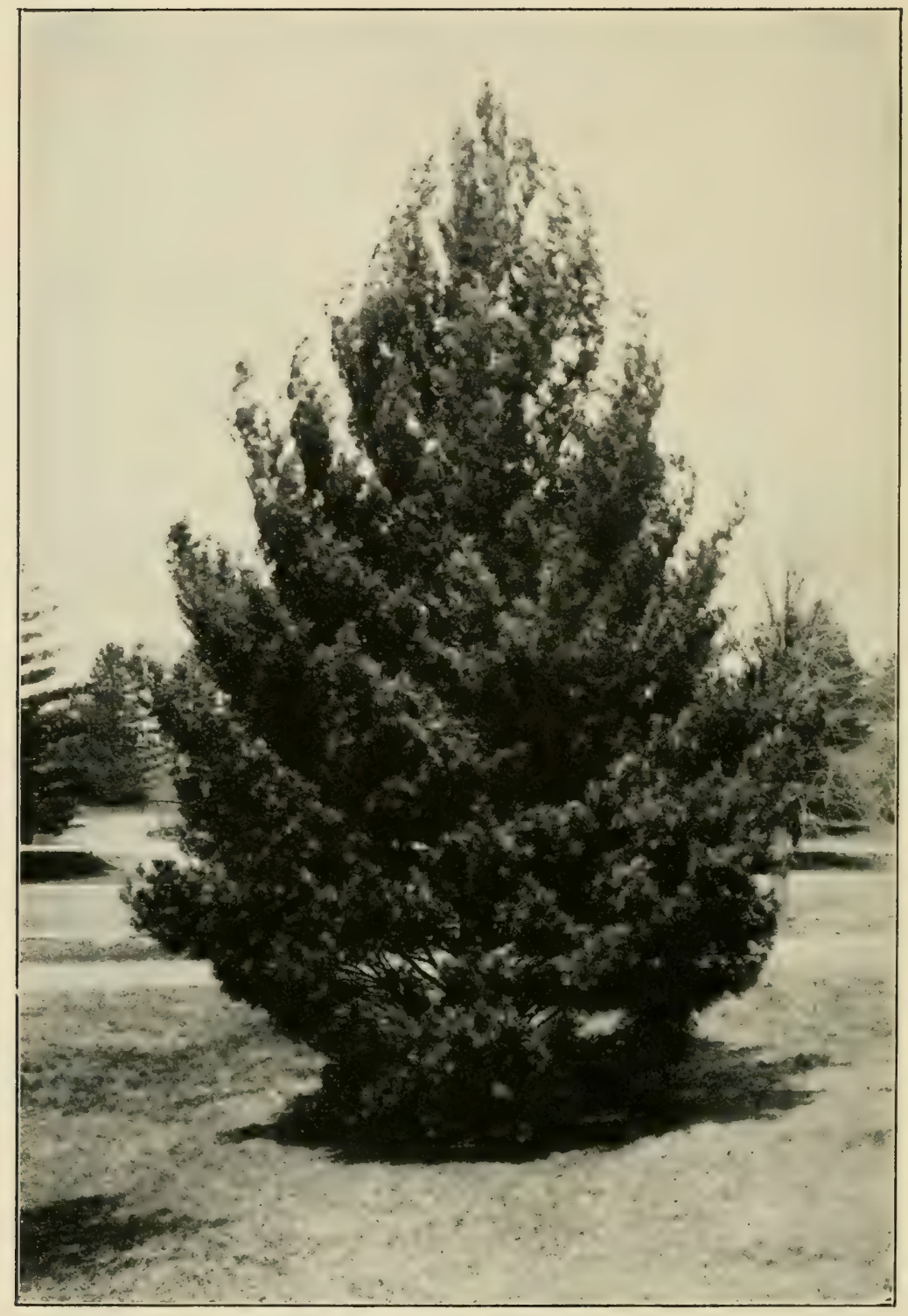

Figure 3, Columnar White-Pine Pinus Strobus var. fastigiata 
seedlings were imported from Germany for reforestation purposes from those very trees that, in the form of seed, originally went from this country. Throughout continental Europe white pine has been planted to such an extent that it is now regarded as a naturalized member of the forests there.

To return to the group at hand we should observe that the splendid tree in the center toward the northern end differs from the others. Its branches are not so horizontal but rather ascending. It is a beautiful thing, indeed, but its beauty is somewhat marred by its setting here. If we look across the road on our left we see a similar tree between the road and path on that side, pyramidal in contrast to the other three white pines adjoining it to the right. These particular trees represent a natural variety of the common white pine, known as Columnar White-Pine, Pinus Strobus var. fastigiata or var. pyramidalis.

Pinus Strobus is further characterized by having its bluishgreen and somewhat feathery-looking foliage distributed in horizontal masses along the branches which occur in regular whorls. Furthermore, there are tufts of hair below the insertions of the leaves. Especially in old age is white pine a thing of beauty, when a tall bole bears high wip near its crown far-reaching limbs that seem to be horizontal arms supporting platters of upright tufts of leaves. At this stage in the life of the tree the needles do not appear below their main boughs. We shall see some of these veterans just beyond the road ahead of us and elsewhere other fine specimens occur in the Garden.

It would be unfair not to mention the two weaknesses of the white pine, for they play a tremendously important role in the reforestation of this species. They are the susceptibility of the tree to the ravages of an insect pest, the white-pine weevil, Pissodes Strobi, and the fungus, Cronartium ribicola, which causes the white-pine blister-rust. It is not within the compass of this book to discuss these destructive agents, but their importance is so great that they must at least be mentioned.

As an ornamental, white pine is extensively planted in this country. There is little of distinctive beatty, however, in the young trees. 


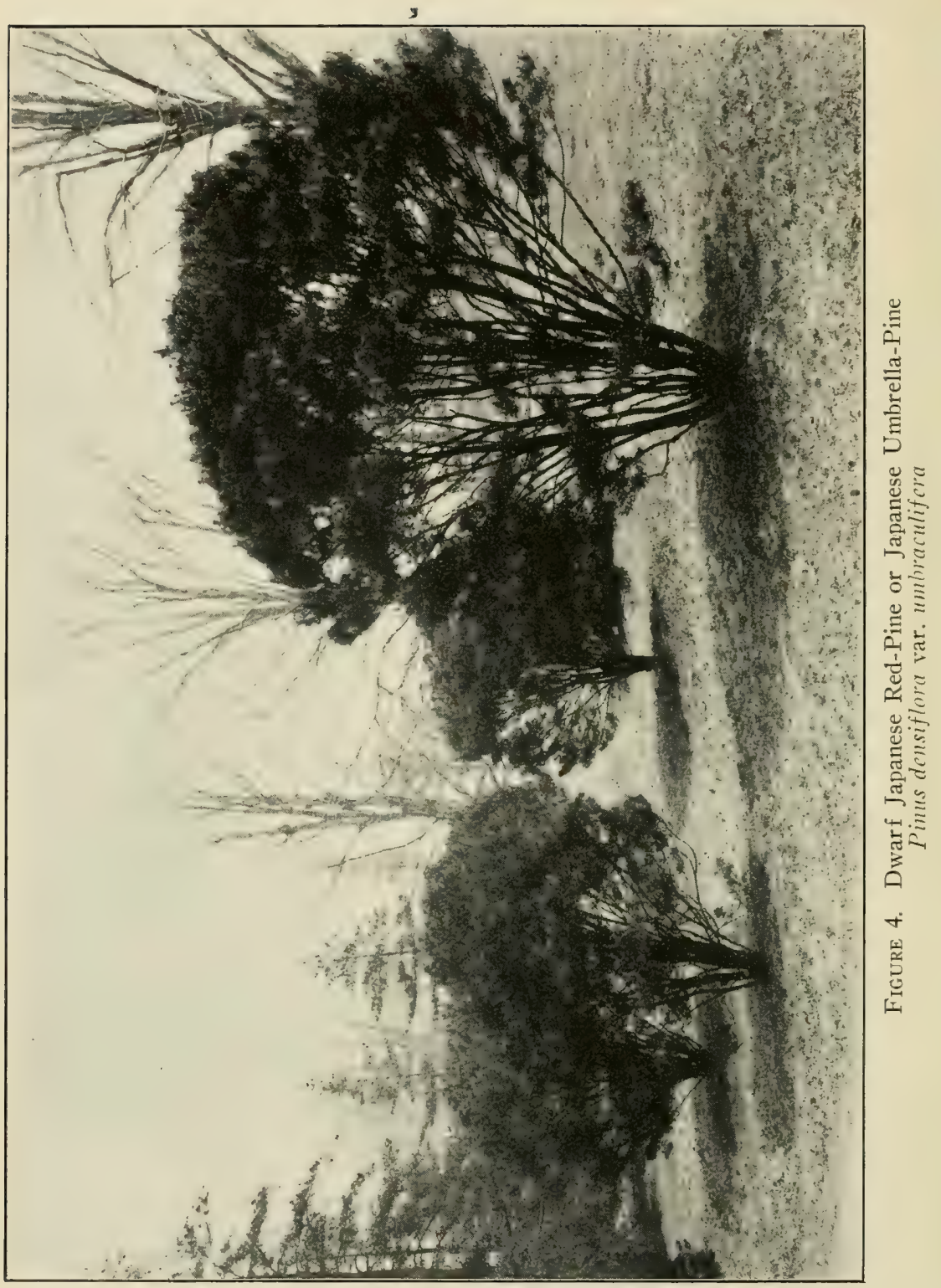


The last of this group of white pines stands with its crown cut off in the little triangular patch between the path and the road that runs to the east, ahead of us.

We must now cross this road and on the other side we meet the pines again. The first to attract our attention are the nine bushy ones right in front of us. There are seven of one kind and two of another. The seven are those with the somewhat scaly yellowish-brown or reddish bark with the leaves in a more or less rouncled head, leaving the lower part of the plant open. These trees are

Pinus densiflora var. umbraculifera, the Japanese Umbrella-Pine

This is one of the best of several garden varieties which the Japanese have developed from their native red pine. To them it is known as Tanyosho. It is one of the choicest varieties of conifers for decorative purposes, attaining a height of twelve feet. The leaves are in groups of twos, offering us our first contact with such leaf arrangement. $A 11$ the pines so far have been of the five-needle type.

The other two bushy pines associated with these seven are conspicuously different; their leaves are in threes, occasionally more or less. They are

Pinus Bungeana, the White-bark or Lace-bark Pine

This pine is native to western China, where in maturity it is one of the most conspicuous and attractive trees. Its oddity lies in the fact that it sheds its bark much as the plane tree or the birch, exposing a white trunk that presents a striking contrast against the green of other conifers frequently associated with it. This trait is already indicated on the trees before us, for on the trunks yellow patches appear as a result of exfoliation of the outer bark. It is not, however, until an age of about fifty years is attained that the whiteness appears. This peculiar habit, shown also by the White-bark Pine of the western United States, $P$. albicaulis, is an anomaly, so far as pines are concerned.

Though of a bushy habit in cultivation, the White-bark Pine 
attains to a height of 80 or 100 feet in its native range. The foliage is rather distinct, being sparsely arranged, rigicl, acute, and light green and having a turpentiny odor when bruised. This tree, much as the Ginkgo, has been cultivated to a considerable degree about the shrines and temples in China, especially at the Buddhist monasteries in the mountains west of Peking. To the natives it is known as Pai-koo-sung.

Little is known of the wood of this tree and in its native land it is not sufficiently abundant to be of commercial importance.

To the right, ahead of us, we come to three trees in a row, which may appear to be Scotch Pine, if we already know that species, because of the orange-colored bark and resinous buds. But closer examination will show that the leares, though in twos as in the Scotch Pine, are longer and not so stiff and are green rather than bluish-green. Moreover, the branchlets are glaucous, that is, they have a bloom. There is another similar tree before these thre: that stands higher up on the slope and just about directly east of the White-bark Pines. These four trees are

Pinus densiflora, the Japanese Red-Pine

This is the tree of which the Japanese Umbrella-Pine is a variet! and which is cultivated in numerous other forms by the Japanese. It is known to them as Aka-matsu and is regarded in Japan more as a forest tree than one of gardening use. It grows to a height of over one hundred feet and has been abundantly planted on barren soil, for it will grow on the poorest sites. The wood of this species, which is coarse-grained but moderately strong, is used for every description of carpentry by the Japanese.

The remaining six pines in this area as far as the next path, begimning with the tall ones along the road next to the White-bark and Unbrella-Pines, are

Pinus Banksiana, the Jack-Pine

This tree possesses little beauty to recommend it for ornamental planting. It is scraggly, unkempt-looking, and relatively short- 
lived. Sixty years is a maximum age and thirty feet an average height. Seventy feet may occasionally be attained. But it has distinct value in its ability to withstand conditions where other trees would fail, particularly on dry and sandy soils. It is frequently used for reclamation work on such sites and is one of the first trees to return naturally to burned-over and denuded areas. It is drought-resistant and the most intolerant of sharle among our northeastern pines. Though it thrives on very dry sites by extending its roots several feet after water, it may also live in swampy land. Its growth rate, moreover, is considerably greater than that of any other pine in its region, another feature that recommends it for reclamation use.

The light, soft, and weak wood of the Jack Pine has little lumber value. It has, however, entered into the manufacture of various secondary products. The Indians used it in making canoes.

The two most distinguishing features of the Jack Pine pertain to the leaves and cones. The former are in groups of twos; they diverge and are the shortest needles found on any native pine, being about one inch in length. The mass effect of all the diverging needles on a well-covered branch is very characteristic. The cones, up to two inches in length, are generally curved or lopsided, bear no stem and persist for many years, sometimes twelve to fifteen, and remain unopened for a great period. The result usually is a tree laden with a mass of crooked cones, some wide open, others tightly shut.

The Jack Pine, known also as Gray, Banks' and Banksian Pine, is the hardiest of American pines, penetrating farther north than any other pine and rivaled by few other trees. It extends to within one and a half degrees of the Arctic Circle as a low and dwarfec shrub. In fact, it is almost transcontinental in distribution, reaching from Nova Scotia across Canada to the southeast corner of the Inkon region. It is, therefore, distinctly northern, though it extends southward to the southern shores of Lake Michigan. Its dwarfness in its most northern reaches is a feature shared by all trees that have such an extended range. They all become stunterl in high latitudes as well as in high altitudes. 
In the next triangle between converging paths are three native white pines, P. Strobus. Five more skirt the main path along the road beyond the triangle. To the east of the first of these fire stands a Japanese White-Pine and above it are the two veteran native white pines already referred to. It is very obvious here how different this tree appears in old age as compared with the younger specimens below it. Behind the last native white pine along the road stands another Japanese White-Pine above which on top of the mound is another similar specimen of the same kind. The remaining four low and bushy evergreens beyond along the path are

Pinus parviflora, the Japanese White-Pine

This is the dwarfed form of those we have just passed. It was mentioned at the rery beginning of our study in this Section. Above the last of these low plants and near the edge of the hardwood thicket the slender evergreen is Pinus pariflora var. pentuphylla, the wild form of the Japanese Thite-Pine and the same as the three we have just passed and the one back with the Swiss Stone-Pines. There has been some discussion concerning the relation of these two forms in an effort to determine whether one is a variety of the other and if so which is which. It matters little to us, however, and we may safely consider either one of them as a variety of the other.

Above the last of these at the edge of the woods, is another Japanese White-Pine.

\section{Section 2}

Section 2 of the Pines lies on the western side of the Central Drive through the Garden which separates it from Section 1, and south of the cross road in front of the Miseum (Map p. 7). To reach it from the end of Section 1, go a bit southward along the main road and follow its first bend to the right. A little beyond the triangle at the junction of the roads and on the south side of the drive in front of the MIuseum we see a path that branches to the right and to the left over the knoll. We shall follow the lefthand branch and consider the pines between this path and the main road, in other words, the trees on our left. 
First we pass two Red Cedars (p. 112), and then come to a large dark-foliaged tree that looks like an Austrian Pine, if we already know that species. Three similar trees stand just opposite on the right-hand side. These trees are a variety of the Austrian Pine and are known as

Pinus nigra var. Pallasiana, the Crimean Pine

This variety is a native of western Asia. There is scarcely any apparent difference between it and the Austrian Pine, and it is most difficult to distinguish them. The variety is said to be distinct in its pyramidal habit, with the main branches growing erect. More will be said concerning these trees when we reach a very fine collection of large Austrian Pines farther on in this Section. Another but less developed Crimean Pine stands next along the path, set back a bit.

The next five evergreens on our left, together with an additional one which stands opposite on the right-hand side, are

Pinus ponderosa, the Western Yellow-Pine

This tree, so far, is relatively anmportant ornamentally in this section of the country.

It is the most widely distributed pine in America, ranging from southern British Columbia south to Mexico and east to South Dakota. In such a range, covering a million square miles, we find geographical variations as we do in other trees of similarly extended distribution. Of three such variations we shall see one a little later, the Jeffrey Pine. In addition, there is an altitudinal variation, for at timber-line in the higher mountains this tree becomes dwarfed.

The Western Yellow-Pine is the most abundant and important hard pine of the West and one of the great American lumber trees. Its annual cut amounts to about two and one-half billion board feet, exceeded only by that of the southern yellow-pines and Douglas Fir. Immense tracts of territory, especially in northern Idaho and Montana and elsewhere in the western states, are cov-. ered with this tree. Probably two hundred and fifty billion board feet of this timber still remain in the Western States, exceeded 
only by Douglas Fir and by the combined stand of the four southern yellow-pines.

In the trade, it is extensively used in general construction work and in almost an unlimited variety of other capacities. The wood is lighter and softer than that of the southern yellow-pines and shows less definite transition between spring and summer wood.

In its native range, this tree may become 150 feet tall and occasionally 230 feet, with diameters ranging from five to eight feet; in fact, it is the tallest of the pines next to the Sugar Pine of California, P. Lambcrtiana, which species unfortunately is not represented in the collections.

As with many other trees of extended distribution, the Western Yellow-Pine bears a series of common names. On the coast it is sometimes erroneously known as California White-Pine. The standing timber is called Bull Pine. It is also often known as Heary Pine, but that term serves merely to distinguish it from the considerably lighter Sugar Pine. In Montana it is Black Pine and elsewhere it has received the name of Sierra Brownbark Pine.

In addition to insect clamage, this tree in the southern portion of its range is serionsly injured by a mistletoe. This parasite, whose relatives, generally, are regarded as harmless to their hosts in the East, causes considerable destruction to several western conifers.

The leaves of the IVestern Yellow-Pine are prevalently in threes. though occasionally they will be found to vary from two to five. They are conspicuously long, five to eleven inches in length, and occur in great clumps with a characteristic appearance.

The taller evergreen behind these yellow pines and close to the shrubbery in the background is another Red Cedar (p. 112).

The next five larger trees ahead of us, three of which are more removed from the path than the others, are

Pinus Thunbergii, the Japanese Black or Thunberg Pine

This species from Japan is truly Japanese, with its characteristic leaning trunk and broad irregular head. In fact, it is the tree that has probably influenced Japanese art more than any other, for it is a familiar subject on paintings, wood-carvings and em- 


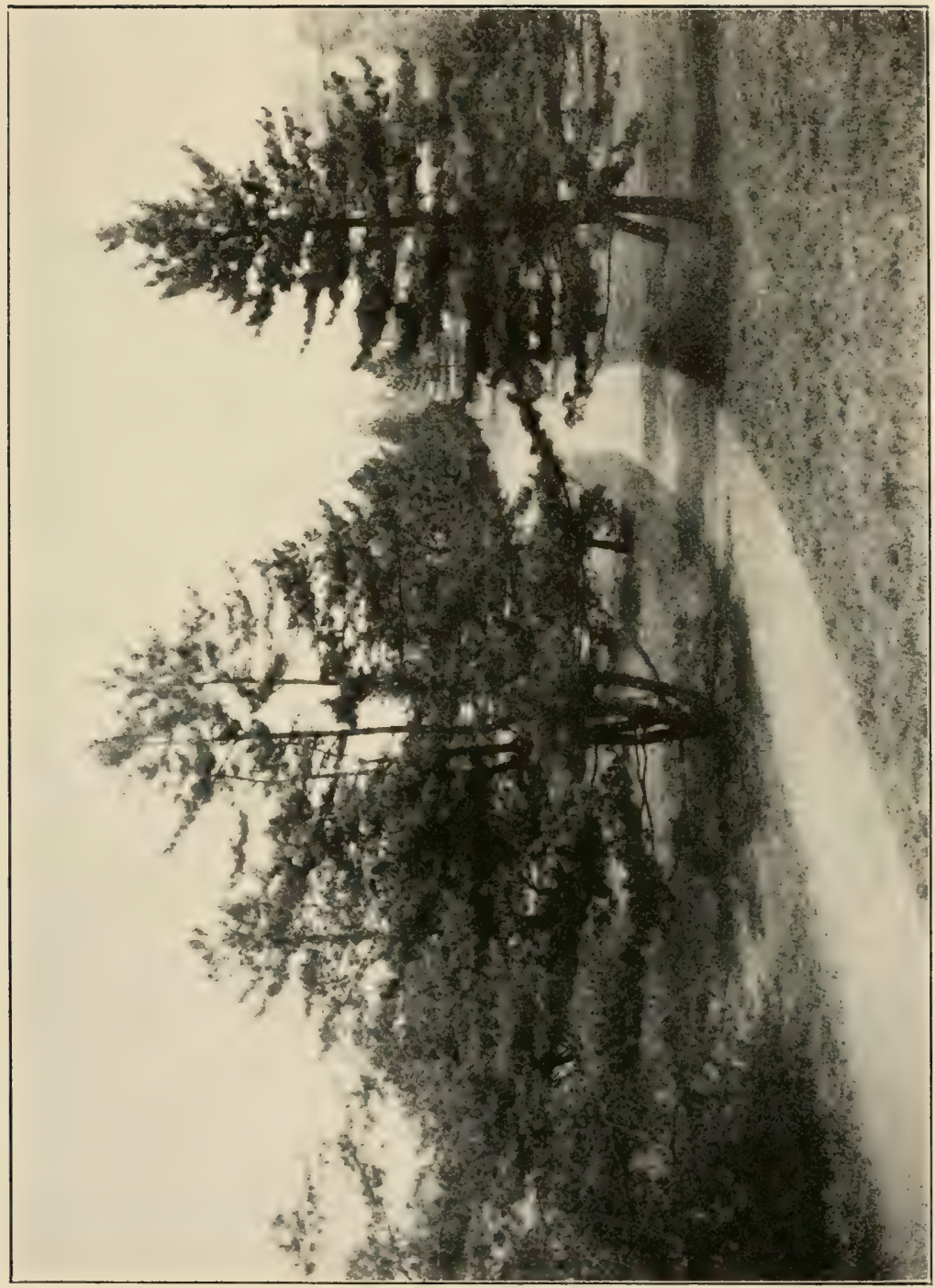

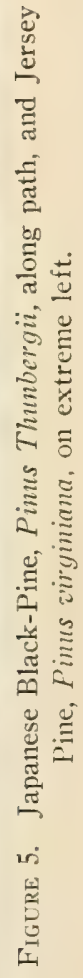


broideries from Japan. To the Japanese it is known as Kuromutsu and has become so endeared to them that with the exception of the Cryptomeria, which we shall meet later, it has been more widely planted than any other tree. The great highways of old Japan were lined with great numbers of these trees.

As a potted or dwarfed and contorted tree, the Black Pine is very frequently seen in the Japanese miniature gardens. It is also trimmed into fancy hedges and other expressions of clever topiary work. Moreover, it is the species used in Japan as stock for grafting all the other pines and their varieties as, for instance. the Japanese Lmbrella-Pines, which we have already encountered.

In addition to its horticultural value, the Japanese Black-Pine is one of the important forest trees of Japan, where, in the wild, it grows to a height of 130 feet. Its wood, though similar in appearance to that of the Japanese Red-Pine, is coarser-grained, more brittle. more resinous, and except for fuel is of considerably less value. It is a species, however, which thrives on both good and bad soils and consequently is much used for reclamation work on sandy sites. Furthermore, it is suited for seaside planting.

The clumps of needles of this pine form a most distinguishing feature, particularly from a little distance. They appear in groups of twos that seem to have been cut off evenly into nicely rounded tufts. The branchlets are orange-yellow, and the winter buds frequently are conspicuously large and silvery.

Three more of these trees stand directly opposite on the righthand side of the path.

Wre now ascend the slight incline ahead of us, following the path, pass the rocky formation on our left, and soon come to a small pine near the path. It is

\section{Pinus sinensis, the China Pine}

This is a relatively unimportant tree from the cold-temperate and subalpine levels of the mountains of central and western China and from Korea. The leaves vary in number but generally occur in twos. The wood of this species has heen used in China for general construction purposes and shipbuilding. 
We now come to the large planting of Austrian Pines already referred to. Some stand along the ridge to the right; all the trees to the left except a few to be pointed out are of this kind. They are

\section{Pinus nigra, the Austrian Pine}

This is perhaps the most successful foreign kind under American conditions. It is entirely hardy and endures exposure unusually well, even by the seashore. In this respect it surpasses the hardy Scotch Pine and competes with that more northern tree in beauty as well. It succeeds in very poor or even limy soil, in heavy loam and clay, and thrives in the pure sand of the beach. Its remarkable resistance to strong sea-breezes makes it especially valuable as a shelter tree for more tender stock, as Scotch Pine, and for human habitation.

The Austrian Pine is widely distributed in southern Europe from Spain to the Crimea and the Caucasus and in Asia Minor to the Taurus Mountains. Consequently there are several geographical varieties, of which we have already met one, the Crimean Pine. In their native range these trees attain heights up to 100 and 150 feet.

Resin has been obtained by tapping the Austrian Pine, but insufficiently to result in serious competition with that secured from the Maritime Pine, Pinus Pinaster, the principal source in Europe.

In this country the Austrian Pine is very extensively used in decorative planting. Its growth is remarkably rapid and its success is usually assured. The dark needles in groups of twos, up to half a foot in length, occur, with a characteristic twist, in great clumps.

As we go eastward now along the south side of this Section that faces the large greenhouse we should notice three trees with orange-colored bark. They are laden with cones and stand apart just below the darker and denser Austrian Pines on the crest. They are $P$. dcusiflora, (p. 24), the Japanese Red-Pine, the same as those we met in Section 1.

Above the most easterly one of these Japanese pines stands a 
smaller evergreen. It is the Jersey or Scrub Pine (p. 39). We shall postpone a description of it until we meet more specimens in the next Section.

The remaining five trees on this side of the slope we should recognize as Western Yellow-Pines, with their needles in threes.

The small evergreen of scanty foliage that grows on what might be termed the dividing line between the eastern and southern faces of this slope is

Pinus Jeffreyi, the Jeffrey Pine

This is one of the hardy western pines found from southern Oregon to Lower California, where in certain areas it forms extensive forests. Its leaves are longer than those of any other hardy native pine. It is a mountain tree and generally occurs above the Western Yellow-Pine at elevations of 3,600 feet in the north to 10,000 feet in the south. It is regarded by some authorities as a variety of the Western Yellow-Pine, from which it is distinguished principally by its more pungently aromatic resinous secretions and its stiffer and more elastic leaves, which persist on the trees for a longer period.

The Jeffrey Pine is also known as Black, Redbark, Blackbark, Bull, Sapwood, and Truckee Pine. In the trade it passes as Western Yellow-Pine.

The three-needled pine north of this Jeffrey Pine and between the path and the bigger Austrian Pines on the slope is a Mestern Yellow-Pine.

The remaining large dark-foliaged trees along the slope facing the road to the east as well as those on top of the knoll are Austrian Pines. There is one odd conifer high up on the rocky formation at its northern end. It is a Red Cedar (p. 112).

Beyond the last of the dark Austrian pines along the path are the last two trees in this Section. They have bluish-green needles and orange-colored bark. They are 
Pinus sylvestris, the Scotch or Scots Pine

The Scotch Pine, like the Austrian, has shown remarkable adlaptability to American conditions. It is one of the most dependable of foreign trees and is very valuable for ornamental purposes. On dry sandy soils and in exposed situations it thrives unusually well; the Austrian Pine, however, is more resistant under severe exposure. The Scotch Pine, furthermore, is one of the most rapid-growing conifers, at least during youth. This feature, together with its hardiness, makes it especially useful for forming screens and as a shelter tree for more tender stock. It seems singularly capable of thriving in regions of hot summers and cold winters. Old trees are especially picturesque, for their frequent odd shapes and colored bark are very effective.

The Scotch Pine is a native of Europe, where its range covers most of the continent, extending from southern Spain and northern Italy to latitude 70 degrees on the west coast of Norway; thence cast through Lapland and Siberia along the Arctic Circle to the Amur and thence through Asia Minor to Persia. It is the most widely distributed of the pines. In Europe it is absent only from the southern portion of the Balkan peninsula. In elevation it ranges from 700 feet in northern Norway to 6,500 on the Sierra Nevada of southern Spain. In the forests of Europe the Scotch Pine may attain to a height of 120 feet. It grows there in dense stands of beautifully tall and straight slender trees, which may attain an age of three and four hundred years. As seen in this country, it generally assumes a rounded shape and frequently distorted growth because of lateral freedom.

In Europe the Scotch Pine has figured very prominently in the practice of forestry, for it is one of the major forest trees on the continent. The uses of its lumber are almost limitless. At one time, at least, tar, pitch, and turpentine were made from its resinous juices. These and other products are obtained by destructive and steam distillation of the wood. In Lapland and northern Russia the bark has been used for covering huts and many other purposes. Stump oil and resin are secured from the roots. The fibre of the leaves has been manufactured into stuffing material 
for cushions, mattresses, and other articles, under the name of pine-leaf wool. The water used in this operation has been used further in Breslau and elsewhere for medicinal baths. Oil obtained from the leaves is sometimes used in medicinal practice. In Ireland, where very old trees have lain for centuries in bogs, shavings have been made from the dug-up trees and utilized for coarse rope.

The Scotch Pine may generally be recognized by its orangecolored bark, particularly prominent on the upper part of the trunk and its bluish-green foliage. The bark, moreover, is inclined to be scaly and the twisted bluish-green leaves occur in twos. It was mentioned previously that this tree might be confused with the Japanese Red-Pine. This latter stands just across the road and it might be well to step over there and note the difference in the leaves. The backward-pointing cones on the branches of the Scotch Pine, when present, are a further mark of identification.

There are numerous varieties of the Scotch Pine, geographical and horticultural. Much of the timber exported from northern Europe is known as "Riga," "Dantzic," or "Yellow Deal." Such an important and widely distributed tree, it should be expected. would bear a burden of names. The Scotch Pine is probably unexcelled in this respect.

Behind these two Scotch Pines are the Japanese Black-Pines we considered from the other side of the Section.

\section{Section 3}

Section 3 of the Pines lies on the western side of the path that separates it from Section 2 (Map p. 7). It is the triangular area directly behind Conservatory Range 1, bounded on both eastern and western sides by paths. We shall begin at its northern end, for it terminates there in an apex where the two bounding paths converge. We shall follow the path along the eastern side of the Section. If we have just completed Section 2, we need but return to where we began on that Section and direct our attention to the right-hand or western side.

The first three large pines that stand in the apex are the same as the one on the left side of the path which we have already considered, the Crimean Pine (p. 27). 
The next tree with long scant foliage along the path is

Pinus Sabiniana, the Digger Pine

This pine is of almost no ornamental value here, for though odd in its heavy trunk and sparse foliage, it is not sufficiently hardy.

The Digger Pine is confined to the western part of California, where it inhabits the foothills of the Coast Ranges and of the Sierra Nevada, almost the entire length of the state. It ranges between elevations of 250 and 4,000 feet. It attains a height of 50 and occasionally 80 feet and is characterized principally by thin, pendulous foliage and crooked straggling branches, which set it apart from all other accompanying coniferous vegetation. The leaves are in groups of threes, 8 to 12 inches long. The young shoots when cut have the same orange-like odor as the Western Yellow and Jeffrey Pines.

The wood of this tree is of little economic importance but the edible seeds have served as food for the Digger Indians, whence the common name of the tree. It is also known as Bull, Gray, Gray-leaf, Nut, and Sabines' Pine.

Directly west of the Digger Pine the three low bushy evergreens, somewhat isolated from the other pines about, are

Pinus Murrayana, the Lodgepole Pine

This pine, too, is of comparatively little ornamental value in this part of the country for under cultivation it assumes a bushy rather than tree-like habit. It also is a native western tree, but differs from the Digger Pine in its very extensive range. It is found from the valley of the Yukon, near the Alaskan boundary, along the Pacific Coast to central California and eastward as far as the Black Hills. It becomes common at an elevation of about 7,000 feet and in southern California it ascends the mountains to 11,000 feet. Great stands of Lodgepole cover the western states in the northern Rockies, where they are the most common conifers, attaining a height of 100 feet or more.

The common name, Lodgepole, has arisen from the use made by the Indians of these trees for the center pole in their lodges. 
Other names that have been associated with it include Black, Murray, Pitch, Prickly, Red, Spruce, Tamarack, Tamrac, and even White Pine.

The Lodgepole Pine is characterized by very short needles in twos and orange-colored branchlets. From other two-leaved pines it may be distinguished by the twisted or stunted appearance of the branches, the short twisted yellowish-green leaves and the long buds encrusted with resin.

The lumber of this tree is inferior to that of other western pines, though it is employed to some extent for local purposes. The greatest value of the species probably lies in its peculiar ability to regenerate cut-over and burned lands. The trees themselves suffei severely from fires but are otherwise benefited, for through conflagration the seeds which are sealed in the cones by accumulater resin are liberated and allowed to germinate. Reproduction on burned over areas, consequently, is very good. Moreover, the seeds themselves have remarkable vitality and in spite of long imprisonment that may occur before liberation they do not seem to suffer.

The Lodgepole Pine very frequently is regarded not as a distinct species but merely as a variety of the western coastal Scrub Pine, $P$. contorta. It is usually found under more favorable conditions than the Scrub Pine and the difference may be entirely due to soil and shelter. The growth is more vigorous, the leaves are broader and the cones larger. Like most conifers, the Lodgepole objects to limestone. It gives excellent results, however, on dry gravelly soils and is very intolerant of shade.

The next four larger trees farther along and set back from the path are

Pinus rigida, the Pitch Pine

The Pitch Pine offers little of ornamental value unless its scrubby appearance just suits a particular location. On dry rocky slopes or sandy areas it may be the only successful tree along with the Jack Pine and there become very picturesque when old. It is hardy and growth is quite rapid. 


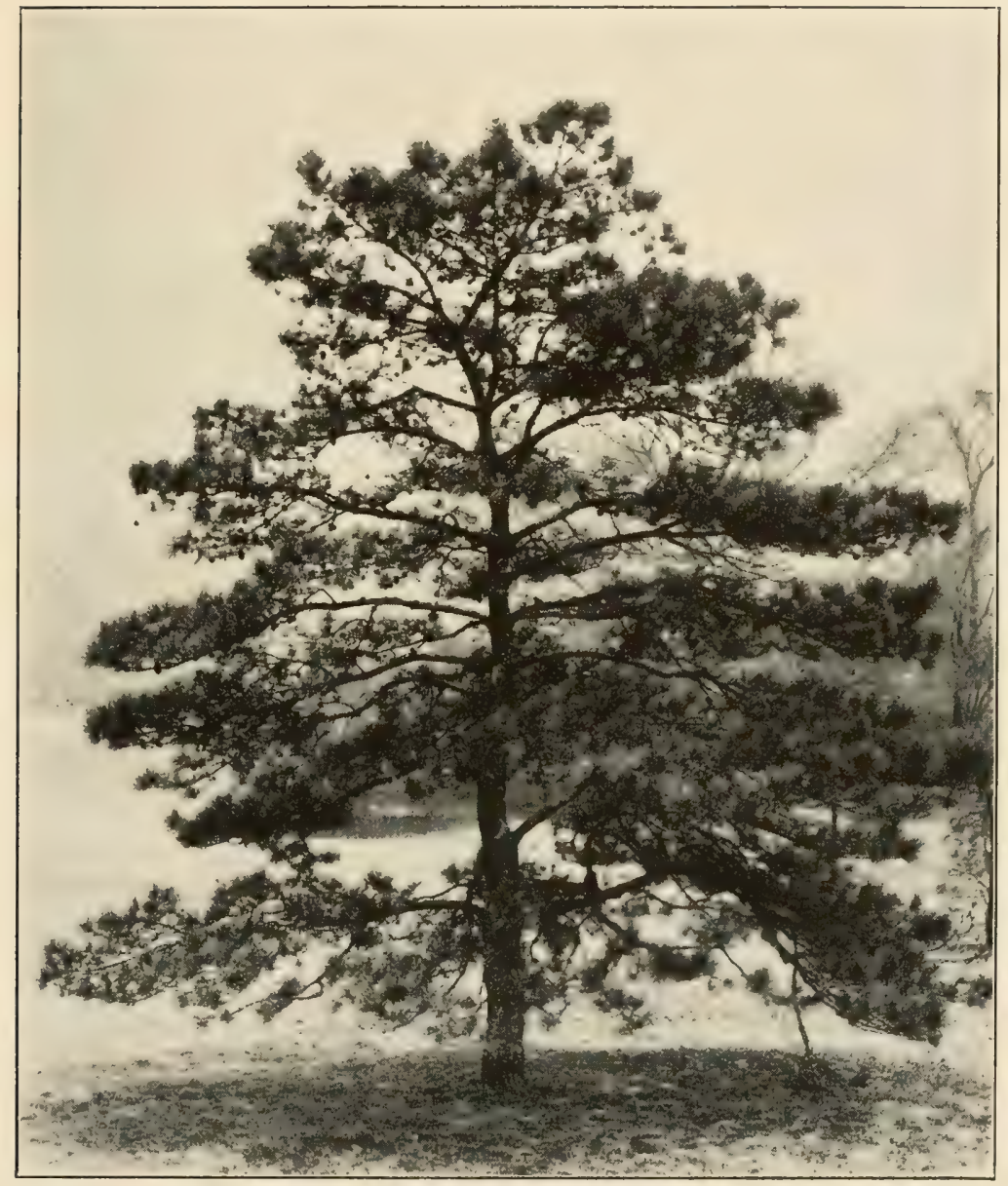

Figure 6. Pitch Pine

Pinus rigida 
It is the only native pine in this section of the country with leaves in threes, which, consequently, is an unfailing mark of identity if it is certain that such a tree has not been imported from outside the region. Furthermore, as may be observed on the specimens at hand, the trunk may be covered with great masses of leaves. The Pond Pine of the South, P. serotina, shows this peculiarity, too. This feature is evidence of a trait peculiar among conifers to this species, namely, that of producing sprouts. It is characteristic of broad-leaved trees, but rare among the conifers. The Redwoods of California exhibit the same ability to a very marked degree. The sprouts of Pitch Pine, however, are shortlived and do not constitute a very successful method of reproduction as sprouts do in the Redwoods.

The Pitch Pine is a typical hard pine of the northeastern United States, ranging from Maine westward to Ontario and Ohio and southward along the Appalachians to northern Georgia and Tennessee. In New Jersey and the Delaware Peninsula it forms extensive forests. It may attain a height of 80 feet, though usually is not over 50 .

The wood has always held a secondary place on the market in comparison with better species, such as White Pine. But with the disappearance of those better woods and with improved forestry practice Pitch Pine as well as other less important pines in the East will undoubtedly gain in favor.

One of the common names of this species, Torch Pine, arose from the extensive use by early settlers of the pitchy pine knots for torches about homesteads and for traveling at night. It formerly was the chief source of turpentine and rosin but is now superseded in this respect by the Longleaf Pine of the south, $P$. palustris. This latter is the American pitch-pine found in European markets. Tar made from the true Pitch Pine was the pioneer's axle grease.

In Delaware it is called Longleaf Pine, since its needles are longer than those of the Scrub Pine, $P$. virginiana (p. 39), associated with it. For the same reasons it is known in some localities as Longschat Pine. In Massachusetts it is Hard Pine; in Pennsylvania, Yellow Pine; in North Carolina and eastern Tennessee, Black Pine; and in New York, Black Norway Pine. 
One favorable feature of the Pitch Pine that recommends it for reforestation is the fact that it is the most fire-resistant pine in the East, for already in its sapling stage it develops a heavy bark that enables it to withstand forest fires where other trees would succumb. Like the Jack Pine it thrives on poor soils.

Between the southernmost of the Pitch Pines and the path stands a feeble specimen of Western Yellow-Pine (p. 27), which species we have already noted across the path. Next we come to three Japanese Black-Pines (p. 28), also belonging to a group in Section 2. The first of these stands back from the path just beyond the lone Western Iellow-Pine and the others are the two larger trees next along the path. On the slope above the first two of these Japanese pines stands a large Austrian Pine (p. 31), and above this on the slope a smaller Japanese White-Pine (p. 15), with wide-spreading branches. Another specimen of this last species stands still higher on the crown of the knoll to the left and the other tree a little beyond it is a Scotch Pine (p. 33).

Returning now to the path, the bushy and spreading tree above the southernmost of the Japanese Black-Pines and a bit to the right is

Pinus virginiana, the Jersey or Scrub Pine

This pine, like the Pitch and Jack Pines, has relatively little ornamental value. It is a tree of poor sandy soil, ranging from Long Island south along the coast to Mississippi and north to Indiana and Ohio. On the coast it is usually a low shrubby tree of the poorest soils, but west of the mountains it appears in mixture with broad-leaved trees on the better sites and there attains a height of 100 feet. Usually it is only 30 or 40 feet tall and very frequently is scrubby. It is characterized by having needles in twos, more twisted and spread apart than in any other pine. Furthermore, the trees are generally laden with numerous persistent small cones. The wood of this species is of comparatively little value. A compensating feature of the trees, however, is their ability to grow on poor sites. 
Nearly twenty different common names have been applied to this pine in various localities.

The Jersey Pine bears considerable resemblance to the Jack Pine (p. 24), which we shall see next. The two evergreens, one approximately behind the other just south of the southernmost Japanese Black-Pine are also Jersey Pines. Their twisted and moderately long needles distinguish them. Furthermore, the branchlets of Jersey Pine are glaucous, i.c., they are covered with a bloom or whitish substance that rubs off, while those of $P$. Banksiana are not glancous. The remaining eight small trees here and beyond are Jack Pines.

We now come to a fine collection of Austrian Pines (p. 31), the same as those we have already observed across the path in Section 2. There are eight big specimens here, extending westward along the slope and with them are three Scotch Pines. One of these latter is the good-sized orange-barked tree that stands lalf way along the top of the slope and above the Austrian Pines. Farther along, behind the last of the Instrian Pines, is the second and somewhat stunted one. And a third Scotch Pine is the last tree with the orange-colored bark along the path next to the last of the Austrian Pines.

The next small tree just west of this last Scotch Pine as well as four other similar ones partly up the slope to the right are Pitch Pines (p. 36), which we should immediately recognize or at least suspect when we notice the needles in threes.

On the eastern slope of this knoll are several small trees with long needles in pairs. They are

Pinus resinosa, the Red or Norway Pinc

This is regarded as one of the best of our native eastern pines for ornamental planting. In the Garden, however, it has been very unsuccessful, for the pine-shoot moth has caused considerable damage to it. Where this trouble is absent the Red Pine is very fine. It is very intolerant of shade and must not be overtopped. 
The Red Pine is native from Newfoundland to Manitoba and south to Massachusetts, Pennsylvania, and Minnesota, attaining a height of 70 and even 100 feet. It is characterized principally by its rather long, slender and flexible needles in twos and its distinctly reddish bark. It resembles most closely the Austrian Pine except for the color of the bark and its more slender leaves. Furthermore, the sheath at the base of the needle clusters in the Red Pine is longer than in the Austrian.

In the Lake States this tree is called Hard Pine to distinguish it from the softer White Pine. In England it is known as Canadian Red-Pine for it is imported from the Canadian provinces. Norway Pine was applied by the early explorers who, in some inexplicable manner, mistook it for Norway Spruce.

The wood of Red Pine was extensively employed formerly, entering into a number of products. In this country and in England it was once popular as ship timber. The slender straight trunks were selected for masts or sawed for decking. White Pine probably surpassed it for masts and Live Oak from the South was the primary wood for hulls. Today, however, its decreased supply has given way to the yellow pine of the South. Large quantities, nevertheless, still enter the trade.

Let us now stand by the uppermost of those small Pitch Pines and turn our attention to the remaining trees on the western side of this knoll. The largest one nearest the top of the slope anil the Museum as well is a Scotch Pine. West of it is a group of Jack Pines with smaller Korean Pines on the other side of them. The tree at the foot of the incline on the extreme left is another Scotch Pine. Just to the right of it are three trees in a row ruming from us. The first and nearest to us is

Pinus sylvestris var. argentea, the Silvery Scotch-Pine

This is a natural variation with silvery leaves, found in the Caucasus. The feature may not always be apparent as is the case very frequently with many similar varieties. We shall meet other specimens in the next Section.

The second tree in the row is a plain Scotch Pine and the third and younger one nearer the path is 
Pinus koraiensis, the Korean Pine

Let us descend the slope to it.

The other five similar-looking trees in the corner of this Section, together with a sixth and smaller one along that next path running toward the Museum, are the same. The Korean Pine is an eastern Asiatic species occurring in Amurland, Manchuria, Korea, and Japan. It is a five-needle species and very much resembles the Swiss Stone-Pine (p. 13), sharing with that tree the three characteristics of dense brownish pubescence on young shoots, of wingless seeds and of indehiscent cones, that is, cones which do not open upon maturity but must decay or be forced open by man or beast to liberate the seeds. However, the leaves on the Korean Pine are stouter and the teeth on the margins more numerous an 1 carried to the tips. Their cones, moreover, are larger.

The Korean Pine attains a height of 100 feet in its native home : the wood occurs in the trade. In pre-war days it was becoming a very valuable article of export to Chinese and other Asiatic and Australasian ports. The seeds are sometimes used as food.

We shall meet several more specimens, some larger, in this and the next Section.

The flat-topped, spreading, and peculiarly shaped pine of very open habit, west of the last Scotch Pine that we noted and behind the first two Korean Pines that we met, is

Pinus pungens, the Table-Mountain Pine

Another tree of this kind stands directly to the west with one other tree intervening. This tree is of comparatively little ornamental importance. It lives under a variety of names, including Southern Mountain, Poverty, Prickly, and Hickory Pine. It is native to the eastern United States in the Appalachian Mountains, from North Carolina to New Jersey and Pennsylvania. Its height varies usually from 20 to 40 feet and the flat nature as seen here is quite typical. It is of little economic value and consequently not very well known though the wood appears on the market, but is not distinguished from the yellow pine with which it is cut. 
The Table-Mountain Pine has leaves in groups of two; therr very stiff, stout and sharp-pointed nature distinguish the tree from other two-needle pines. Furthermore, the cones, which may remain on the trees for 15 or 20 years, are armed with distinct prickles on the scales. The cones appear in clusters of three to eight, not scattered.

The tree which stands between the two Table-Mountain Pines as well as 13 other similar ones scattered over the remaining portion of this Section, some of which we have already noted, we should recognize as the common Jack Pine (p. 24), by their cones and general appearance. On the eastern side of these Jack Pines the tree farthest up the slope is another Scotch Pine.

Now, to finish this Section, let us begin at the corner of the two paths just between the little Korean Pines we have already noted and the fine Blue Spruces on the opposite side. Proceeding along the path toward the Museum, the taller tree just beyond the last small Korean Pine we should recognize by its clumps of leaves on the trunk as a Pitch Pine (p. 36). Directly east of it toward the slope the tree with the softer-colored bluish-green leaves is an older Korean Pine. Along the path are scattered fourteen more young trees of this species. And still one more, an older specimen, is that very bushy-looking, stunted tree with rather striking bunches of needles that stands east of these younger ones with the Jack Pines for a background. The two remaining trees here are just to the right of this last Korean Pine and are Pitch Pines.

\section{Section 4}

The fourth and last section of the Pines lies directly east of Conservatory Range 1 (Map p. 7). We shall begin at the northwest corner and proceed along the gravel path that runs south between the Section and the flower beds on the east side of the Conservatory.

The first six trees on our left along the path we should recornize as Japanese Black-Pines (p. 28), for we have already encountered others like them in Sections 2 and 3. The fourth an.1 sixth of these are set back from the path more than the others. 
Behind the second and third of these Japanese pines stand two tall Austrian Pines (p. 31). Beyond the last of the Japanese pines along the path are three large (rimean Pines (p. 27), the first of which is set back near the top of the mound.

Beyond the ones along the path are three more small Austrian Pines, two of which are nearer the top of the knoll. Then comes another large one.

The three low bushy evergreens that hug the ground at the turn in the path are

\section{Pinus montana var. Mughus, the Mugho or Kinee Pine}

This is one of the most extensively used evergreens for ornamental planting. Though it may hecome four or five feet tall after many years, it generally remains low and close to the ground. It conserpuently has a valuable place in foundation plantings and in other places where a truly clwarfed plant is desired. It is perfectly hardy and seems to withstand city conditions quite well. I very large group of Mngho Pines is located at the west end of the bridge that crosses the Bronx River some distance behind the Nuseum. In spring the new growth on these pines is very attractive. The many shoots are covered with a whitish resin and stand erect on the plants, like-so many candles. The needles are in groups of two.

The Mugho is a natural variety of the Swiss Mountain-Pine and ranges at high altitudes in Europe from the eastern Alps to Bosnia.

Behind these three Mugho Pines is a small Austrian Pinc, a bit to the right. A large one stands straight up the slope, and above it, near the top of the slope, is a fine Scotch Pine. The last is easily recognized by its orange-colored bark and general habit.

To the right are eleven small trees on the slope. They are all Korean Pines (p. 42), the same as thọse we met in Section 3.

The crown of the slope we are now on supports quite a selection of pine trees. We can best pick them out by first locating ourselves by the uppermost of the little Korean Pines on the south 


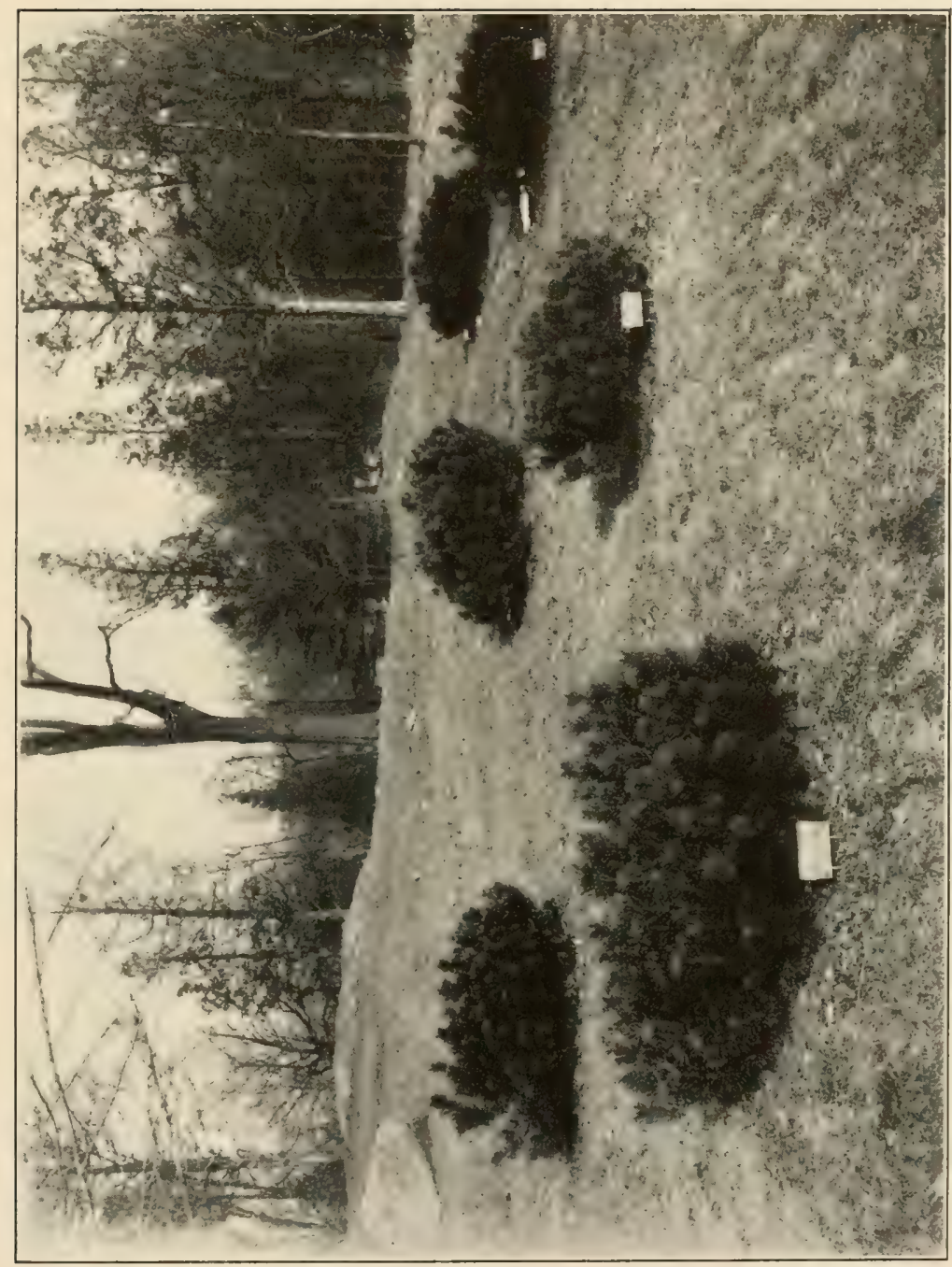

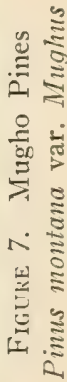


side of the large Scotch Pine. Having done so, let us first note the tallest and broadest tree in the group on top of this Section. It stands approximately in the center of the planting on top of the knoll and is a common White Pine (p. 17). Almost in a line with it and us is a smaller tree with its darker leaves in distinct tufts. To the right of this latter and about 15 feet in front of us, the nearest of all the trees, is a similar one. These two are Limber Pines. There are altogether thirteen specimens of this tree distributed over this area. We shall consider them more in detail a little later.

On the far side of the big center White Pine and in line with our station at the little Korean Pine are two more trees. The first of these is another Korean Pine and the second a Limber Pine. To the right of both of these is another isolated common White Pine.

If we step two paces to the right of the second of the two Limber Pines before us, we should notice a row of three trees extending from us. The first is a common White Pine and the other two are Limber Pines. The three small trees to the extreme right are all common White Pines.

Now we must step to the left of our original position until we come in line with a row of four low trees to the left of the big center White Pine. The big Scotch Pine is now behind us. The four trees in the row before 11 , with the exception of the second, are Korean Pines and the second one is another common White Pine.

Still more to the left and ahead of us are more Korean Pines. They are lighter-colored than the others about them. The darker eight include the more or less distinct group toward the end of of this planting. They are

\section{Pinus flexilis, the Limber Pine}

Not much is known concerning this tree as an ornamental in this section of the country. It is a native of western North America, ranging from Texas to Alberta and westward into California at altitudes up to 12,000 feet. It is particularly a Rocky Mountain tree. In its native range it may attain a height of 80 
feet, though usually it is only about 50 feet tall. It is a hardy species of slow growth and frequently occurs as a stunted tree, at least, at the higher limits of its range. In some sections it forms extensive forests and is cut for lumber; elsewhere it occurs in mixture with other species.

Both the common and botanical names of this species have arisen from a remarkable flexibility of the wood, for a branch of the tree can be bent to any angle without fear of breakage.

The Limber Pine is a five-needle evergreen and is distinguished from all other five-needle pines, except $P$. albicaulis and $P$. pumila, by the fact that its needles are practically without teeth. This, however, can be determined only by the aid of a microscope, for a pine needle may appear perfectly toothless until examined under the lens. In fact, there are only five pines whose needles may be regarded as entire, that is, having no teeth. The two in addition to the three already noted are $P$. aristata, the Bristlecone Pine, and I'. Balfouriana, the Foxtail Pine. The Limber Pine is the only one of these five that is represented in the collection.

Pinns flexilis, like $P$. Combra and $P$. koraiensis, has wingless seeds, but differs from those two in having dehiscent cones that open upon maturity and liberate the seeds. This character of wingless seeds occurs only in three other pines, which are absent from the collections. Lustrous yellow cones, when present, are a further distinguishing feature of the Limber Pine.

Beyond all the Limber Pines and at the northern end of this Section are two large dark-colored Austrian Pines, one of which is more to the right. A third stands along the edge of the slope on our right.

We shall now turn our attention to the remaining trees on the slope to the right. To do so we shall go down to the path, face the slope, and commence with the low evergreen to the extreme left. It is

\section{Pinus sylvestris var. Watereri, Waterer Pine}

This plant was secured from a nursery under this name. It may, however, be incorrect, for the Waterer Pine is usually of upright columnar habit. 
Proceeding along the path we next pass a tree with reddishorange scaly bark. It stands a slight distance up the slope and is a Silvery Scotch-Pine (p. 41). thove it up the slope stands a good-sized common White Pine.

Next, along and nearer the patls, stands another White Pine. To the right of it is a row of three more Silvery Scotch-Pines extending up the slope.

Next and nearer the path, is another common White Pine. The very slender small tree some distance behind it with upward pointing branches is

Pinus sylvestris var. fastigiata, the Pyramiclal Scotch-Pine

This is another horticultural variation of the Scotcl Pine. It is quite distinctive and rather pleasing in shape when properly located.

The next very low evergreen along the path with tufted glancous leaves we should recognize as the dwarf form of the Japanese White-Pine (p. 15). Behind it is another large native White Pine. The very nice low compact globular tree behind and almost concealed by this large White Pine is a Macedonian Pine (1) 14). Abore it the broad short tree to the right is a Limber Pine (p. +6), and the one to the left of this is a common IThite Pine.

Let us now return to the path. First we pass another large White Pine. The next pyramidal compact tree that stands near the path is a Swiss Stone-Pine (p. 13). Behind it to the right and to the left are two large Thite Pines, and behind these the two big trees with drooping needles are Himalayan IThite-Pines (p. 16). These are two of the finest trees in the entire collection and can be fully appreciated only at close range.

Behind and between these two big Himalayan White-Pines is a Limber Pine and to the right and left a bit farther up the slope are two more native White Pines.

Back to the path, the broad bluish evergreen behind the concrete seat is a Macedonian Pine. Its top has been cut off. The next along the path is the same and behind these two the taller 


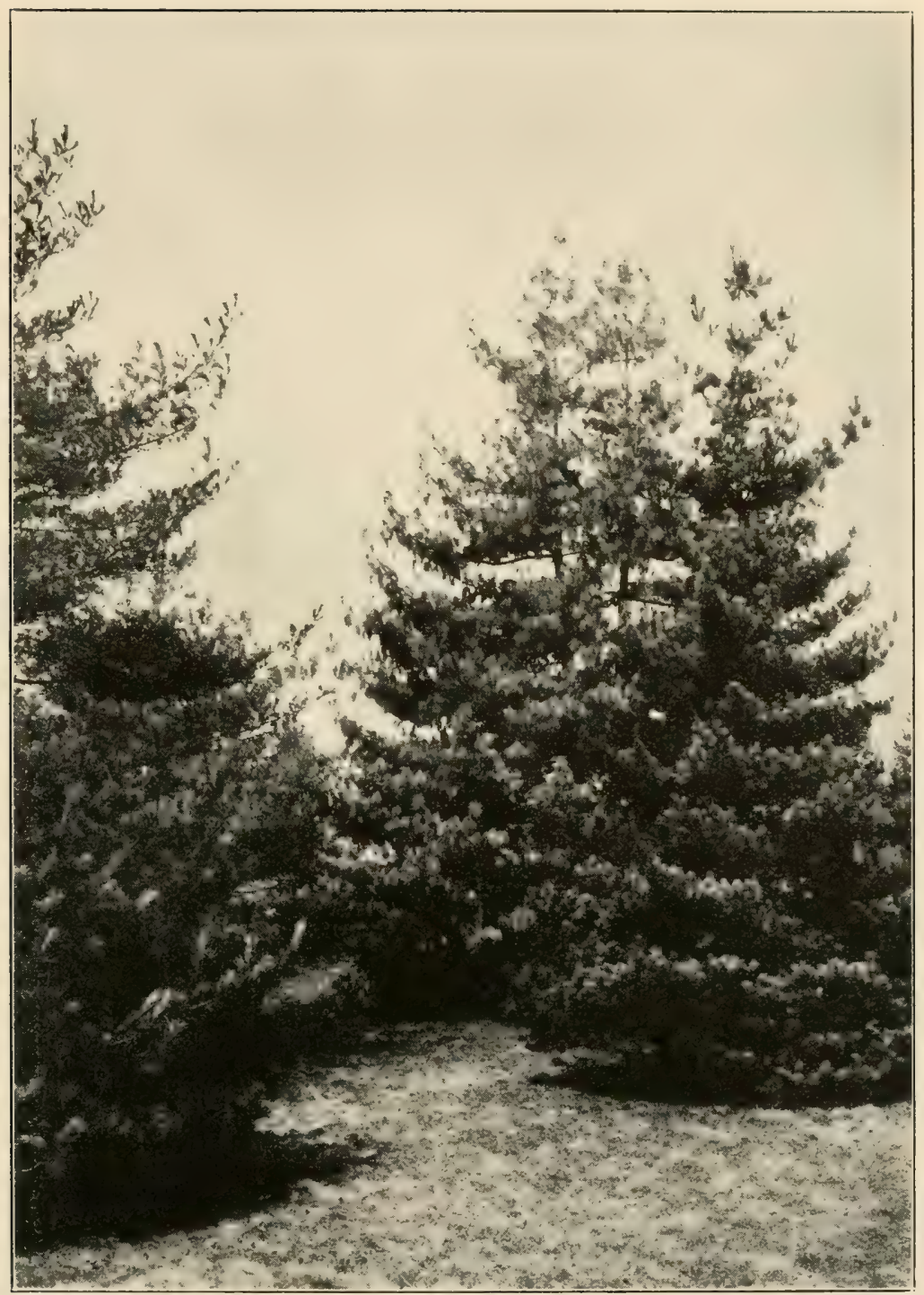

Figure 8. Macedonian Pine, P. Pcuce, right and left foreground; Himalayan White-Pine, P. nepa!ensis, center background; Eastern WhitePine, P. Strobus, above left-hand Macedonian Pine. 
tapering tree is yet another; three Macedonian Pines in a triangle here. The two front ones are rather similar to the Swiss StonePine just back to the left. But if we look carefully at the young branchlets near their tips we will see that those of the Stone-Pine are very distinctly hairy while those of the Macedonian Pines are smooth and yellowish. It is well to notice here that dust and dirt accumulates on these otherwise smooth surfaces and may appear as a fine hairiness. However, these three trees will very quickly show the difference between genuine hairiness and what may merely appear as such.

Farther along the path, we notice a large boulder half buried in the ground. By it stands another Himalayan White-Pine and two more trees of the same kind are in the nearby vicinity. One is the large tree farther up the slope and a bit to the right and the last one is farther along the path, betrayed by its long foliage. There is one more tree right here just before we get to this last Himalayan White-Pine. It stands at the same distance from the path and is a Korean Pine (p. 42). Moving on a bit, we come to an opening in the planting and the low dense evergreen half way up the slope is a Macedonian Pine.

Following the path now to the left, we pass four larger trees that we recognize as Austrian Pines.

The remaining four small evergreens near the last Austrian Pine are

\section{Pinus edulis, the Nut or Piñon Pine}

This tree so far is unimportant ornamentally in this section of the country. It is native to the Rocky Mountain regions at elevations up to 11,000 feet in New Mexico, Colorado, Utah, Arizona, and northern Mexico. The Nut Pine is normally of small stature, not more than 30 or 40 feet in height and its scraggly and stunted form on dry and gravelly uplands of the Southwest is one of the characteristic marks of that region.

The leaves on the Nut Pine vary in number, occurring singly or in threes, but usually paired. The wood is highly esteemed for fuel and railroad-ties, but otherwise has little value. The seeds. 
however, give the Piñon Pine its local popularity in the Southwest, for they are a delicacy to the people and when roasted are much prized. The gathering of these so-called nuts constitutes quite a little industry in the region and furnishes occupation for many.

\section{General Discussion}

Now that we have completed our study of some of them individually, let us consider the pines as a whole.

All pines are evergreen. That is, though their needle-like leaves are shed and new ones appear each year, only a portion of their foliage is lost at any one time. Consequently, the trees as a whole are always green. There is no regular periodic shedding and renewal of the foliage all at one time, as in the deciduous broad-leaved trees.

The pines constitute the largest and most widely distributed group of conifers. They are found throughout the Northern Hemisphere only, from the Arctic Circle to Mexico and the West Indies, North Africa, and the Malayan Archipelago; in tropical and subtropical regions they are usually confined to the mountains.* Including all the varieties that occur as a result of this wide distribution and those that have arisen through garden practice, more than six hundred kinds of pines have been described.

According to one authority, who recognizes sixty-six distinct species scattered over the Northern Hemisphere, the distribution is as follows:

Eastern Hemisphere-23

1 exclusively African (Canary Islands)

2 exclusively European

2 common to Europe and northern Asia

4 about the Mediterranean Basin

14 exclusively Asiatic
Western Hemisphere-43

28 in western North America, of which 12 are confined to Mexico and Central America

15 in eastern North America, of which 2 are exclusively West Indian

\footnotetext{
* Most plants, if they enjoy a wide geographical distribution from north to south and are normally inhabitants of temperate and northern climes, ascend to higher elevations in the southern limits of their range. This tends to lessen the contrast in temperature and other environmental factors
} 
According to this tabulation there can be in the United States no more than twenty-nine different pines. Including several distinct varieties, we may safely say that there are about thirty-five kinds. Is many different pines, therefore, are found in the continental United States as in the rest of the world. They are scattered from one end of the country to the other. As a survival from the first and most obvious classification of these trees that sprang up with the beginnings of lumbering in this country, the pines are still frequently classified as "hard" and "soft" pines. This distinction was originally based upon certain features of the wood and upon that basis it is often inaccurate. Certain so-called "hard" pines may be softer than certain so-called "soft" pines. These two groups, however, are recognized in further technical considerations where there is more accurate distinction.

Of the thirty-five native pines, twelve are spoken of as "soft" $\dagger$ and the other twenty-three as "hard." $\neq$ In the eastern United States the common White Pine is the only truly "soft" pine. The remaining pines in this section of the country are twelve different "hard" species, namely, Pitch, Red, Jack, Table-Mountain, Jersey or Scrub, Longleaf, Shortleaf, Loblolly, Cuban, Pond, Spruce and Sand Pine. The last seven of these are typically southern trees and consequently cannot be represented in the Garden collections. The other five northern species are all in the Pinetum.

Of the western species, Sugar Pine and Western White-Pine are the most important of the soft pine group. Neither of these occurs in the Garden, but there are six other western species, namely, Digger, Western Yellow, Lodgepole, Jeffrey, Limber, and Piñon Pine.

The most popular and convenient manner in which the pines are frequently divided and most commonly thought of depends upon

\footnotetext{
$\dagger$ These are White Pine $(P$. Strobus); Sugar Pine $(P$. Lambertiana): Western White Pine $(P$. monticola); Mexican White Pine $(P$. strobiformis $)$; Limber Pine $(P$. flexilis); Whitebark Pine $(P$. albicaulis $)$; Foxtail Pine $(P$. Balfouriana $)$; Parry Pine $(P$. quadri. folia); Mexican Piñon $(P$. cembroides); Piñon $(P$. edulis); Singleleaf Piñon $(P$. monophylla); Bristlecone Pine (P. aristata).

$¥$ These are Longleaf Pine ( $P$. palustris), Shortleaf Pine ( $P$. echinata), Loblolly Pine $(P$. Tacda), Cuban Pine $(P$. caribaea), Norway Pine $(P$. resinosa), Western Yellow Pine $(P$. ponderosa), Chihuahua Pine $(P$. chihuahuana), Arizona Pine $(P$ arizonica), Pitch Pine $(P$. rigida), Pond Pine $(P$. scrotina), Spruce Pine $(P$. glabra $)$, Monterey Pine $(P$. radiata), Knobcone Pine $(P$. attenuata), Gray Pine (Pinus Sabiniana), Coulter Pine $(P$. Conlteri), Lodgepole Pine $(P$. contorta), Jack Pine ( $P$. Banksiana), Scrub) Pine $(P$. virginiana), Sand Pine $(P$. clausa), Table-Mountain Pine ( $P$. punaens), California Swamp Pine ( $P$. muricata), Torrey Pine ( $P$. Torroyana)
} 
the number of needles that vocur together in a bundle or sheath. Altogether there are 27 different species and varieties of pine in the collections of the Pinetum and it will be well to list them here according to the number of their leaves.

Of 18 different known species with needles in 5's, seven are in the Garden, viz.:

P. Cembra, Swiss Stone-Pine of Europe and Siberia

$P$.excelsa, Himalayan White-Pine of the Himalayas

$P$. flexilis, Limber Pine of western North America

P. koraiensis, Korean Pine of northern Asia

$P$. parviflora, Japanese White-Pine of Japan

P. Peuce, Macedonian Pine of southeastern Europe

P. Strobus, Eastern White-Pine of eastern North America

Of 20 or 25 known species with needles in 3's, six are in the Garden, viz. :

P. Bungeana, White-Bark Pine of China

P. Sabiniana, Digger Pine of western United States

$P$. sinensis, China Pine of China

$P$. Jeffreyi, Jeffrey's Pine of western United States

$P$. rigida, Pitch Pine of eastern North America

$P$. ponderosa, Western Yellow-Pine of western North America

Of 20 or 25 known species with needles in 2 's, eight are in the Garden, viz. :

P. sinensis, China Pine of China

P. sylvestris, Scotch Pine of Europe and western Asia

$P$. Thunbergii, Japanese Black-Pine of Japan

$P$. nigra, Austrian Pine of southern Europe

$P$. virginiana, Jersey or Scrub Pine of eastern United States

$P$. pungens, Table-Mountain Pine of eastern United States

P. Banksiana, Jack Pine of eastern North America

$P$. densiflora, Japanese Red-Pine of Japan

P. resinosa, Red Pine of the United States

The other 6 pines not included here are varieties of these species.

()rnamentally some of the pines are distinctly valuable. As a whole, they are surpassed by the firs and spruces. They are, for the most part, trees; few are shrubby. Consequently, they serve for backgrounds or as individual specimens and do not as a rule fit into small plantings. For permanent and large settings they are especially fine, for they do not lose their beauty with age as do 
many spruces and firs. On the contrary, they gain in character and picturesque appearance. A number of dwarf, pendulous, and varicolored varieties have been developed by nurserymen from several pines, particularly the common native White and Scotch. Interesting bushy freaks are produced from the Canary Pine, $P$. canariensis, ${ }^{*}$ and the Italian Stone-Pine, P. Pinea, by layering. In this manner, single leaves, as the primary needles of young seedlings, are produced instead of two in a sheath.

The pines are not suited to pruning. Their foliage is too open to permit such operations and attempts in that direction generally result only in malformation. If their shape is to be controlled at all, the center buds may be removed from such shoots as project beyond proper limits. This will not only hinder the further growth of such undesirable branches, but will tend to direct growth into a more compact form.

Pines, furthermore, are not adapted for hedges. Their growth is too open and coarse and pruning cannot be resorted to. In addition, they are not shade-enduring and would soon thin out in the interior if they could be trimmed into hedges. The White Pine and the Mugho Pine have, however, served as hedges with some success.

The pines, as a rule, are less exacting in their soil requirements than are many other evergreens. They are essentially inhabitants of poor sandy soils and dry situations. Their stout deep root system enables them to seek scanty water supplies where other trees find it difficult. They respond best to medium conditions. Their heavy tap root needs a deep mellow well-drained sandy loam soil. Compact clay soils are inimical; shallow soils cause spindly growth. Wet lowland soils are not to their liking. They prefer well-drained or even dry hilltops to low bottomlands. Generally, they withstand southern exposures better than spruces. Too rich condition is apt to induce rank luxuriant growth that leads to poor form.

The White Pine lends itself most readily to a variety of soils, including clay. The Red Pine of the North and the Loblolly and the Longleaf of the South exhibit departures from the general

* Specimens of this species will be found in Conservatory Range No. 2. 
aversion of pines toward excessive moisture. The former will thrive in a swamp as well as on upland gravel and the latter makes magnificent trees in the southern swamplands. The Pitch Pine, too, is at home both in wet and dry places. The Scrub Pine of the West, Pinus contorta, as well as the Cuban Pine, I'. caribaca, and the Pond Pine, $P$. serotina, of the South, likewise seem indifferent to water conditions about their roots.

It must be borne in mind when combining pines with other trees in any setting that they are essentially light-demanding trees. Consequently, they will not endure overtopping or crowding unless by vigorous height growth they can extend above more shadeenduring competitors. If planted thickly in pure stands they will either soon lose their lower limbs and maintain a marked uniformity or the more vigorous trees will crowd out the others. The fiveneedle white pines, particularly Pinus Strobus, are the most tolerant and the dwarf Mugho Pine is markedly so too.

In respect to rapidity of height growth the leaders are the common White Pine, P. Strobus, Cuban, P. caribaea, Scotch, P. syliestris, and Austrian Pine, P. nigra. Under favorable conditions these will produce annual shoots of from one to two feet for a number of years. Pines of high altitude, on the other hand, are slow growers; e.g., Swiss Stone-Pine, P. Cembra.

In the matter of maximum height growth the common White Pine again is a leader. Before the days of excessive lumbering many of these trees exceeded 150 feet in height. This height is exceeded among the pines only by that of the very closely related western Sugar Pines and Western Yellow-Pines, which may become over 200 feet tall. Most others as a rule remain under 100 feet and the big majority seldom become over fifty feet tall.

While the pines as a whole may be inferior to the firs and spruces for ornamental purposes, they are unsurpassed as a group in the lumber world. No other trees of the temperate zone have contributed so much to the development of civilization in modern times as they. The common White Pine has long been regarded as the American wood par excellence. Its rapidity and quantity of production, its adaptability to variations of climate and soil, and the excellence of its wood have placed it in the lead. Reduced 
supplies, however, have curtailed its use. In 1850 White Pine surpasised all other woods in production. Today two-thirds of the lumber cut in this country consists of the four southern yellow pines, I.ongleaf, I'. palustris; Shortleaf, P. echinata; Loblolly, I'. Tacdu; and Cuban, $P$. caribaea. Other lesser kinds also contribute to this production.

In the West, the most important are the Western White, Pinus monticola; Sugar, P. Lambertiana; and the Western Yellow, P. ponderosa. In Mexico, the Mexican White-Pine, P. Ayacahuite, replaces our white pines, and the Arizona Pine, $P$. arizonica, and the Montezuma Pine, P. Monteatumae, are the important yellow pines.

In northern and central Europe, the Scotch Pine is the important tree, furnishing the bulk of supplies. In southern Europe, the Iustrian Pine, along with its several geographical variations, supersedes the Scotch Pine.

In Japan and northern China, the Japanese Red- and Blackl'ines are the important timber species. In the Himalayas the Himalayan White-Pine and the Long-Leaved Indian-Pine, $P$. longifolia, are the leaders.

And in the Philippines, the Khasia Pine, P. insularis,* forms important mountain forests.

In addition to its high lumber value the Longleaf Pine possesses further value in its productions of naval stores. The turpentine, tar, and pitch that is annually derived from its resinous contents constitute an important source of additional revenue for the Southern States. Pine wool is made from the leaves of this and other species; essential oils are distilled from leaves and young shoots and used medicinally and the seeds of the western nut pines furnish food.

\footnotetext{
* Specimens of this may be found in Conservatory Range No. 2.
} 


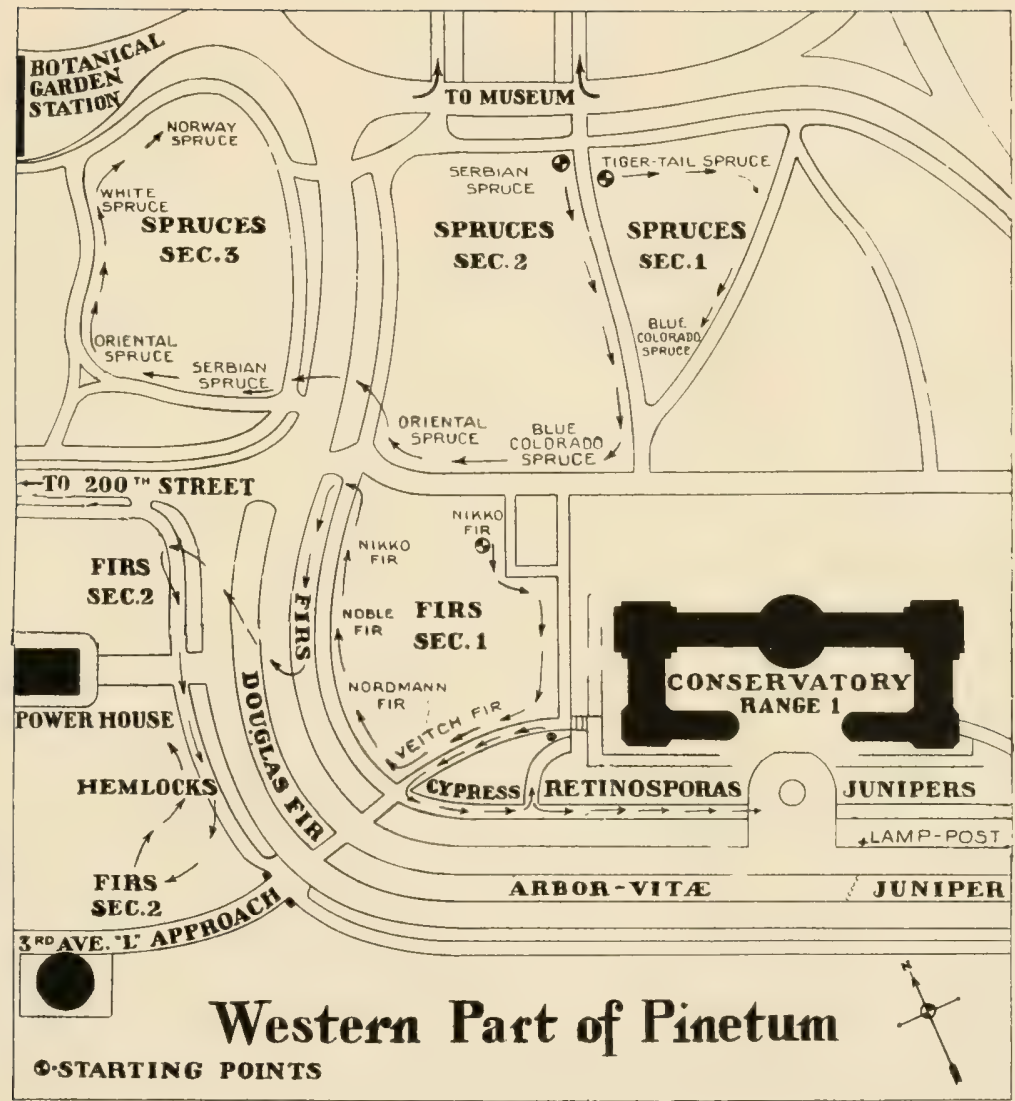




\section{PART 3-SPRUCES}

THE PRINCIPAL SOURCE OF PAPER-PULP

VALUABLE ORNAMENTAL EVERGREENS WITH HEAVY FOLIAGE

Section 1

The collection of Spruces lies north of Conservatory Range I and west of the Pines. Section 1 is the sloping triangular areat whose base lies along the south side of the cross road in front of the Museum (Map p. 57). In this Section are only two kinds of evergreens, arranged in four groups. All the evergreens in each of the basal corners near the road as well as those in a scattered group half way up the slope along the eastern bounding path are

Picea polita, the Tiger-tail Spruce

This is one of the most distinct of spruces. First contact with it cannot fail to impress one indelibly by the hostile rigidity of its needles. No other spruce resembles it in this respect. Its dark reddish-brown winter buds also are very conspicuous. It is very ornamental, quite hardy, and should prove excellent when young as a protective hedge.

The Tiger-tail Spruce is native to Japan, where it is the tallest of several spruces, attaining a height of 130 feet. Usually, however, it is only about half that size. It is generally found there on volcanic soils of recent formation and even on old lava flows. Under cultivation it succeeds in moist loamy and peaty soils but growth is slow. In Japan it is much cultivated for decorative purposes especially about temples. The wood is used to some extent for general construction purposes.

To the Japanese this tree is known as Bara-momi, Hari-momi and Toranoo-momi. The first name in each instance has reference to the sharp nature of the stout leaves. It is also known as White Fir, Siro-momi, in Japan. The Chinese know it merely as Common or Native Fir, Jo-bi-sjo.

All the trees in the apex of this Section nearer the Conservatory are 
Picea pungens var. glauca, the Colorado Blue-Spruce, and Picea pungens var. Kosteri, Koster's Blue-Spruce

The Colorado Blue-Spruce is probably the best known ornamental evergreen tree, for it is very extensively used. In fact, its unusual beauty has become almost common during recent years through overuse. It is very frequently set in most inappropriate places that fail to show the tree's true value. It is unusually hardy and generally a safe tree to plant.

A careful observer should notice in any number of these trees and particularly in those about us now that there is variation in the shades of color. During the winter the differences are scarcely apparent but in spring and summer they are very striking. The typical Colorado Spruce, several trees of which stand directly across the path to the west in the next Section, has green foliage. But this tree, as we shall also see in the Douglas Fir, seldom is typically green. It shows a variety of bluish tints and the Colorado Blue-Spruces represent the extremes in this variation. Many years ago an unusually blue variety appeared among some trees that were imported by Koster's Nursery in Holland from this country. It was propagated there by grafting in order to perpetuate its color and all the trees that have since been secured by grafting from that original stock are known as Koster's BlueSpruces. They are the most beautiful of the varieties. It should be understood, however, that all the blue spruces represent merely natural wild differences in degree of color and that one extreme variety has been perpetuated through grafting in the Koster's variety. All the other varieties may arise from seed.

While the blue spruces are magnificent for the first twenty years of their life they later tend to lose their lower limbs. This is especially true of the grafted forms. A side twig is usually employed for grafting and it has been claimed that the side of the mature tree which corresponds to the lower side of the original slip will first tend to show defects in later years.

The eight trees which are nearest the apex of this Section are Koster's Blue-Spruces. Those behind them are Colorado BlueSpruces. 


\section{Section 2}

Section 2 of the Spruces is the large and for the most part unplanted area directly west of Section 1 (Map p. 57). Beginning at the northeast corner near the fountain we find a group of small trees. They are

\section{Picea Omorika, the Serbian Spruce}

There is a group of four taller trees of this kind on the other side of the road. They stand at the foot of the right hand drive leading up to the Museum and on its eastern side. It might be well to step over there to see these larger trees also.

This is regarded as one of the best spruces for ornamental planting in the northeastern states. It assumes under cultivation a narrow pyramidal habit when young and is very hardy. It may be used as far north as New England and southern Ontario. It is, however, slow of growth. Furthermore, it thrives on limestone soil, which is a departure from the general rule among conifers. Moreover, it seems to endure a hot dry soil and impure atmosphere.

The Serbian Spruce has a very restricted natural range. It is found only in the valleys of the river Drina in southeastern Europe, where it occurs at elevations of 2,000 to 4,000 feet. It may attain a height of 100 feet there.

In the case of the pines, we found such very distinctive features as a certain number of needles in a sheath. In the spruces, however, no such simple distinctions occur. To identify them we must carry clear-cut impressions of the foliage and it is only by repeated comparisons that we can hope ultimately to be able to separate these trees. The Serbian Spruce, though it may not appear so at first, is one of the most distinctive. Its needles are flat and do not project from all sides of the twig but are arranged more or less in a horizontal plane and point forward. Furthermore, the branches are quite short in proportion to the height of the trees, thus giving a spire-like habit. The lower branches tend to curve up at their tips in older trees, and the small branchlets are hairy. 
Let us now go south along the ascending path on which we started. Near the top of the incline we come to a fine collection of spruces that stand just across the path from the Colorado Blue and Koster's Blue-Spruces in Section 1. The first ten trees on our right, some of which stand behind others, are

\section{Picea pungens, the Colorado Spruce}

This is the tree of which the beautiful blue forms that we considered on the other side of the path are variations. This green form is more or less rare, for the great majority of these trees show some degree of blueness.

This tree, too, is very fine for decorative purposes, but has the same failing as the blue forms, losing its lower limbs in later years. With its numerous color gradations it occurs wild in New Mexico, Colorado. Utah, and Wyoming, at elevations ranging from 6,000 to 10,000 feet. It may attain a height there of 150 feet. In addition to its names of Colorado and Colorado Blue-Spruce it is also known as Parry's Spruce, Prickly Spruce, White Spruce, Silver Spruce, and locally merely as Spruce or Balsam.

Next to its distinctive color in certain individuals the most characteristic feature about this tree is the general character of the foliage. The needles are relatively long, stiff-pointed, and project forward and outward from all sides of the twigs. The main branches, furthermore, are quite horizontal and occur in whorls.

The soft weak wood of this tree has little commercial value and is used only locally.

The next seven bluish trees are all Colorado Blue-Spruces.

Beyond them and near the path is another blue but very low nearly prostrate evergreen. It is

Picea pungens var. glauca pendula, IVeeping Colorado Blue-Spruce

This is merely a pendulous form of the blue varieties which originated in Holland. Another and bigger specimen of this form stands propped up between the road and path near the north end of Section 1 of the spruces. 
All the remaining trees with one exception that fill the southeast corner of this Section are Colorado Blue- and Koster's BlueSpruces. The one exception is a plain Colorado Spruce which stands behind the first Colorado Blue-Spruce next to the low pendulous form along the path. We shall not attempt to separate the others, hut shall proceed to the next path and then turn right.

All the blue spruces are now on our right once more as we go westward. Beyond them along this new path are six more new trees. They stand opposite the first small garden with a low wooden fence around it on our left. They are smaller trees, not so dense, and their foliage tends to droop. They are

\section{Picea Engelmannii, Engelmann Spruce}

This tree does not thrive so well here as its very close natural associate, the Colorado Spruce. The causes are difficult to determine exactly. They undoubtedly include such factors as polluted atmosphere, short winters, curtailed dormant season, too warm summers, and improper soil conditions with respect to drainage and nutrition. In other sections of the Northeast where the winters are severe the Engelmann Spruce becomes a handsome tree of pyramidal habit.

The native home of this tree is at elevations ranging from 3,000 feet in the Rocky Mountains of Alberta and British Columbia up to 11,500 feet in Arizona and New Mexico. It extends westward to the Cascades of Washington and Oregon, often forming pure forests.

Five of these eight trees are bluish varieties known as Picea Engelmannii var. glauca. At the proper season they are distinguishable by the color of their foliage.

The remaining thirty-one trees in this Section that stand ahead of us and extend around the next turn to the right include fifteen of the green type and eleven of the blue type of Colorado Spruce. We shall not attempt to separate them all. The first two, close together, that stand very near the path came from a nursery as Compact Colorado Blue-Spruce, Picea pungens var. glauca compacta. 
Mixed in with these Blue Spruces near the next bend are six trees of distinctly different foliage. Two of them stand just inside the low railing. Their needles, which are very much shorter than those of the Colorado Blue-Spruce, make the branches considerably more delicate looking. These trees are

\section{Picea orientalis, the Oriental Spruce}

This is one of the most attractive of all the spruces because of its dark-green short needles. Its cones are beautifully purple when young, later turning brown.

The Oriental Spruce is native in the mountain ranges of Asia Minor, Armenia, and the Caucasus, at altitudes rarying from 2,500 to 7,000 feet. There it may attain a height of 100 feet and more.

In its native region the wood of this tree takes the place of that used elsewhere in Europe from Norway Spruce. Both are commonly used abroad for Christmas trees.

\section{Section 3}

This third and last Section of Spruces lies between the railroarl tracks and the drive on the west side of the Garden and between the railroad station and the entrance into the Garden south of it at 200th Street (Map p. 57). We shall begin at the south end of the Section. If we have just completed Section 2, we need but cross the road and go down the gravel path on the other side flanked by bushes on both sides. A few steps in we meet the spruces again on the right. The first two evergreens are

Picea Maximowiczii, Maximowicz's or Japanese Bush-Spruce

This is a relatively rare kind of spruce, for even in Japan, where it is native, it grows only in remote mountainous sections. Unlike the Japanese Black-, Red-, and White-Pines, this spruce is not so commonly found about gardens and temples in Japan. To the Japanese it is known as Hime-bara-momi, i.e., Daughter or Small Bara-momi, which, we will recall, is the vernacular for the Tigertail Spruce. This derivation of the name has arisen from the similarity of adult trees of these two species. As its name implies, this one is generally of low stature, though it may attain a height of 80 or even 100 feet. 
It is difficult to mention any particularly distinguishing feature of this spruce. Perhaps most characteristic of it are its short leaves, which point out on all sides of the shoots, and the very resinous buds. The leaves, moreover, are quadrangular and rather pungent and the branchlets are not hairy.

The next four larger evergreens are Serbian Spruces (p. 60).

Of the next four small trees beyond these taller Serbian Spruces, one is

Picea jezoensis, the Yezo or Hondo Spruce

It is the inner tree in the second row of two trees.

This species has the widest distribution of any spruce in northeastern Asia and Japan, where it attains a height of 100 or 150 feet and is the only flat-leaved spruce of that region. From other flat- or compressed-leaved spruces, it may be distinguished by the pale shoots and dark-green leaves, which are crowded on the upper side of the shoots, and bluish or silvery-white on the lower surface. The wood of this species is of good quality and, since the trees are plentiful in Japan, as a source of timber the Yezo is by far the most valuable of the Japanese spruces.

Yezo Spruce is rare in cultivation in this country and does not grow well in the eastern Lnited States. It frequently suffers from late frosts owing to its early leafing.

The other three small trees are Norway Spruces. We shall consider this kind later when we meet larger trees.

The next two trees nearest the path are Oriental Spruces (1). $63)$. Behind them stand three other spruces. The single one directly in back is

\section{Picea mariana var. Doumetii, Doumet's Spruce}

This is regarded as one of the most ornamental garden forms of the native Black Spruce, which species is not at present represented in the Garden. In its typical growth Doumet's Spruce is featured by ascending crowded branches forming a dense conical pyramid.

The two other spruces behind this last one are Serbian Spruces.

Next to the Oriental Spruces along the path is 
Picea bicolor, Alcock's Spruce

This species, a native of Japan, is rare in cultivation and even in its homeland it is not common. To the Japanese it is known as Iro-momi. Whitish lines on both upper and lower surfaces of the leaves constitute the principal characteristic.

The next and last tree along the path right here is the same as those which stand in a group farther along the path to the right. They are

Picea canadensis, the White Spruce

This is one of the native spruces of the eastern United States with a transcontinental distribution from Labrarlor to Alaska and south to Montana, Minnesota, and New York. It is essentially a northern tree, reaching to within twenty miles of the Arctic Ocean. It is of more economic importance in Canada than in this country because of its abundance there. Some trees attain a height of 100 feet. In New England it is extensively used for paper pulp manufacture.

The White Spruce is characterized by curved needles with pointed hardened tips of a bluish-green color, by reddish or yellowish flowers, and by shining light-brown cones. Moreover, the needles stand out from all sides of the twigs in very regular pattern.

The foliage of the White Spruce, when bruised, has a rank odor. This feature has led to some of its common names, among which are Single, Bog, Skunk, Cat, and Double Spruce.

This spruce makes a handsome ornamental evergreen in cold moist regions, but does not thrive well where summers are warm and dry.

On the eastern side of these White Spruces are two other different ones. The smaller one nearer the Museum is probably $P$. Abies var. Gregoryana and the other one $P$. Abies var. compacta.

The remaining evergreens in this Section we see in a group just ahead toward the Museum. A weeping beech tree stands near them. The most westerly of the evergreens, a small dense globular plant, is a White Spruce. 
The five taller trees in the background whose needles do not project below the branchlets are

\section{Picea Abies or P. excelsa, Norway Spruce}

This is probably the best-known foreign evergreen that we have. It is very extensively planted in this part of the country and large veteran trees are not uncommon. Their principal distinguishing feature is the pronounced drooping habit of the countless evergreen branchlets that hang from the rigid boughs. This feature is just barely noticeable in trees before us. The Norway Spruce is one of the best conifers for shelters and windbreaks.

The Norway Spruce is native to most of the mountainous parts of central and northern Europe, east to the Ural Mountains. Though not wild in Great Britain, it has been cultivated there for four centuries. On the continent it attains a height of 100 and sometimes of 150 feet. Its wood is highly valued and extensively used in many wood-using industries. Burgundy pitch is the purified resin extracted from these trees. It is used in Europe in medicine for plasters and in the composition of varnish. Spruce beer, another by-product, is made from an essence of young shoots and leaves of Norway Spruces. The majority of Christmas trees in Europe and some in this country are this species.

1 great many garden forms have been developed from the Norway Spruce, some of which we shall see presently.

We shall now proceed eastward along the south side of this group. The two outer small sickly trees are

Picea canadensis var. coerulea, the Blue White-Spruce

This is a variety of our native White Spruce with extremely glaucous foliage.

The two tall trees with yellowish and somewhat drooping foliage next to the Norway Spruces are

Picea Abies var. finedonensis, the Finedon Spruce

This variety is strikingly pale yellowish in spring, later becoming green.

The two small dense evergreens in front of these last are

Picea Schrenkiana, Schrenk's Spruce 
This spruce comes from central Asia, where it forms large forests up to 10,000 feet elevation in Russian Turkestan. It is not well known in cultivation.

The taller tree with sloppy hanging branches nearby is

Picea Abies var. pendula, the Weeping Norway-Spruce

On the east side of this is a narrow opening. The outermost hroad tree on the right-hand side as we enter into the group is an undetermined variety of spruce.

Behind it is another Weeping Norway-Spruce and a similar one stands on the left. The next tall pendulous tree on the right is

\section{Picea Abies var. inversa}

This variety is almost identical with the Weeping NorwaySpruce but the branches are said to be denser and more closely appressed to the stem. Two other larger trees of this variety stand to our left and set back from the opening we are in. Their odd shape betrays them.

The more normal open-foliaged tree on the left side of the opening is

Picea Abies var. pyramidalis, Pyramidal Norway-Spruce

The very large and innermost tree in this opening which stands on the right with hanging branchlets is

\section{Picea Abies var. Cranstonii}

This tree was received over a quarter century ago under this name, which does not appear to be recognized at present. The long pendulous branchlets, however, seem quite distinctive.

As we regard this tree from its western side the next equally tall tree to the right is a Norway Spruce, as is the tall one behind and between these two. The tree to the right of the first of these two is

\section{Picea Abies var. Barryi, Barry Spruce}

This tree received under this name is distinguished from others with difficulty. The four smaller trees closely set together on the west side of this Barry's Spruce are

Picea Abies var. rubra, Red Norway-Spruce

This name, too, is not recognized and so no information can be given concerning this tree. 
Let us now go outside the group at this point. The very small compact evergreen with bristly foliage is

Picea Maxwellii, Maxwell's Spruce

This is a very dwarf compact variety with short stiff needles.

Behind it are the Red Norway-Spruces and next, to the right. is an unidentified one. East of this one is a larger Blue WhiteSpruce, behind which is the Barry's Spruce we have already noted.

The remaining large trees to the right are Picca Abies and its variety aurea. The latter have very yellow foliage in spring. There is one more Maxwell's Spruce and the taller though small dense evergreen to the right of it is

Picea Abies var. Gregoryana, Gregory Spruce

This variety is similar to the Maxwell Spruce, but the branches are slightly hairy.

\section{General Discussion}

The spruces, in the same sense as the pines, are all evergreens. There are thirty-eight different kinds in the colder and temperate climates of the Northern Hemisphere from the Arctic Circle to the high mountains of the temperate zone. These trees are distributed in the following manner:

Eastern Hemisphere-31

28 exclusively A s iatic, of

which 18 are confined to

China alone

2 exclusively European

1 European and Asiatic

In the United States there are only seven native spruces, three in the East and four in the West. The three eastern ones are the White, Black, and Red Spruces. Picea canadensis, P. rubra, and $P$. mariana respectively. The western ones are the Colorado, Engelmann's, the Weeping and the Sitka Spruces, Picea pungens, $P$. Engelmannii, $P$. Breacriana, and $P$. sitchensis, respectively.

The pines, as we have seen, may conveniently be divided into three classes according to the number of needles in each cluster. In the spruces, howerer, the needles occur singly in a spiral arrangement on the twigs. But three groups may be distinguished according to the shape of these leaves. 


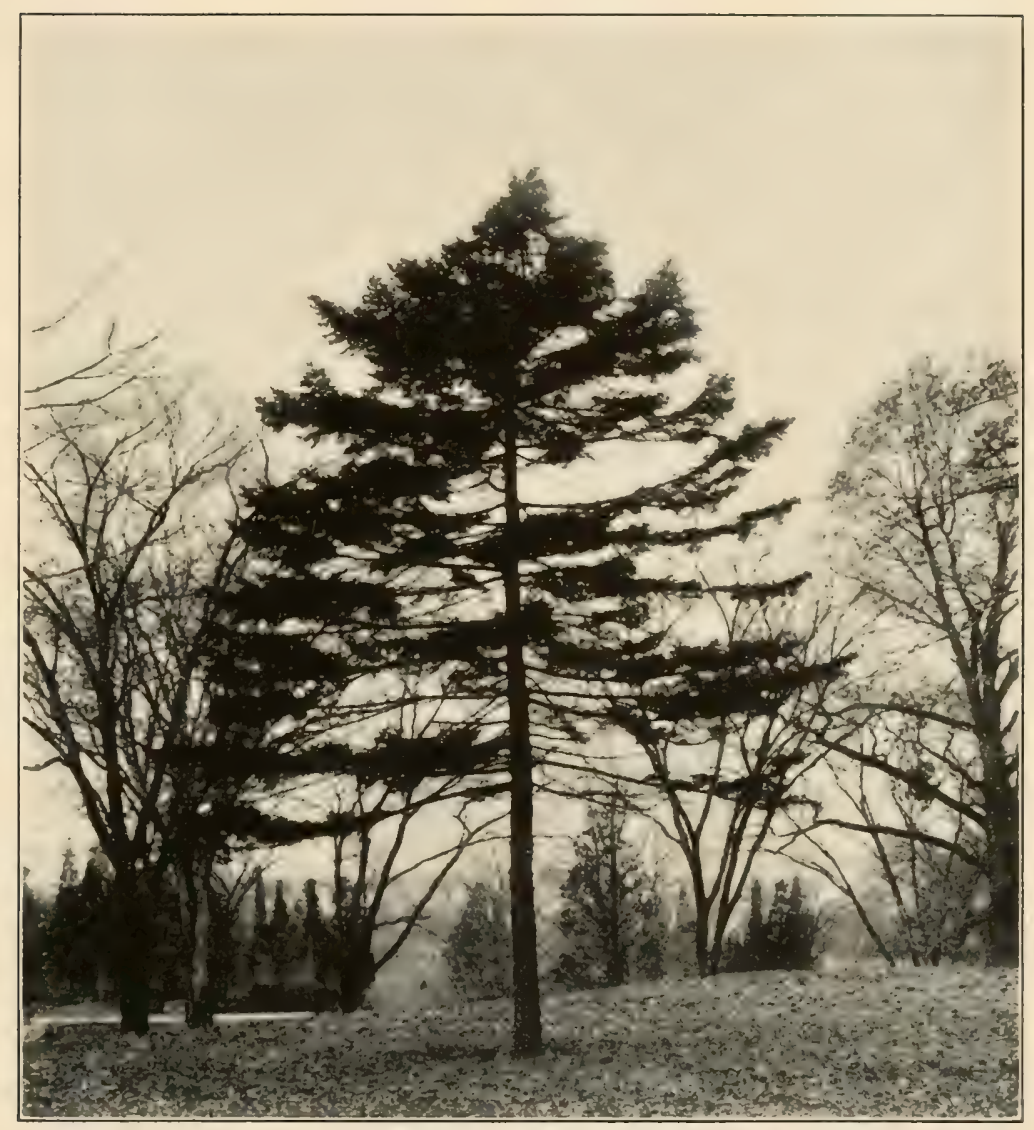

FIgURE 9. Black Spruce Picea mariana 
Of six known species with flat leaves having whitish bands on the upper side, which, however, face downward because of a twist in the leaf stalk, two are in the Garden, viz.:

$P$. Omorika, the Serbian Spruce of southeastern Europe

$P$. jezoensis, the Yezo or Hondo Spruce of Manchuria and Japan.

Of five or six species with four-angled and four-sided leaves having whitish lines conspicuous on two sides and inconspicuous on the other two, two are in the Garden, viz.:

P. Engelmannii, Engelmann Spruce of the western United States.

P. pungens, Colorado Spruce of the western United States

Of about eighteen species with four-angled four-sided needles equally marked on all four sides, seven are in the Garden:

P. Schrenkiana, Schrenk Spruce of Central Asia

P. Maximowiczii, Japanese Bush-Spruce of Japan

$P$. polita, Tiger-tail Spruce of Japan

$P$. Abies, Norway Spruce of Europe

$P$. orientalis, Oriental Spruce of Asia Minor

$P$. bicolor, Alcock Spruce of Japan

P. canadensis, White Spruce of eastern North America.

It would be very unusual for a pine and spruce to be confused, for the former always has its needles in clusters and the latter never. Spruces, however, may be confused with firs, which we shall see next. But the spruce needles are borne on persistent stalks which make a twig rough after the leaves have fallen but on the firs smooth round scars are left.

The spruces thrive best in moderately moist sandy loam but will grow in almost any kind of soil provided it contains sufficient moisture. They are somewhat more exacting in soil requirements than the pines, for they endure neither wet nor dry conditions. Northern slopes are well suited to them and they endure shade better than most other conifers, surpassing the pines in this respect. While the pines generally have a deep taproot and require deep soil, the spruces spread their roots more horizontally. They will grow, consequently, in shallow soil and are easily transplanted even as large trees. For the same reason they are easily windblown. 
( )rnamentally, the spruces rank very high, possibly exceeding the pines in some respects. They are more symmetrical and compact during youth but tend to lose their shape with age. There is considerable variety in their forms, ranging from the stiff Colorado Spruces through the delicate-foliaged Oriental Spruce to the pendulous Brewer's Weeping Spruce.

Commercially, the spruces are less important than the pines, so far as lumber is concerned. For paper pulp, however, especially in Canada and the northeastern states, they have long been regarded as the best source and great forests have gone into paper manufacture. 
PART 4 -FIRS

SOURCES OF BALSAM AND HANDSOME ORNAMENTAL TREES

\section{Section 1}

The collection of Firs lies west of Conservatory Range 1. Section 1 is directly across the path from the flower beds on that side of the Conservatory (Map p. 57). We shall begin at the northeast corner of this Section directly across the path from Section 2 of the Spruces and on the west side of two small flower gardens that have been cut out of this corner. Proceeding south the first thirty-one trees are

\section{Abies homolepis, the Nikko Fir, and Abies homolepis var, umbellata}

The Nikko Fir has proved to be one of the most satisfactory ornamental firs for planting in the eastern states. Its principal clistinguishing feature is the presence of deep regular grooves on the under side of the branchlets, particularly on two-year-old ones. The needles are rather firm and rigid though not prickly and form a distinct $V$-shaped trough along the upper side of the hranchlet. The buds, furthermore, are resinous and very distinctive.

This is the common fir of Japan, where it attains a height of 125 feet at elevations between 2,500 and 5,000 feet. It is there known as Dake-momi. Its commercial use as a lumber tree in Japan is precluded generally by its relative inaccessibility. Though it may attain a greater height, it is seldom over 80 or 90 feet. A very prominent gross feature is that the upper branches grow longer than the lower ones. This is apparent in some of the trees before us.

The Nikko Fir has purple cones whereas the variety umbellata has cones that are green before maturity. Other distinctions are so minute and variable that we shall not attempt to separate the two forms here. The variety is also a native of Japan.

All the remaining trees along the eastern side of the Section and 
twenty-five smaller ones in two rows at the southern end extending westward down the slope are

\section{Abies Veitchii, Veitch's Fir}

An additional tree of this kind is mixed in with the Nikko Firs. It stands at the western side of the group and just north of the last two Nikko Firs.

From the Nikko Fir this new kind may be distinguished by its shorter prominent whitish leaves and by its more slender shoots, which are pubescent. The small resinous purplish buds, too, are quite distinctive.

Veitch's Fir is the smallest of the Japanese firs, though it may attain a height of 80 and even 100 feet. It is typically alpine rarely descending below 3,000 feet. Its wood is of no particular value in Japan, but in this country the species ranks as an ornamental tree next to the Nikko Fir among the Asiatic species. In Japan it is known as Shirabiso, Shirabe-momi, and Shira-tsuga.

In the two parallel rows of trees containing the twenty-five Veitch's Firs along the flower bed at the south end of this Section, there are actually twenty-eight trees. The sixth in the inner row proceeding down the slope is noticeably different from the surrounding Veitch Firs, particularly in its branches and buds. We should recognize it as Nikko Fir. The flat-topped and tallest tree in the two rows that stands next to the last in the outside row going down the slope is

\section{Abies Momi or A. firma, the Momi Fir}

This is one of the most distinct of firs and can scarcely fail to impress one by its very broad, long, light-colored, almost yellowgreen needles. They stand out very rigidly in a single plane from two sides of the branchlets in the manner of the teeth of a comb. Each leaf generally bears two teeth at the end; and the shoots are grooved.

This is the only fir known from southern Japan, where it is regarded as the largest and handsomest of the genus. It attains heights up to 150 feet and ascends to 7,000 feet elevation. It is much cultivated in temple grounds and parks in Japan. The soft, 
straight-grained and easily worked wood is used for building purposes and cheap paching cases, but is not greatly ralued. Most of the boxes in which Japanese lily bulbs are packed for export are made of this wood as well as much of the paper pulp of Japan.

Though the Momi Fir is a thing of beauty in Japan, it does not do so well in this country. for it is not quite so hardy as some other species.

The well-developed tree with longer needles standing at the end of the inner row is

\section{Abies Nordmanniana, Nordmann's Fir}

This tree is regarded, along with the Nikko Fir, as one of the must desirable of foreign firs for ornamental planting in this part of the country.

It is native to the Caucasus. Asia Minor, and Greece and attains a height of 150 feet in the mountains around the Black Sea. Some commercial importance is attached to the tree there. It is readily listinguished by its long narrow leares with two whitish lines helow and by its scattered hairs on the young shoots. The leaves. iurthermore, are arranged in a characteristic horizontally forwardpointing manner.

Near this Nordmann's Fir, the tree close to the path at its bend and a few feet beyond the end of the flower bed is

\section{Abies cilicica, the Cilician Fir}

This species resembles the last in the arrangement of the foliage but the leaves are less crowded on the shoot, are narrower and are more or less pointed at the apex. We shall meet a better specimen later. The buds, moreorer, are rough with the prominent tips of the scales.

The Cilician Fir hails from about the same regions as the Nordmann's. It is native of Asia Minor and northern Syria. occurring on Mount Lebanon and the Antitaurus in association with the famous Cedars of Lebanon. In this range it attains a height of 100 feet. 
Now we shall work our way toward the Museum along the western side of this Section. The flat-topped tree that stands a few feet directly north of that first Nordmann's Fir is another Momi Fir. West of it and ahead of us, are seven more Nordmann's Firs. The finest of these is nearest the path and Museum. Directly east of it are two trees with wide-spreading horizontal branches. The one nearest the road we should identify ats another Momi Fir and the other very similar to it in foliage as well as form is

Abies homolepis var. Tomomi, the Tomomi Fir

Another specimen of this tree stands in the open about half way up the slope toward the Conservatory. Is already mentioned. the foliage of these two trees is somewhat like that of the Momi Fir, but if we inspect the twigs we find them conspicuously grooved, indicating the affinity with the Nikko Fir. It is characterized by shorter leaves, a more sparingly branched form, and occurs wild in Japan.

We now come to a number of smaller trees. Two of them are near the path. The first of these is another Cilician Fir and the second poorer-shaped tree is a Greek Fir, which we shall soon consider. Directly toward the Conservatory from this last is another Greek Fir and the surrounding six small trees including four we have passed are

Abies nobilis, the Noble Fir

The last of these is the low flat-topped one about four feet high to our left.

The Noble Fir is one of the massive species of the Pacific Northwest, where it is native on the Cascade and Coast ranges from Vashington to northern California. It frequently excceds a height of 250 feet in this range, but under cultivation in the East is usually of a dense bushy form. This species is distinguished from other firs except Abics magnifica, another great species of the West but absent from the collection here, by the crowded leaves on the upper side of the branchlets, having their bases flattened against it. 
The nine small evergreens that are spread out east of the Noble Firs and toward the Museum are

\section{Abies cephalonica, the Greek Fir}

The Greek Fir is a native of the higher mountains of Greece and the Isle of Cephalonia once boasted a forest of this species 12 to 15 miles in length and 36 miles around. This fir is distinguished from others by its departure from a general feature of the firs. Its foliage is spruce-like, that is, the needles are radially arranged on the twigs growing in all directions rather than in certain planes as with other firs. Moreover, the leaves have spiny tips.

Now we come to another group of taller and more developed trees. The first one along the path beyond the Noble Firs is a Momi Fir (p. 73), and the second of similar size and shape is another Veitch Fir. The four large and similarly shaped and broader trees to the right and beyond are Nikko Firs (p. 72). Beyond the one of these along the path the tree with somewhat drooping branches is a Cilician Fir. To the right of it are two more of similar size. The remaining eight trees along the path, the first of which is the poorest specimen, are all Nikko Firs, with possibly one specimen of the variety umbellata. All the remaining trees in this Section east of these Nikko Firs are

\section{Abies concolor, the White Fir}

The White Fir is the most successful of our native firs as an ornamental tree in the Eastern States. It withstands heat and drought well and generally forms a very fine tree. It is fairly tolerant of shade.

In the West it is one of the largest conifers, attaining, at times, a height of 250 feet. In the Rockies it is a tree of ordinary size. The weak brittle wood is generally unsuitable for lumber, but well adapted for butter- or lard-box material, for it is free from objectionable odors.

This fir is readily distinguished by its foliage. The leaves are quite long, flat, glaucous, and curve outward and upward. The bark on the trunk usually shows numerous balsam blisters whose contents are employed as Canada Balsam. 
A few more firs are located between the path and road on the west side of this Section. Proceeding south along the path and beginning opposite the corner of the Section we have just completed, the first two evergreens with a yellow hirch between them are Nikko Firs.

The next three beyond the intervening white poplar are Veitch lirs. Farther south after an open space is a Cilician Fir. All the other trees on this narrow strip between path and road we shall consider later, for they belong to another genus, the Douglas Fir.

\section{Section 2}

Section 2 of the Firs consists of two small separated areas on the west sicle of the two roads that separate them from Section 1 (Map p. 57). The first little area is on the north side of the Power House and in the depression partially surrounded by the bank that borders the walk. There are two small firs in the depression. They are

\section{Abies lasiocarpa, the Alpine Fir}

This species is native at high altitudes from Alaska south to Oregon and Colorado. Under optimum conditions it may attain a height of 160 feet, but at the upper limits of its range it is generally stunted and dwarfed. It is exceedingly hardy and can endure temperature conditions ranging from $90^{\circ}$ above to $40^{\circ}$ below zero. This is one of the few firs having leaves with white lines on both sides. Furthermore, the buds are completely covered with resin, the branchlets are pubescent and the needles are directed upward and forward. It is not a satisfactory tree in the Eastern States.

Now we must go south again, this time along the western side of the road and almost as far as the Elevated Station, passing the collection of hemlocks on our right. Two big sugar maples stand on the inside of the path just before we get to the elevated approach and west of them we see the last of the firs. 
Nearest the Elevated Station there is a distinct group of four trees. Of these the two nearer the station are

Abies grandis, the Grand or Lowland Fir

This species has very distinct foliage, which is conspicuously pectinate, that is, it stands out on two sides of the branches as the teeth of a comb and the needles are quite long.

The Grand or Great Fir, native to the Northwest from Vancouver Island to northern California and east to Montana, is one of the biggest trees of the country, attaining a height sometimes of 300 feet. This tree, too, is not very satisfactory as an ornamental in this part of the country.

The other two trees in this group are Tomomi Firs (p. 75).

There remain now six more fir trees a few steps northward. The first we come to is a Nordmann's Fir (p. 74), and then comes a row of three extending westward. The one nearest the road is another Nordmann's and the middle one is a Nikko Fir.

The last specimen in the row nearest the railroad tracks is

Abies Picea var. pendula, the Weeping Silver-Fir

This is a pendulous form of the Silver Fir of central and southern Europe.

Of the two remaining firs in the last row the one nearest the railroad is a Cilician Fir and the other is a Nikko Fir.

\section{General Discussion}

There are about 35 different kinds of fir trees distributed in northern and mountainous regions of the Northern Hemisphere. They are all evergreen and to a great degree cold climate trees, though in the New World they extend as far south as Guatemala and in the Old World to North Africa and the Himalayas.

The firs are easily distinguished from the pines by not having their leaves in clusters. From the spruces they differ in having smoother twigs and trunk since the fallen needles leave only a scar and no spiny stalk. Furthermore, the cones of firs, when present, stand erect on the branches while those of spruces hang down. 
The firs may be conveniently divided into two groups accordin:; as the tips of the needles are single-pointed or double-pointed by a tiny cleft.

Of a dozen different species having single-pointed leaves, four are in the Garden, viz.:

A. cephalonica, Greek Fir of Greece

A. concolor, White Fir of the western United States

A. lasiocarpa, Alpine Fir of the western United States

A. nobilis, Noble Fir of western North America

Of about twenty-five kinds with double-pointed leaves, six are in the Garden, viz:

A. Momi, Momi Fir of Japan

A. homolepis, Nikko Fir of Japan

A. grandis, Grand Fir of western North America

A. Nordmanniana, Nordmann Fir of Caucasus

A. Veitchii, Veitch Fir of Japan

A. cilicica, Cilician Fir of Asia Minor

Of the nine species of fir indigenous to the United States, only two occur in the East, neither of which is in the collection. They are the common Balsam Fir found in the Northeast and extending well into the West. A. halsanca, and the Fraser fir, A. Fraseri, that has a rather limited range at high elevations in the Appalachian region from West Virginia to North Carolina and Tennessee.

Of the seven western species, four occur in the Garden. The three lacking species are the Red Fir, Ahies magnifica, one of the tallest firs of the Pacific Coast; the Bristle-cone Fir, A. venusta, that occurs in west central California; and the Cascade Fir, $A$. amabilis.

The firs are characterized, in one respect, by peculiar exudations from the resin vesicles in the bark. These exudations appear as blisters on the trunks and branches of the trees and when punctured yield their contents. In the north woods this juice is collected at certain times of the year from the Common Balsam. $A$. balsamea, and manufactured into Canada balsam, a preparation much used as a transparent cement in microscopic slide work.

Though possessing some timber value, these trees are of less lumber importance as a whole than the pines and spruces. The wood is soft and perishable and generally inferior. In Europe the 
wood of Abies Picea is somewhat valued and in the Pacific States that of $A$. grandis, $A$. concolor, and $A$. magnifica is employed in the manufacture of fruit boxes and woodenware.

The firs are, however, handsome in cultivation and though usually of relatively short-lived beauty possess much ornamental value.

They prefer moist well-drained soil and cool situations. Around New York City summers are generally too warm for them for they normally are high-altitude trees. The most successful in the eastern states are $A$. concolor, A. homolepis, A. Veitchii, A. cilicica, and A. Nordmanniana. 


\section{PART 5-HEMLOCKS}

\section{BEAUTIFUL SHADE-ENDURING EVERGREENS}

The collection of Hemlocks occupies a rather small area between the railroad and drive on the west side of the Garden. The area lies south of the 200th Street entrance and is a continuation of the last section of the Firs adjacent to the Elevated Railroad Approach (Map p. 57).

The first four low bushy spreading evergreens near the path on the west side of the road are

Tsuga canadensis var. pendula, the Weeping or Sargent's Hemlock

This is one of the most graceful and pleasing of pendulous conifers. It forms, generally, a flat-topped low broad mound of remarkable beauty. It is extensively used and worthy of recommendation.

This handsome variety of our Canada Hemlock is of native and natural origin. It was discovered about 1870 by General Joseph Howland near the summit of Fishkill Mountain near Beacon City on the Hudson River. Four plants were found and distributed to a corresponding number of persons, including Professor Sargent. whose name the plants now bear. One was retained by the discoverer himself. In 1924 the two plants thus originally disposed of were the only remaining living specimens of the original forms. The plants in cultivation are grafts, which vary in habit and appearance and have a less dense character than the originals, for they tend to form an erect stem and are looser and more tufted in habit. The remaining original of Professor Sargent is 6 feet high, 23 feet through, and has a circumference of 70 feet.

Other specimens of this handsome evergreen will be found at several places in the Garden. One that is particularly attractive in spring, when the loright green new growth covers it, overhangs the water in the fountain before the Museum Building.

The isolated and more upright though small hemlock just north of these weeping forms is 


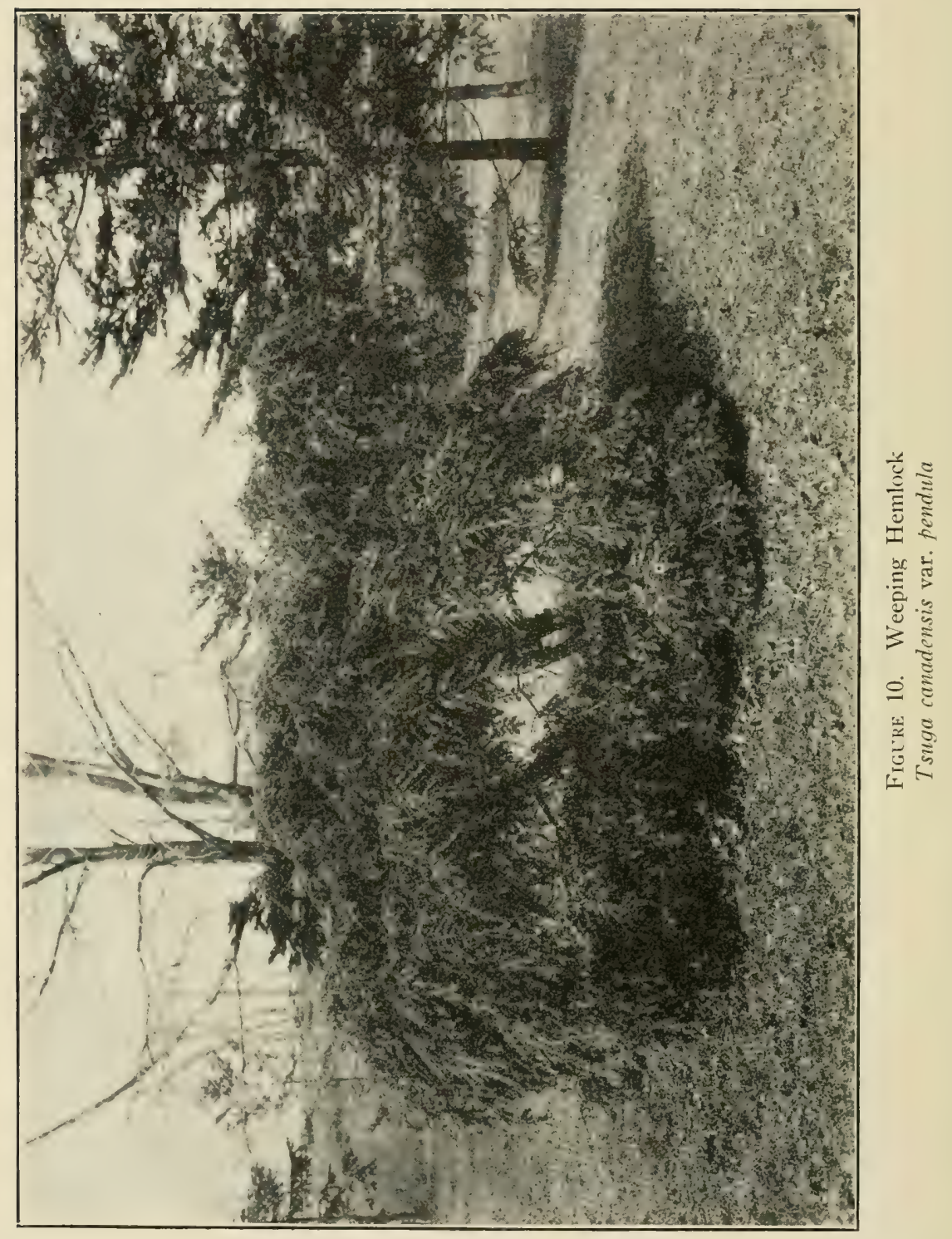


Tsuga Tsuga or T. Sieboldii, Siebold's or Japanese Hentock

This is one of two hemlocks native to Japan, where it attains a height of 80 feet. The wood is quite durable and is used in Japan for house construction and for paper pulp. The bark is rich in tannin and is employed there for tanning purposes. The tree is distinguished by its polished notched rather broad needles and hairless shoots. Other specimens stand ahead of us.

Under cultivation this hemlock forms only a low bushy tree of very slow growth. It is not so hardy as the other Japanese Hemlock, which we shall soon meet, and should be planted in a sheltered situation.

Proceeding north, the next small evergreens stand in rows, not parallel, but generally extending toward the railroad from the road. The first such row, lying with a distinct bias to the others, has three small trees. The first of these near the road is

\section{Tsuga canadensis var. compacta, the Dwarf Canada-Hemlock}

This is a variety of the Canada or Common Hemlock. The specimen before us does not betray its varietal habit well.

The next in the row is another Siebold's Hemlock, and the last one is either the Canada Hemlock or some variety of it; its exact identity has not been determined.

In the second row of four trees, starting with the low branching one nearest the road we find first another Siebold's Hemlock, then another Dwarf Canada-Hemlock. The third and largest tree in the row is

Tsuga canadensis, the Canada Hemlock

This is one of our finest native evergreens, highly valued for its ornamental use. In addition to its beauty, its shade-enduring qualities recommend it. Its range extends from Nova Scotia to western Wisconsin, south to Delaware and southern Michigan and along the Appalachian Mountains to northern Alabama and Georgia. The original stand of hemlock that stood in this area at the advent of the white man was enormous. Most of it was left standing when the better white pine was first cut out but subsequent 
logging operations began to remove this material that at first was regarded as rather inferior. Today hemlock is largely manufactured into coarse lumber for outside uses.

The bark of this tree has long been the principal source of tanning material. Today the tanning industry still depends to a marked degree upon the remaining hemlock forests of the eastern United States for its raw material.

The needles of the hemlock constitute its main distinguishing feature. On their lower surface they bear two distinct white lines, which give the lower side of the foliage a glaucous or silvery appearance. Other conifers, however, are similarly marked but the needles of the hemlock are smaller and delicate and stand out in two opposite rows on the branchlets. The cones, moreover, are rather small and characteristic. Furthermore, the inner bark on mature trees is generally red, as is betrayed by picking off the outer layers. The trees attain heights of 80 and 100 feet.

One of the best natural features of the Garden is the Hemlock Grove that borders the Bronx River on both sides as it flows through the Garden. Here a bit of the virgin forest of old hemlocks has been maintained. Behind the large Canarla Hemlock, recently mentioned, stands another Siebold's Hemlock.

The next row begins with the small tree that stands nearest the road of any in this entire group. The row extends at an angle away from the last and contains four plants. The first is

Tsuga diversifolia, the Hairy-twigged Japanese-Hemlock

There are but two hemlocks native to Japan, one of which we have already met and this is the other. At first one might very easily confuse them or note no difference, for they are incleed very similar. Closer observation, however, will soon show that the leaves of $T$. diversifolia are shorter than those of $T$. Tsuga, giving a rather distinctive appearance and that the branchlets are hairy while those of Siebold's Hemlock are not. There is another specimen of this Hairy-twigged Japanese-Hemlock ahead of us, the first in the next row.

To the Japanese this species is known as Komi-tsuga or Kurotsitga. 


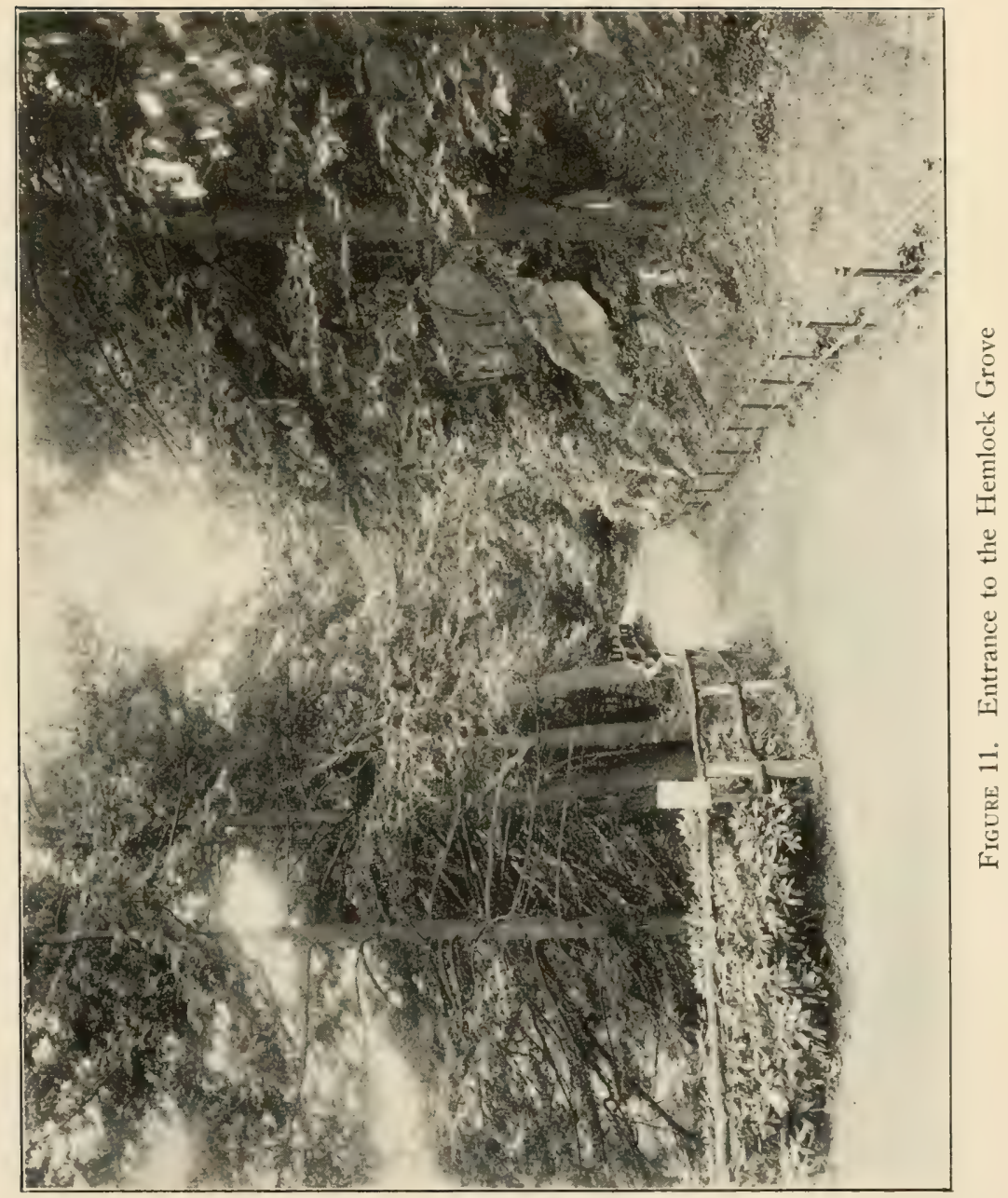


The second specimen in the diagonal row is a Dwarf CanadaHemlock and the next very low shrubby plant is

Tsuga caroliniana, the Carolina Hemlock

This is a native species, with a very restricted range, extending in the mountains from southern Virginia to northern Georgia. It is regarded as one of the handsomest evergreens for ornamental purposes, possessing great beauty and grace in its very dark compact and drooping habit. The specimen at hand unfortunately shows none of the fine qualities of the species.

The fourth and last plant in the diagonal row is a siebold's Hemlock and directly back of it toward the railroad but not in the diagonal row stand two Canada Hemlocks, the first a small and sickly specimen and the last a large more mature one.

The last row contains three trees and is approximately parallel to the preceding bias row. The first is a Japanese Hemlock, the second is a Canada Hemlock and that last rather nicely shaped rounded specimen that stands near the road leading into the power house is another Hairy-twigged Japanese-Hemlock. There remains one more small tree, a Canada Hemlock.

\section{General Discussion}

There are altogether nine or ten different known hemlocks. Four of these are native to the United States; two in the Eastern States, Tsuga canadensis and T. caroliniana, and two in the West. T. Mertensiana and T. heterophylla. Of the foreign ones, two are found in Japan, $T$. Tsuga and $T$. diversifolia. The others, of little importance, grow in China and the Himalayas.

The hemlocks are all evergreens, bearing rather small cones about one inch in length. They are generally recognized by their flattish needles arranged on the twigs in two opposite ranks. In this respect they resemble the firs. The leaves of the latter, however, are attached directly to the twigs, leaving a circular scar when they fall while those of the hemlocks arise from a slender stalk which lies pressed against the twig.

Excepting that of the western and Japanese species, T. heterophylla and T. Tsuga, the light, soft, brittle and coarse-grained 
wood of hemlock is not durable or much valued. The bark is rich in tannin, as has already been stated concerning the Canarla Hemlock.

Ornamentally the hemlocks rank very high. They are stately and graceful without the stiff formal appearance of many of the other conifers. They are not particular as to soil, providing it contains constant and sufficient moisture. They are easy to transplant and propagation is secured by seeds or by grafting on stock of the Canada Hemlock. The varieties and the Japanese species are also raised from cuttings. 


\section{PART 6-DOUGLAS FIR}

\section{AMERICA'S GREAT TIMBER TREE AND A FINE}

ORNAMENTAL EVERGREEN

The collection of Douglas Fir is located near the entrance to the Elevated Railway Approach and on the narrow planted area between the roads there (Map p. 57). All the evergreens north of the path that runs across the strip at the entrance from one road to the other are Douglas Fir. Eight other similar trees stand on the slight embankment across the inner road.

I very much larger grotu stands in another part of the Garden, near the Iris, Peony, Tulip, and Narcissus collections. These trees are

Pseudotsuga mucronata or P. taxifolia, the Dotglas Fir or Douglas Spruce

This is one of our finest large ornamental evergreens. It is native to the western part of our country and in its range shows two distinct types. Along the northern Pacific Coast it becomes a tall tree up to 300 feet in height and is of outstanding lumber importance. But that form is inclined to be tender. In the Rocky Mountain part of its range it becomes a smaller tree of slower growth, but is not so tender. This is the form that is extensively used for ornamental planting in this part of the country.

Much as we found in the case of the Colorado Spruce, the Douglas Fir shows color variations. The tender coastal form is typically green and the Rocky Mountain type bluish with graditions between. Any group of seedlings will exhibit these chance rariations and any especially blue individuals may be perpettated by grafting.

Ornamentally, the Douglas Fir is highly esteemed. It makes a handsome tree of rapid growth and is one of the finest of our larger evergreens.

For about two decades, more Douglas Fir timber has been felled in this country than of any other single kind of tree. Only the combined output of the four or five southern yellow-pines 


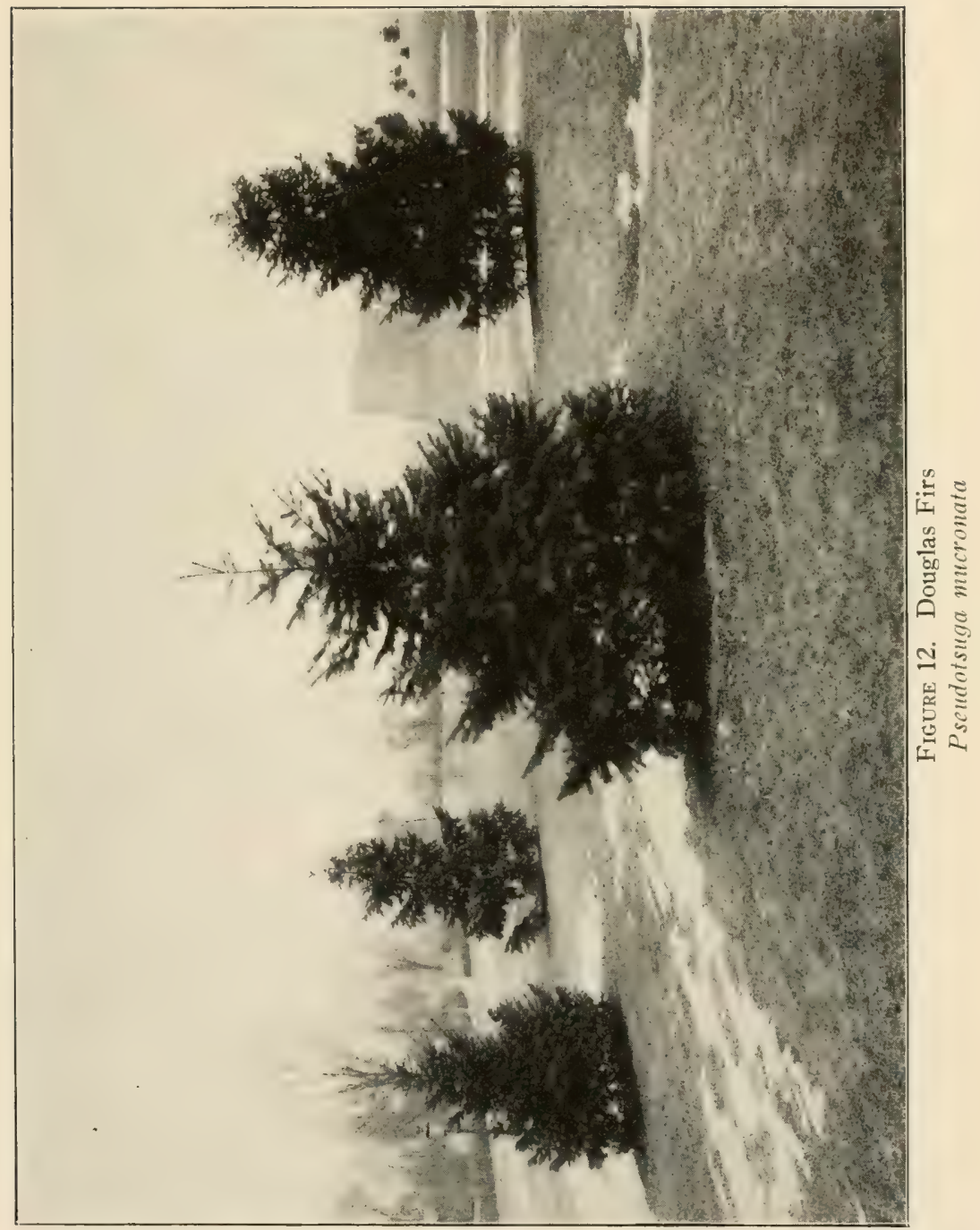


excels it in quantity of production. Moreover, its cut has been increasing steadily while that of the pines has been waning. In 1923 about 81/4 billion board-feet of Douglas Fir were felled on the Pacific Coast, which constituted almost a quarter of the total lumber production in the country. All this timber comes from a relatively small territory concentrated in Washington and Oregon. But the lumber is distributed and consumed all over the country. Here lies one of the greatest forestry problems, the increasing localization of timber production on the West Coast and the nation-wide distribution with high transportation charges.

The Douglas Fir has long suffered a variety of common names. Lnder cultivation it is generally known as such or as Douglas Spruce. The former is favored by the smooth twigs and soft foliage. Other names that have been associated with it, particularly in the lumber trade on the West Coast, are Red Fir, Yellow Fir, Spruce, Fir. Pine. Red Pine. Puget Sound Pine, Oregon Pine, and others.

The range of this tree extends from southern Alaska along the coast to the Sierra Nevada Mountains in central California and eastward through the Rocky Mountains into Colorado. The finest development is found in Washington and Oregon between the Cascades and the ocean, where heights up to 250 feet and diameters of 12 feet are attained.

The Douglas Fir is quite readily distinguished from other similar evergreens. The form of trees in cultivation is well exemplified by those at hand. The foliage is somewhat pandulous at the tips, the twigs are smooth as in the true firs and the buds are non-resinous, reddish, and very distinctly pointed. These trees thrive best in a porous sandy soil and their cultivation is very similar to that of the spruces. Growth is rapid. Though the Rocky Mountain form, which is the one in cultivation, is quite hardy, severe exposure is apt to be injurious. Consequently, groups of the trees are safer than exposed individuals unless somewhat sheltered. It is, therefore, a mistake to use Douglas Fir for a windbreak. Unlike the true firs they have fibrous roots like the Norway Spruce and so transplant readily. 


\section{General Discussion}

There are four different kinds of Pseudotsuga, only one of which is of great commercial importance. In addition to the one which is in the Garden there is another native one found on the steep, rocky slopes in the mountains of southern California, $P$. macrocarpa. This species is tender and consequently not suited for ornamental use in colder regions. It has local lumber value and is distinguished by its large cones that may be half a foot in length. The other species are native to China, Japan, and Formosa and are scarcely known in American cultivation.

There is striking similarity between the Douglas Firs and the true firs but in the latter the scales of the cones gradually fall off while in the Douglas Firs they do not. 


\section{PART 7-CYPRESSES}

\section{VERY VALUABLE ORNAMENTAL EVERGREENS}

\section{Section 1}

Section 1 of the Cypresses is located along the western half of the path close to the drive in front of Conservatory Range 1 (Map p. 57). As indicated on the map, we shall begin at the eastern extrenity of the path that extends from the western side of the Conservatory toward the Elevated Railway Approach. The evergreens here serve as a background for the flower bed. All the trees in this first Section are either Sawara Cypress or Hinoki Cypress, both natives of Japan, or some form of these two trees. The number of known varieties is great and the nursery name of "Retinospora" is applied to nearly all of them.

The first evergreen nearest the Conservatory is

Chamaecyparis obtusa var. nana, the Dwarf Hinoki-Cypress

This is one of the finest ornamental evergreens. It is characterized by its dark color and (lenseness of foliage caused by short branchlets and by very slow growth. It may attain a height of ten feet or more and when in a thrifty condition is very handsome because of its dense rich dark-green foliage.

Next we see two larger plants set back a bit with prominently bluish feathery foliage conspicuously different from that of the form we have just passed. There are several similar trees filling the interior of the group behind these two. They are all

Chamaecyparis pisifera var. pseudo-squarrosa, the Moss Retinospora

This is a rather common variety of the Japanese SawaraCypress and is very readily recognized by its bluish color and feathery foliage. The botanical name assigned to it here is not generally found in the literature, where it usually is designated merely as Chamaecyparis pisifcra var. squarrosa. The additional name Veitchii is sometimes added to this, for the plant is also 
known as Veitch's Sawara-Cypress. In the Garden, however, the shorter scientific name just given has been reserved for another lower and more prostrate form which we shall see later.

I more pleasing shape which the Moss Retinospora assumes in the open will be apparent when we meet other specimens.

The next tree to the right of the two just pointed out and close to the bed we should recognize as another Dwarf Hinoki-Cypress and behind it we can see the Moss Retinosporas or Veitch's Sawara-Cypresses within the group.

The next five larger trees extending in a row down the bed are

Chamaecyparis pisifera var. plumosa, the Plumed Sawara-Cypress

This is one of the most extensively planted forms, commonly known as the Plumed Retinospora. Unfortunately, it is subject to windburn, when the foliage turns brown.

At the end of this row we find another Dwarf Hinoki-Cypress, set back a bit, taller but not so fully foliaged as the other specimens we have already passed. To the right of it and closer to the flower bed is another dark-green conifer, low and close to the ground. Except for its height it is scarcely distinguishable from the Dwarf Hinoki-Cypress. It is

Chamaecyparis obtusa var. gracilis, the Slender Hinoki-Cypress

This and the Dwarf Hinoki-Cypress are very similar and at times difficult to separate. The former is characterized by its stringy new growth in spring and the foliage is not so compact. A taller tree of this variety stands ahead of us.

Directly to the right of this little Slender Hinoki-Cypress, the small lighter-colored evergreen of about the same size is a Sawara Cypress, which we shall consider when we see larger trees. To the right of it are four small yellowish plants with stringy foliage. These young ones and the six larger yellowish ones in a row behind them are 
Chamaecyparis pisifera var. filifera aurea, the Golden Thread-Retinospora

This second example of compound variation is very distinctive, with its slender stringy branchlets of yellow. Another specimin stands somewhat concealed to the left of the last Dwarf HinokiCypress and directly behind the last Plumed Retinospora.

The Golden Thread-Retinospora is a very striking plant during summer. when its golden color stands out against a green background. It is admirably suited for giving a splash of color to masses of darker planting.

In a great many horticultural forms of evergreens the particular feature that makes a plant this or that variety or form is noticeable at only certain seasons and at other times may be alsent. In the specimen before $11, \mathrm{~s}$ the yellow or golden color of the tips of the foliage is conspicuuns only in the early summer. This fact must be borne in mind when we consider any colored variety of evergreen.

The taller trees that stand in a towering mass behind these six are

Chamaecyparis pisifera var. plumosa aurea, the Golden Plumed Sawara-Cypress

Known also as the Golden Plumed-Retinospora these are merely the golden variety of those we have already noted along the flower bed. They, too, show their varietal coloring only in summer.

At the end of the double row of Golden Thread-Retinosporas stands a taller Slender Hinoki-Cypress already referred to. Beyond it, also along the bed, are eight feathery bushy evergreens in a row. If it is late spring or summer we will notice that five of them are yellowish, the third, fourth, and last three going down the bed, while the others have the bluish green we have already encountered. The latter three are Moss Retinosporas (p. 92). while the five yellowish ones are

Chamaecyparis pisifera var. pseudo-squarrosa sulphurea, Sulphur-colored Moss-Retinospora 
During the clormant season these eight shrubs look all alike but when new growth appears the light-yellowish foliage on five of tham is very striking. These yellow ones obviously are merely forms of the Moss Retinospora. All these specimens show the very attractive appearance which Veitch's Retinospora may exhibit at its best.

The last evergreen in the row at the corner of the bed is another Plumed Retinospora.

Now we shall turn the corner and observe that a path or opening extends into the group behind those we have just noted. At the left side of this opening behind those last ones along the flower bed are three more Plumed Retinosporas while on the right hand side are several golden forms of this variety.

Let us now go into the opening. Behind the first two trees along the right-hand side as we go in the next two are Plumed Retinosporas. Beyond the second of these the line of taller trees curves in an arc to the right. The first two trees in this arc next to the last Plumed Retinospora are

\section{Chamaecyparis pisifera, the Sawara Cypress}

This is one of two kinds of Cypress native to Japan. It has given rise to a great many valuable horticultural forms which we are now encountering.

Trees of the genera Chamaecyparis, Thuja, Juniperus, and certain others have two kinds of leaves, the one scale-like and the other pointed. The latter form occurs only in young plants, especially seedlings, to be lost later in their development. This so-called primordial foliage is very different in appearance from that of the adult plants. The occurrence of these two kinds of foliage on the same plant was not always known and when these plants were first studied they were regarded as entirely different according as they had scaly or pointed leaves. The name Retinospora was assigned to the pointed juvenile forms of the two Japanese Cypresses. Later, when their identity was disclosed, these trees were given the generic name of the adult trees. But in horticultural nomenclature the name "Retinospora" has been 
retained in connection with the jurenile forms of Chamaccyparis and of other genera, as Thuja, which we shall see later.

In some of these plants, especially if they have insufficient nourishment, the pointed primordial foliage is retained longer than usual. These forms if propagated by cuttings tend to retain the juvenile foliage without change to the more adult type. By repeated successive cuttings through many generations of very distinct juvenile forms the many garden varieties which are about us have been established.

The foliage of these juvenile forms very closely resembles that of some junipers, as we shall see. The leaves are usually pointed, spreading, and in pairs but are softer and not so sharp as are those of the junipers. Moreover, they are mostly marked with whitish or grayish lines beneath, which is never the case in junipers. The latter have whitish marks on the upper side of the leaves.

Frequently, howerer, one or more branches on these plants will revert to the more natural foliage and be quite noticeable. We shall see several examples of this. Occasionally, however, fruit is borne on the juvenile foliage without change to adult form. Seeds thus formed produce typical plants that do not retain their juvenile foliage much longer than usual.

In Japan the Sawara Cypress attains a height of 150 feet and a girth of 25 feet. In that country it has long been cultivated in gardens and temple grounds and its wood is used to some extent as lumber. IVe shall meet other specimens of it and only ly. repeated observation can its recognition be assured.

After these two trees comes another Plumed Retinospora and the last two tall trees completing the arc are Golden PlumedRetinosporas. Within this arc of taller trees are three smaller bushier ones. The more open tree-like specimen is another Golden Plumed-Retinospora whose colored foliage is exceptionally striking in summer. The other two more bushy and denser forms are

Chamaecyparis pisifera var. plumosa sulphurea, the Sulphur-colored Plumed-Retinospora

This is another very distinctive and handsome variety when its 
sulphurous color shows on the new growth in summer, changing the plant into a great yellow hall. Close comparison with the neighboring tree will show that this variety differs from var. plumosa aurca in its more delicate foliage, not so distinctly plumed but finer, as well as in its more compact habit. There is another and very similar specimen which we can see tucked in behind those yellow stringy shrubs along the flower bed.

On one of these specimens we should notice our first example of reversion which we mentioned as being frequently found in these plants. One of these three shrubs at least presents a branch whose foliage is different from that on the rest of it but which matches with that of the Golden Plumed-Retinospora close by.

Let us now return to the main path along the road and proceed eastward. We should first notice a single bluish feathery Moss Retinospora or Veitch's Sawara-Cypress surrounded by the Golden Plumed-Retinosporas, already noted. Directly behind it the tallest tree is the Sawara Cypress we spotted from within the group. There is another apparently cut-off specimen of this lastmentioned species as well as another Plumed Retinospora a bit to the right and behind the last Golden Plumed-Retinospora along the path. Their foliage should betray them.

Next we come to seven stringy yellow-foliaged plants, two of which are somewhat separated from the others. They are Golden Thread-Retinosporas. Behind them the tall trees in the background are mostly Plumed Retinosporas. The bushy bluish feathery plant close to the path that separates the last of the yellow ones from the others is a Moss Retinospora or Veitch's SawaraCypress, with its bluish foliage.

To the left of it and behind the fifth Golden Thread-Retinospora is another yellowish form with flat frond-like foliage. It is

\section{Chamaecyparis obtusa var. crispata aurea}

In this specimen we discover another feature of all these forms which should be understood. This name of var. crispata aurea has been retained for this plant and others like it though it is not to be found in general usage. It is a name assigned by the 
nursery that furnished these plants and that has attributed to them some varietal feature. This is a rather common practice though ofttimes it is exceedingly difficult to detect any particular distinguishing characters of these nursery forms. In the specimen before us we can be sure it is at least an aurea variety of Chamaecypuris obtusa and any other name that may be added is a matter of choice and viewpoint.

To the right of this last one is the sixth Golden ThreadRetinospora and directly behind this the taller evergreen is

Chamaecyparis obtusa, the Hinoki Cypress

This is the other cypress native to Japan which also has given rise to so many of the forms we are considering. In that land it attains a height of 150 feet, though usually it is smaller. The bark of this tree is highly valued by the Japanese for roofing purposes, since it peels off the trees in long thin strips and withstands the extremes of heat and damp and is very durable. The wood itself is regarded by the natives as superior to that of any other of their conifers and on this account is much used for reforestation work.

It will be observed that the Hinoki Cypress resembles its horticultural varieties much more closely than does the Sawara Cypress its varieties.

To the right of the bluish Moss Retinospora along the path, the last Golden Thread-Retinospora is surrounded by three similar bushy evergreens whose many stems arise from the ground close together. They are

Chamaecyparis obtusa var. gracilis compacta, the Compact Slender Hinoki-Cypress

This is a very pleasing upright bushy variety quite distinct in its habit. Directly behind these the taller tree is a Sulphur-colored Plumed-Retinospora which shows considerable reversion to the Golden Plumed-Retinospora.

We now come to the service road that runs under the big greenhouse. As we turn into it, the first two bushy plants on our 
left are Compact Slender Hinoki-Cypresses. All the bushy bluish ones behind these are Moss Retinosporas.

There are other trees within the group which may be identified by their tags.

This completes our survey of the Cypresses and Retinosporas west of the service road. On the other side of this short road and nearer the inner end are five Golden Thread-Retinosporas. Their branches extend to the road and five or six more are located behind. The latter scarcely show their yellow foliage because of their shaded position. The taller trees in the background are for the most part Sawara Cypress. We shall note them again, along with others in the background, when we consider them from the other side.

Directly behind the two right-hand Golden Thread-Retinosporas along the service road are three taller dark-colored evergreens with very distinct and peculiar foliage. They are

Chamaecyparis obtusa var. filicoides, the Fernspray Retinospora

This is one of the oddest and most distinctive forms in the collection.

The two yellowish bushy shrubs to the right of the Golden Thread-Retinosporas and nearest the corner are Sulphur-colored Plumed-Retinosporas (p. 96). Between these and almost concealed by them is a slender dark Dwarf Hinoki-Cypress. The large green ones behind them are Slender Hinoki-Cypresses.

Now we shall proceed eastward along the main path. The first bush around the corner is another Sulphur-colored PlumedRetinospora. To the right of it is a Dwarf Hinoki-Cypress. Next are two taller Golden Plumed-Retinosporas separated by another bushy Sulphur-colored Retinospora (p. 96). Behind this last one is another Compact Slender Hinoki-Cypress.

The next yellow evergreen to the right, back a bit, is a Golden Thread-Retinospora (p.94). A similar one is to the right of it and a bit back, while directly behind and almost concealed by it, is

Chamaecyparis pisifera var. filifera pendula aurea, the Golden Weeping Thread-Retinospora 
The habit of this form is quite distinct from that of the nonpendulous form.

To the left of these and within the group the large prominent bushy green specimen is

Chamaecyparis pisifera var. filifera, the Thread Retinospora

This is one of the most dependable forms of Retinospora, for it is very hardy.

The tallest trees in the background are Sawara Cypress.

The next two trees along the path are

Chamaecyparis obtusa var. gracilis aurea, the Golden Slender Hinoki-Cypress

These are merely yellow forms of the Slender Hinoki-Cypress.

Behind these two are two low and rather concealed Golden Thread-Retinosporas and two larger Thread Retinosporas. To the right of the uppermost of these two inside Thread Retinosporas is a single slim specimen of another new and odd form. It is

Chamaecyparis obtusa var. lycopodioides, the Club-moss Retinospora

This is an odd form of the Hinoki-Cypress. It may become a very attractive dark-green dense evergreen. The specimen at hand is, of course, very poor.

The next two large broad and very open plants along the path are old Sulphur-colored Plumed-Retinosporas. Behind the left hand one is a large Thread Retinospora, and behind the right hand one a Golden Plumed-Retinospora.

The next very large tree along the path is another Golden Plumed-Retinospora. To the right in front and close to it is a very fine Dwarf Hinoki-Cypress. Next comes a very nicely shaped and larger

Chamaecyparis obtusa var. aurea, Golden Hinoki-Cypress Behind these the very tall tree is a Golden Plumed-Retinospora. Next to the Golden Hinoki-Cypress the lower bushier plant is Chamaecyparis pisifera var. filifera pendula, the Ireeping Thread-Retinospora. 
Behind it is another Golden Hinoki-Cypress and close behind this latter a Dwarf Hinoki-Cypress.

The next yellow bushy plant by the path is a Sulphur-colored Plumed-Retinospora.

Next, close to the path, is a Plumed Retinospora and the four very large trees behind and to the right of it are Sawara Cypresses with arar. plumosa in the middle rear and var. aurea nearest the path.

Next by the path is a Hinoki Cypress and then the very compact low and very small evergreen is

Chamaecyparis obtusa var. nana compacta, the Compact Dwarf Hinoki Cypress

This form is certainly one of the finest of dwarf evergreens, for it is exceedingly slow-growing. The plant at hand is quite old.

Immediately behind it are two

Chamaecyparis pisifera var. sulphurea, the Sulphur Sawara-Cypress

Close examination will show the foliage of these two plants to differ in form from that of the var. plumosa plants.

Next along the path is a Moss Retinospora and then come two Golden Thread-Retinosporas, one behind the other, with a big Plumed Retinospora in the background. Next to the right is another specimen of the peculiar Fern-spray Retinospora and then a very nice Dwarf Hinoki-Cypress. Then comes a broad globose Sulphur-colored Plumed-Retinospora. A large Sawara Cypress stands in the background. To the right of it is

Chamaecyparis obtusa var. aurea Youngii, Young's (iolden Hinoki-Cypress

This form, lonmyii, is clamed to differ from the plain variety, aurea, in a paler yellow color and more pendulous foliage.

Next by the path is a large Sulphur-colored Plumed-Retinospora and behind it a greener Thread Retinospora. Next by the path 
is a Moss Retinospora and then another big Sulphur-colored Plumed-Retinospora in the back, with a Dwarf Hinoki-Cypress to the right. The very open scraggly one next by the path is

Chamaecyparis pisifera var. plumosa albospica, the

White-tipped Plumed-Retinospora

At the proper season, when new growth appears, the whitishtipped plumes of this form are noticeable.

Behind it are a Thread Retinospora to the left and a lower Weeping Thread-Retinospora to the right.

To the right of the White-tipped Plumed-Retinospora is a Moss Retinospora. Behind it the low creeping form is

\section{Chamaecyparis pisifera var. squarrosa}

The next two small dark-colored and similar-looking trees, one behind the other, are both Dwarf Hinoki-Cypress. The very dense bushy specimen next is a Sulphur-colored Plumed-Retinospora with a plain Plumed Retinospora close behind it. To the right of this last one is a Golden Thread-Retinospora and in front of this one is a Chamaecyparis obtusa var. crispata aurea (p. 97). Still further front nearer the path is a darker Dwarf HinokiCypress.

Next we see three trees, one behind the other. The foremost is another Chamaecyparis obtusa var. crispata aurea. The middle one is

\section{Chamaecyparis obtusa var. magnifica}

This variety is very similar to the var. gracilis and certain others and presents difficulty in separating it.

The third and largest tree in the rear is a Plumed Retinospora. The two remaining equally tall trees to the right are the same. Between the first two of these three is another Chamaecyparis obtusa var. magnifica crowded in and a var. crispata farther front, another specimen of which stands just between the path and the second big Plumed-Retinospora. To the left of this last one is a 
Dwarf Hinoki-Cypress, and to the right is the last low dark evergreen. It is

Chamaecyparis obtusa var. pygmaea, Pigmy Hinoki-Cypress

This is a low prostrate form similar otherwise to var. nana.

The remaining five globose shrubs at the end are Sulphurcolored Plumed-Retinosporas.

It might be well, now, to inspect this entire group east of the service road from the bank behind the trees. Beginning at the western end we see first a (iolden Thread-Retinospora surrounded by four large equally sized Sawara Cypresses. To the left are sereral more Sawara Cypresses. Turning eastward there are, half way down the bank, two Thread Retinosporas. Below them are the two Golden Slender Hinoki-Cypresses already noted from the path.

Next along the bank nearer us, is another Sawara Cypress and below it one of the old Sulphur-colored Moss-Retinosporas with a Thread Retinospora between them. The slender one close by us is the Fern-spray Retinospora.

Next to the left we pass a Golden Plumed-Retinospora and below it is the other Sulphur-colored Plumed-Retinospora. Then to our left is a lower dense Sawara Cypress near us and then a big Golden Plumed-Retinospora with a similar one below it.

Next comes a Golden Hinoki-Cypress and a Dwarf HinokiCypress together, followed by a big Sawara Cypress to the left. Ifter that is an equally tall Plumed Retinospora and then a great Sawara Cypress.

Next is a smaller Sulphur-colored Retinospora with a similar me below it. Then a large Plumed Retinospora followed by an even taller Sawara Cypress.

Next we see a very nicely shaped round Thread Retinospora with a Sulphur-colored Plumed-Retinospora below it ; in the middle is a Young's Golden Hinoki-Cypress (p. 101) close to the big Sawara Cypress. Next to the left is another Sulphur-colored Plumed Sawara-Cypress similar to the one nearer the road. 


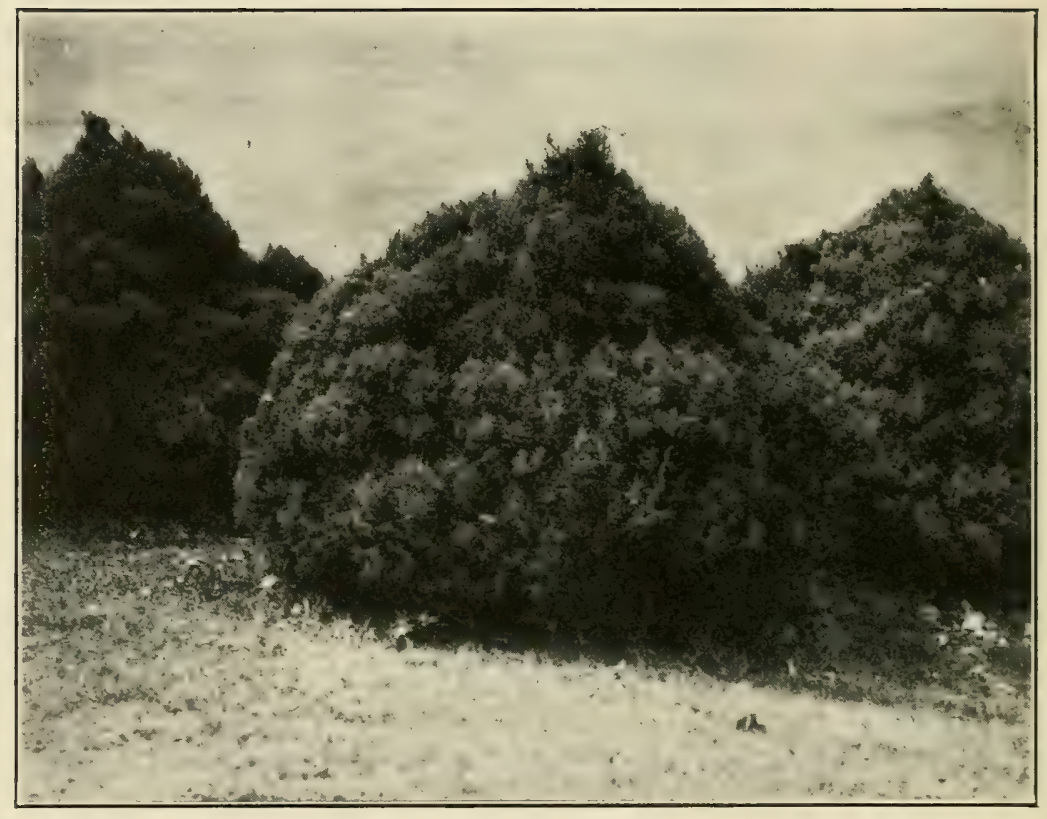

Figure 13. Sulphur-colored Plumed-Retinospora Chamaecyparis pisifera var. plumosa sulphurea 
Then comes another Thread Retinospora with a Dwarf HinokiCypress to the right below it. To the left of the Thread Retinospora is a Weeping Thread-Retinospora. Then comes the low Chamaecyparis pisifera var. squarrosa, spreading on the ground. Next is a taller Plumed Retinospora followed by a Golden ThreadRetinospora and then three more tall Plumed Retinosporas. Between the first two is a Chanaecyparis obtusa var. magnifica.

The last yellow bushy shrubs are Sulphur-colored Plumed Retinosporas.

\section{Section 2}

Section 2 of the Cypresses is located on the south side of the outer road in front of Conservatory Range 1 and near the eastern end of the road. The trees stand near the apex of the area between the road and the path on its south side (Map p. 7). Going westward down this sloping path from the road the first two evergreens on our right are

Chamaecyparis Lawsoniana var. Alumii, the Blue Pyramidal Port-Orford Cedar or Scarab Cypress

This is one of the handsomest blue-tinted evergreens. The foliage is more delicate and softer than that of the Colorado Blucspruce and in spring when the fresh new leaves appear this variety is exceptionally fine. Its habit is very erect and pyramidal, as we shall see in other trees just ahead.

The next smaller evergreen near the foot of the low stone wall is

Chamaecyparis thyoides var. andelyensis, the Andelyan White-Cedar

This variety shows III particular characters and does not thrive well in the Garden.

The next tall evergreen close to the stone wall and a similar one almost directly in front of it are

Chamaecyparis Lawsoniana, the Port-Orford or Lawson Cypress 
This is one of our handsomest ornamental evergreens but unfortumately it does not do well in a dry climate. If it has sufficient moisture it is very hardy and valuable. It is native to the moist coastal region from southern Oregon to northern (alifornia. In this very limited range this cypress sometimes attains a height of 175 feet. The wood is very aromatic and is made into clothes chests and many other articles. It was formerly much used in shipbuilding on the Pacific Coast.

Almost seventy different garden varieties of this tree have originated in one place or another. The leaves are exceedingly minute and give the almost feathery fineness to the foliage.

The tall bluish-colored tree close to this last one on its eastern sicle is another Scarab (ypress. The shorter one in front of these is another Lawson's Cypress.

Next along the path we see three low pendulous forms. They are

Chamaecyparis nootkatensis var. pendula, the II eeping Yellow-Cypress

This is a weeping form of the Yellow Cypress which stands farthest to the left.

Behind the first of these pendulous forms are two trees next to one another. They are

Chamaecyparis thyoides, the Cuast IThite-Cedar

This is the common White Cedar of the Atlantic Coast, sometimes known as Southern White-Cedar to distinguish it from the Northern White-Cedar or Arbor-Vitae.

Behind the right hand one of these and near the stone wall is a pendulous form.

Chamaecyparis nootkatensis var. glauca, the Blue Nootka-Cypress

The next tall tree to the left close to the wall is a Lawson's Cypress and directly in front of it is a smaller Scarab Cypress. Next are four more Scarab Cypresses, forming a rectangle with a 
Coast White-Cedar in the center. The last tall tree in the background is another Scarab Cypress.

The two remaining lower trees in the foreground with somewhat drooping foliage are

Chamaecyparis nootkatensis, the Yellow Cypress or Yellow Cedar

The Yellow Cedar, known also as Nootka Cypress, attains heights of 100 feet and mure along the Pacific Coast, where it is native from Mlaska to Uregon. In the Garden this species does not grow well, undoubtedly because of the relatively dry warm summers.

The foliage of this species somewhat resembles that of Lawson's Cypress but it is coarser and duller green. The cones, furthermore, have triangular pointed processes which are absent from those of Lawson's Cypress.

The wood of Yellow Cedar is very valuable on the West Coast. where it has been much used in shipbuilding and other industric.s.

\section{General Discussion}

Only six kinds of Cypress are known. They are native to the Atlantic and Pacific Coast regions of North America, to Japan and to Formiosa. In eastern North America is Chamaecyparis thyoides, the White Cedar, and on the West Coast are C. Lawsoniana, the Port-Orford Cedar, and C. nootkatensis, the Yellow Cedar. In Formosa one species is endemic, C. formosensis, and in Japan are the two remaining species, C. obtusa and C. pisifera. They are all trees of great size. C. formosensis grows 190 feet tall, with a trunk 60 feet in girth, the largest of all coniferous trees indigenous in the Old World north of the Equator and rivaled only by the great Cryptomeria of Japan, which we shall meet later.

All these trees are of considerable timber value and ornamentally, as we have seen, their numerous forms are unexcelled.

These trees grow best in somewhat moist but well-drained sandy loam and partial shade. They all require shelter against drying 
winds. Port-Oxford and Hinoki Cypresses like drier, the others, more moist situations and $C$. thyoides grows well in swamps. All the Retinosporas and dwarfer forms may be increased by cuttings and in others veneer grafting is preferable.

The cypresses are the first evergreens we have met so far with scaly leaves in their wild forms. It is difficult at times and well nigh impossible to distinguish their foliage from that of the ArborVitae which we shall soon see. Both genera differ markedly, however, in their fruit, which is seldom present to assist in distinguishing them. The cone of Thuja is small and elongate with each scale as long as the whole cone while that of Chamaecyparis is also small but more globose and composed of shield-shaped scales. 


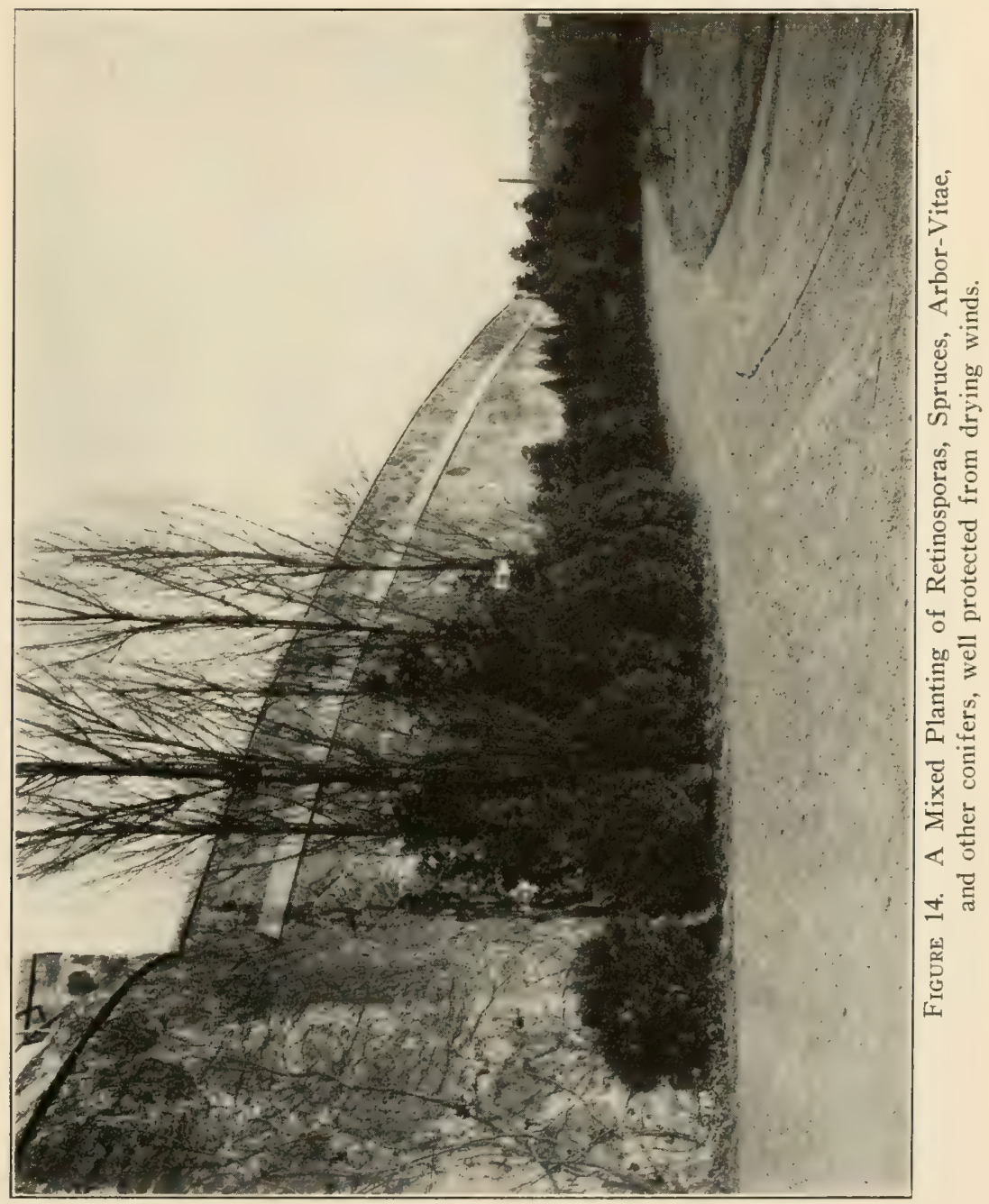




\title{
PART 8-JUNIPERS
}

\section{VALUABLE ORNAMENTAL EVERGREENS OF LITTLE ECONOMIC}

\author{
IMPORTANCE
}

\section{Section 1}

Section 1 extends along the inside of the path on the east side of the circular drive leading to Conservatory Range 1 (Maps pp. 7 and 57). Near the junction of the path and drive is a conspicuous clump of dense evergreens. The plants composing it are

Juniperus chinensis var. Pfitzeriana, Pfitzer's Juniper

This is one of the best and most popular ornamental evergreens. Individual plants make a fine showing and groups of them, as we see here, form splendid evergreen masses. These plants branch very low and their heavy foliage very frequently causes the stems to split near the base.

East of this clump the collection extends along the inside of the path and consists of individual separated trees. If we step inside the group it will become apparent that they are set in three approximately parallel lines. One of these rows extends along the foot of the bank. Let us begin with the first tree at the western end of this row close to the clump of Pfitzer's Juniper and follow it, disregarding, for the time, the other trees. This first slender tree is

\section{Juniperus chinensis, the Chinese Juniper}

The Chinese Juniper is native to China, Mongolia, and Japan, and may attain a height of 60 feet. It may usually be distinguished from the native species, which we shall soon see, by the occurrence of both adult scale-like leaves in pairs and jurenile pointed leaves in threes on the same trees. Both species are the two most common tree-like junipers found in gardens. Both, as we shall see, have given rise to a great number of varieties.

The next five trees, of which the third is a bit out of line, are 
Juniperus virginiana var. glauca, the Silver Red-Cerlar

This is a very fine natural variety of the native Red-Cedar. Its bluish-gray foliage, though not always very apparent, has value in modifying the possible monotony of an evergreen setting.

Next, straight ahead along the bank, is

\section{Juniperus virginiana var. Cannartii, Cannart's Recl-Cedar}

This variety is said to be "a compact pyramidal form with dark green foliage and bluish bloomy fruit."

The next two trees are Chinese Junipers, followed by a Silver Red-Cedar and then another Cannart's Red-Cedar. Then comes a Variegated Pyramidal Chinese-Juniper, better specimens of which we shall see later.

Then comes a Silver Red-Cedar, a bit out of line, followed similarly by a Chinese Juniper. Next in line, along the bank again, is a Chinese Juniper, two Silver Red-Cedars, and then a low

Juniperus Sabina, the Savin Juniper

This is a spreading or procumbent species native to the mountains of central and southern Europe extending into the Caucasus and western Asia. The branchlets have a rather strong disagreeable odor when bruised. We shall meet other specimens of this species and gradually become familiar with it.

Following the Savin, comes a

\section{Juniperus sphaerica, Fortune's Juniper}

This species is generally regarded as identical with $J$. chinensis. However, plants secured under this name seem to be hardier in the Garden.

Next are two more Silver Red-Cedars. The last one stands just beyond the bend of the embankment on our left. Before observing the trees in this broader area let us finish with those in the narrow strip we have just traversed. So we must return to our starting point at the Pfitzer's Junipers. 
Including the first one with which we began enumerating the trees in the first row along the bank, there are six Chinese Junipers. The first two trees along the path are of this group and the other four are the remaining first trees.

Now we can follow a second, rather distorted, line of trees that extends along the middle of the Section between the row we have already gone over and the rather distinct row along the path.

The first five beyond the Chinese Junipers are Silver RedCedars. Next is a Chinese Juniper and then a small Savin Juniper. Next are two large Silver Red-Cedars followed by a round-headed Cannart's Red-Cedar and a Chinese Juniper. Here our line ends and we must once more return to our starting point. Let us walk on the gravel path this time and there will be no confusion.

The first five trees are Chinese Junipers. The next two are

Juniperus chinensis var. Reevesiana, Reeves' Juniper

This form has scale-like leaves and bears female flowers and fruit. It, apparently, is a clonal variety.

Next is a Cannart's Juniper. Then comes a Chinese Juniper followed by a small Conical Chinese-Juniper (p. 121). The next two taller trees are Chinese Junipers. Next are four trees in a row, more in the center. The first is a Chinese Juniper, the second a Silver Red-Cedar, the third a Red Cedar and the fourth one Fortune's Juniper. Beyond this is a low Pfitzer's Juniper followed by a Savin.

The last tall tree, partly surrounded by the Pfitzer's Junipers along the path, is

\section{Juniperus virginiana, the Red Cedar}

This is the common Red Cedar of hillsides and woodlands in the eastern states. Specimens in the Garden, unfortunately, do not have the very characteristic and distinct conical shape which this tree assumes in the wild. It is to be found over the entire country east of the Mississippi and in parts of Canada. In some localities it is known as Savin, elsewhere as juniper and in parts of the south as cedre. 


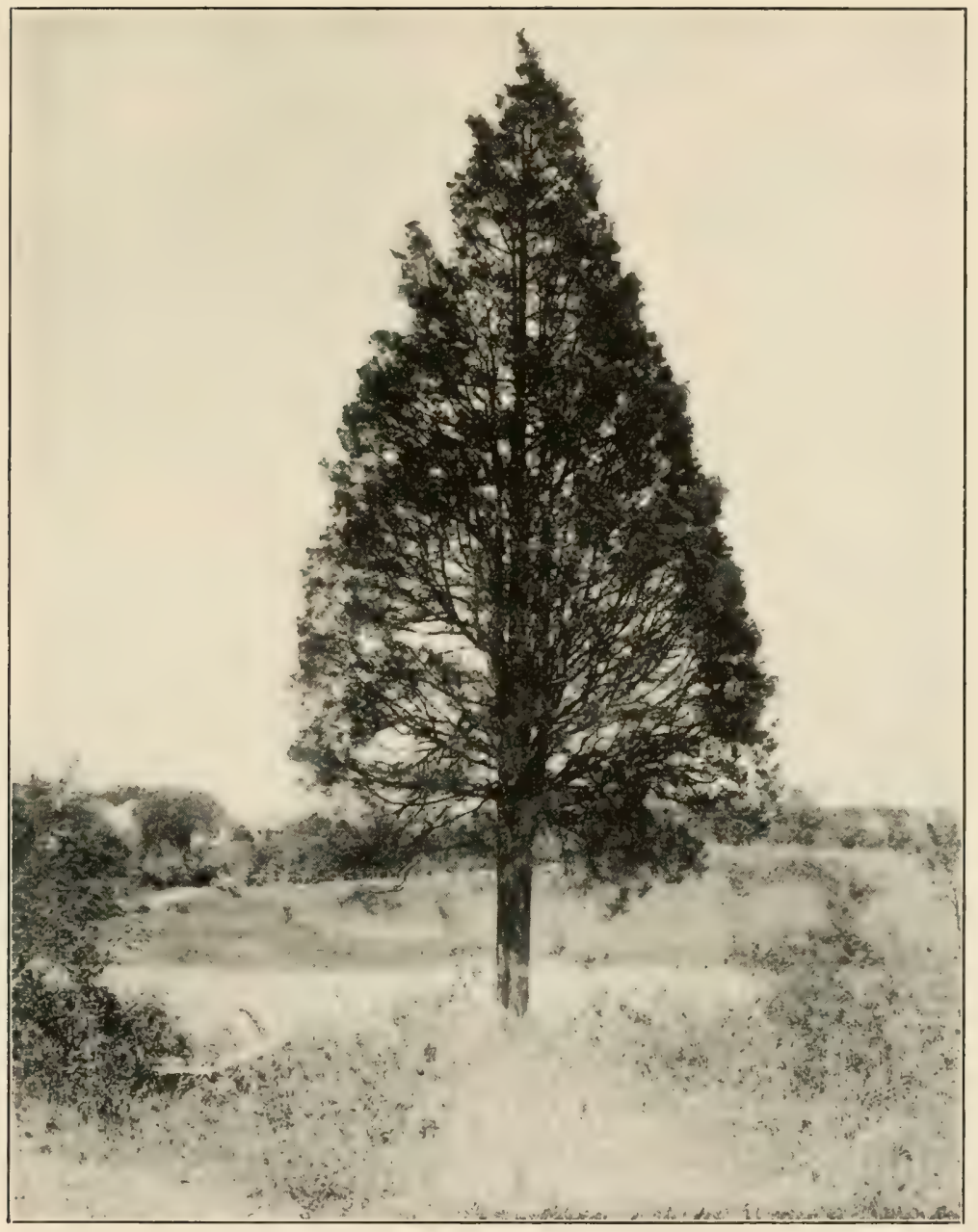

Figure 15. Red Cedar Juniperus virginiana 
The Red Cedar generally becomes only a medium-sized tree, though it may attain a height of 100 feet. It is most frequently found on old abandoned fields and rocky slopes, not because it prefers such sites, but because other trees crowd it from more favorable locations. Very frequently rows of these trees iine fences where birds have dropped the seeds after eating the pulp of the fleshy berries.

The brittle fragrant wood of Red Cedar has long been used in a number of ways. As a protection against insects it is extensively employed in cedar chests. Its principal use is in the manufacture of pencils. Railroad ties, sills, and a host of other articles have laid claim to the wood. An extract from the fruit and leaves is used in medicine and oil-of-red-cedar, distilled from the wood, enters the making of certain perfumes.

Is an ornamental Red Cedar is highly valued, especially for perpendicular effects. It is perfectly hardy and transplants well but, as so many evergreens, does not like the polluted atmosphere and unfavorable conditions of cities.

Let us now direct our attention to the trees in the wider part of this planting to the left. We shall begin with that last Silver Red-Cedar that concluded the first row and which stands as a pivotal tree at the point of the embankment. The trees are lined up in approximate rows parallel to this bank and the first row at the foot of the slope, beginning with that corner Silver Red-Cedar, contains eight trees. The first five, including the pivotal one, are Silver Red-Cedars. Then comes a lower Conical Chinese-Juniper (p. 121). 'The next scraggly one is

Juniperus virginiana var. tripartita, the Fountain Red-Cedar

This is an odd form, difficult to distinguish.

The last tree in this row is

Juniperus excelsa, the Greek Juniper

This species is native to southeastern Europe, Asia Minor, and the Caucasus, attaining heights up to 100 feet. In cultivation, var. stricta is better known, for it is a handsome little compact evergreen of perfectly conical form scarcely over three feet in height. 
The Greek Juniper is distinguished from the American and Chinese species by having twice or thrice as many seeds in each fruit.

The four trees in the next row are all Silver Red-Cedars.

The third row begins with a Silver Red-Cedar close to the Pfitzer's Junipers. Next in the row is a Greek Juniper and beyond this two more Silver Red-Cedars.

The next row we may regard as having only two trees, both Silver Red-Cedars. The first one stands close to the Pfitzer's Junipers and the other one within the group some distance from the first one.

Next is a row of four trees. The first three tall ones are Chinese Junipers, and the next lower one is a Greek Juniper.

Now let us turn around at this last tree and consider the remaining evergreens, proceeding in the opposite direction, that is, toward the road.

The low broad and very prickly mass of evergreen that hugs the ground in a circular area is

Juniperus squamata, the Needle-leaved Prostrate-Juniper

This fine prostrate species comes from Afghanistan and high elevations in Himalaya and China. The needles are unusually sharp and masses of this juniper should make very formidable barriers against small animals.

Between this plant and the path to the left is a very small

Juniperus chinensis var. nana, Dwarf Chinese-Juniper

Next are two slightly bigger plants of about equal height. The one nearer the path is

Juniperus chinensis var. globosa, Globe Chinese-Juniper

The other one directly next to the Needle-leaved ProstrateJuniper is a Savin Juniper (p. 111).

Next are two more trees. The narrower one to the left is

Juniperus virginiana var. plumosa argentea, Silver-spotted Red-Cedar 
The more spreading inner one is a Greek Juniper.

The next weeping tree to the right is

Juniperus chinensis var. pendula, Weeping Chinese-Juniper

Straight ahead of it is another and very similar specimen.

Between these two and close to the Pfitzer's Juniper is a smaller

Juniperus virginiana var. albospica, White-tipped Red-Cedar

Another similar specimen of almost equal height stands straight ahead of it nearer the path.

Close by between the spreading Pfitzer's Junipers and the path along the road is an upright juniper with ascending branches and needles in whorls of threes. It is

Juniperus communis, the Common Juniper

This species has the greatest distribution of any tree or shrub. In the Old World its range extends from central and northern Europe across Asia to Japan. In North America it is found wild from New England to North Carolina. Naturally we should find great variation of habit in such a widely distributed species. In valleys and lowlands it attains a height of 25 feet, on exposed hillsides it is scarcely over 5 feet tall and in the highest elevations and latitudes of its range it is very prostrate, rising only a few inches.

Because of its small size, this world-wide tree has little economic value. In India the twigs have been burned as incense and in Europe the berries have been extensively used on account of supposed medicinal properties. In essential oil may be distillerl from the crushed fruits. The flavor of Westphalian hams is attributed to juniper berries, which are used with beechwood in the smoking process.

This juniper is valuable ormamentally because of its ability to thrive on limestone sites. Numerous varieties of it are known.

Returning now to the first Weeping Chinese-Juniper that we met within the group close by, we shall turn directly eastward toward the path. The first tree, incidentally the tallest here, is

Juniperus virginiana var. Schottii, Schott's Red-Cedar 
This is a "narrow pyramidal form with bright green scale-like leaves."

Between it and the path are two smaller ones. The inner and taller one is a Silver-spotted Red-Cedar.

The low one near the path is

Juniperus virginiana var. globosa, Globe Red-Cedar

Now going along the path toward the road the next taller tree is a Chinese Juniper.

Then come three of

Juniperus chinensis var. fastigiata, Upright Chinese-Juniper

Behind these stand two Schott's Red-Cedars.

Nearer the main path is another broad Needle-leaved ProstrateJuniper. To the east of it is a

Juniperus chinensis var. procumbens, Prostrate Chinese-Juniper

Seven trees remain in the apex of this corner. The next one along the main path is a Globe Chinese-Juniper.

The three similar-looking ones nearest the apex are Savin Junipers. The low broad spreading one just around the corner is another Prostrate Chinese-Juniper. The two remaining ones nearer the center of the apex are Globe Red-Cedars.

\section{Section 2}

Section 2 of the Junipers occupies a part of the eastern half of the long narrow planted area between the two roads in front of Conservatory Range 1 (Map p. 7). We shall begin at the eastern end by the path which crosses the strip from the inner road to the gateway at Southern Boulevard.

The first evergreen by the inner road and near the cross path at this point is

Juniperus virginiana var. Keteleeri, Keteleer's Red-Cedar

This variety is practically indistinguishable from the typical Red Cedar. It is regarded as a compact form with ascending branches.

The next two trees in a row of three that extends toward the outer road are common Red Cedars (p. 112). The other eight 
trees of approximately the same size in this corner are Chinese Junipers.

The next two smaller trees of about equal size are Fortune's Juniper (p. 111).

The two very low evergreens close to the ground nearer the inner road are Needle-leaved Prostrate-Junipers (p. 115).

The next four small globular trees which are unmistakably alike are

Juniperus chinensis var. pyramidalis, the Pyramidal Chinese-Juniper

This is one of the most distinctive varieties in the collection. In the spring the fourth or most westerly of these four bushes has whitish- or yellowish-tipped foliage in spots and is known as Juniperus chinensis var. pyramidalis variegata, the Variegated Pyramidal Chinese-Juniper.

Between the first three of these bushy junipers and the inner road are two more Fortune's Junipers p. 111). Close by, the next taller tree with drooping foliage is a Weeping ChineseJuniper (p. 116). Beyond it the next low-spreading evergreen with open center by the inner road and east of the lamppost is a Savin (p. 111).

Next we see several low evergreens close to the ground. The nearer one in the center and a similar plant by the inner road are

Juniperus Sabina var, tamariscifolia, the Tamarix Savin

This is a handsome low-spreading variety of the Savin.

The second low-creeping evergreen in the center and a similar one by the outer road are

Juniperus horizontalis var. prostrata, the Creeping Juniper

This name accompanied these two plants from the nursery that supplied them. The varietal name, var. prostrata, is unnecessary, for the Creeping Juniper is a distinct prostrate species found wild on sandy and rocky soils in southern Canada and the northern United States. Large patches of it make beautiful ground covers of bluish tint for banks or rock gardens. It is very difficult to 


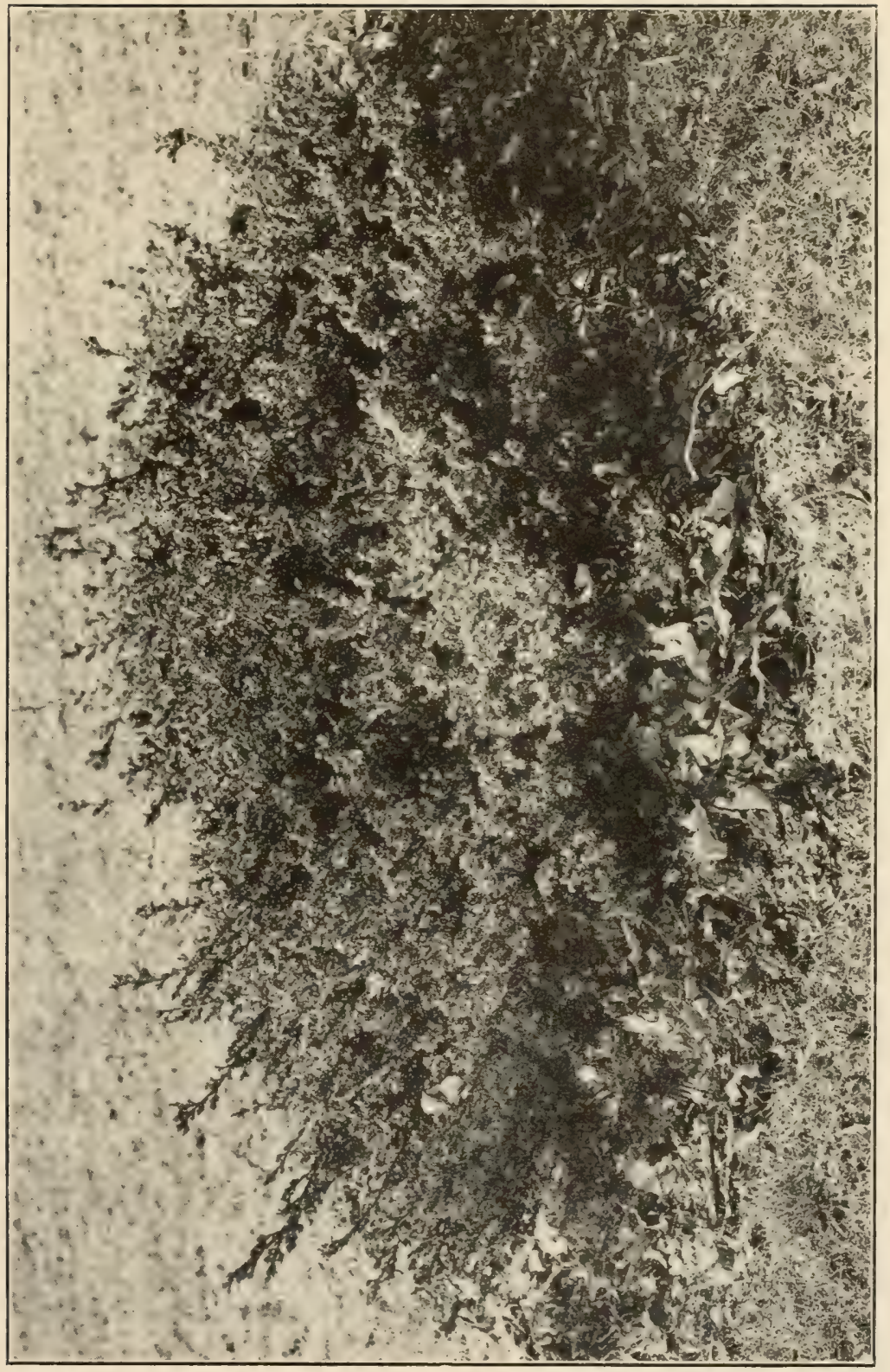

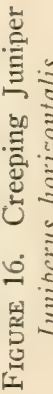


distinguish between immature specimens of various prostrate junipers, as the two which occur together here.

The distorted and somewhat Japanesque small tree nearer the outer road is unidentified.

Next are four low-spreading plants of the Needle-leaved Prostrate-Juniper (p. 115) and next to them is a large group of several Pfitzer's Junipers.

Beyond these the next evergreen by the inner road is

Juniperus chinensis var. aurea, the Golden Chinese-Juniper

This variety does not do well in this location. It is bright yellow in spring. Another similar plant stands directly ahead by the inner road. The two narrower and greener plants between these two are young

Juniperus virginiana var. pyramidalis, Pyramidal Red-Cedars

The taller tree by the outer road is a Chinese Juniper.

The small bushy plant with bluish spiny foliage near the outer road is

Juniperus squamata var. Meyeri, Meyer's Juniper

This is one of the most brightly colored evergreens, rivaling the Koster's Blue Spruce in spring. It is native to China.

Next we see two large Pyramidal Chinese-Junipers (p. 118). The one by the inner road is var. variegata. Then come several creeping forms nearer the inner road. The first of these is a Creeping Juniper (p. 118). Next to it is a Tamarix Savin, another very similar specimen of which is two paces directly ahead. The more upright bushy plant midway between these two and nearer the inner road is

Juniperus communis var. depressa, the Prostrate Juniper

This is a geographical variety of the Common Juniper found in eastern North America. The specimens in the collection are old and do not show the pleasing low-spreading nature of this plant.

In the center the low-creeping plant was received as Juniperus Sabina var. prostratu, which probably is the same as Juniperus horizontalis. 
Next in the center is a Savin Juniper; to the right a step ahead is another P'rostrate Juniper; the tree to the left by the outer road is probably a conmon Red Cedar.

Before us now are the three tallest trees in this entire Section. They are Silver Red-Cedars (1). 111). Between the last of them and the outer road the smaller tree is probably a common Red Cedar again.

Next we see five more Pyramidal Chinese-Junipers. The second and third, or middle ones, are variegated forms (p. 118).

Between the first of these five bushy trees and the inner road the low droopy evergreen is

\section{Juniperus virginiana var. nana pendula}

This is an odd form secured from some nursery and apparently not generally known.

Next we see five low Savin Junipers in a somewhat diagonal line running through the middle of the strip. A sixth plant stands to the right by the inner road. But east of it is an evergreen of somewhat yellowish foliage that is

\section{Juniperus chinensis var. aurea-variegata}

The next two tall slender trees, one beyond the other and near each of the roads are

Juniperus virginiana var. glauca pendula, the Weeping Silver Red-Cedar

Approximately between these two taller trees the smaller one is

Juniperus chinensis var. neaboriensis, the Conical

Chinese-Juniper

This variety, supposedly, assumes a dense columnar form. Three more specimens stand just ahead in the center.

The taller poorly shaped tree near the inner road just before the three last-mentioned ones is a Schott Red-Cedar (p. 116).

The low flat-topped evergreen next by the inner road is a Globe Chinese-Juniper.

The next two taller trees are Schott Red-Cedars. In the middle the very small plant is a Savin Juniper. 
Next by the inner road is a row of three low plants. The first is a Savin Juniper and the other two are

Juniperus chinensis var. argenteo-variegata, the Whiteleaf Chinese-Juniper

In the middle between these two and the outer road are two Fortune's Junipers (p. 111). Next in the center is a Silver RedCedar, with the upper portion of its main trunk divided into three branches. Beyond it are two more Fortune's Junipers in the center and nearer the outer road; nearer the inner road is a Variegated Chinese-Juniper. Next are two Chinese Junipers, one a few steps beyond the other and both near the outer road. By the inner road is a Chinese Juniper.

The next low-spreading plant in the center is unidentified. It appears to be a golden variety of the Chinese Juniper.

The last two junipers with slaty gray color by the inner road are

Juniperus occidentalis, the Western Juniper

This pleasing grayish-green juniper is native to the Pacific Coast from Washington to California.

\section{General Discussion}

About forty known species of junipers are distributed in the north temperate hemisphere. Without fruit they are difficult to distinguish, not only among themselves, but from closely related genera. The scales of the cones are so modified that they lose all semblance as such and form a fleshy berry-like fruit. This is the most distinctive feature of the group. The number of seeds in these berries furnishes a definite basis for distinction. In the native Red-Cedar, for instance, there are only one or two seeds and in the very similar Chinese Juniper two or three. Another distinguishing feature, almost impossible to use, is that the fruit ripens either the first year, as in the Red Cedar, or the second as in the Savin and most other species or in the third as in the Common Juniper. But since it is difficult to find berries on ornamental junipers the difficulty of distinguishing them is hardly lessened.

One distinctive feature, however, is that the juvenile needleshaped leaves of junipers have whitish lines on their upper surface. 


\section{( 123 )}

On allied genera these lines are on the lower surface of the needle leaves.

The junipers thrive best in sandy and loamy, moderately moist soil, but grow well on dry gravelly ground too. Limestone formation and open sunny situations are favorable. They are suited for use as hedges and windbreaks; also for seaside planting.

A few of the junipers furnish lumber for furniture manufacture and other purposes in their native countries. Oils and beverages have also been secured from the fruits. 


\section{P.IRT 9-ARBOR-VITAE}

\section{VALUAHLE ORNAMINTAL EVERGIRENS}

The collection of Arbor-Vitae occupies the western hall of the long narrow planted strip between the two roads in front of Conservatory Range 1 (Maps pp. 7 and 57). It adjoins the collection of Junipers directly, and if we have just finished that group we can continue into the Arbor-Vitae. Otherwise we must find the very low bushy evergreen that begins the collection. It lies in the center of the strip and approximately opposite the lamppost at the eastern side of the circular drive leading to the steps of the Conservatory. Between it and the inner road is the last tree in the Juniper collection. This first Arbor-Vitae is

Thuja occidentalis var. globosa, the American Globe Arbor-Vitae

This is one of several compact globose forms that have been developed from the native American Arbor-Vitae. We shall see others later. They all present considerable difficulty in identification, for the characters that supposedly distinguish them are frequently very obscure. The same is true of many other forms that we shall see and this condition must be kept in mind as we consider them. The same names, both common and scientific, very frequently are applied to more than one type by various persons. The names used here have been selected as the most suitable for various reasons. They may, however, be found to differ from those used elsewhere. This, of course, applies to the entire guide.

The American Globe Arbor-Vitae forms a very dense ballshaped evergreen, which because of its shape and limited height lends itself well to many situations.

Proceeding westward among the trees, the next upright evergreen with strikingly perpendicular branches nearer the outer road is

Thuja orientalis, the Chinese Arbor-Vitae

The Chinese Arbor-Vitae has produced quite a number of garden varieties, all of which like the tree itself are readily recognized by the distinct perpendicular arrangement of the branches and 
foliage. These forms are usually known as Biota and some of them, especially the dwarf ones, are among the favorites of nursery practice.

The Chinese Arbor-Vitae is native to northern and western China, where it does not attain heights much over 40 feet.

Just beyond this tree and the outer road is another low bushy American Globe Arbor-Vitae. Directly beyond it are two more Chinese Arbor-Vitae with their characteristic perpendicular habit.

The four trees along the inner road which we have passed are

Thuja orientalis var. aurea, the Golden Chinese Arbor-Vitae

Here is another form where confusion of names may exist. These trees in spring have bright yellowish foliage.

The next taller and very narrow evergreen by the outer road is

Thuja occidentalis var. pyramidalis, the American Pyramidal Arbor-Vitae

This is merely a narrower form of the common native ArborVitae, which we shall soon see.

The four larger broad trees that face us now are

Thuja Standishii, Japanese Arbor-Vitae

This is one of the most successful and best-looking of the several kinds of Arbor-Vitae in the Garden. Its heavy foliage is the most open of the species of Thuja and readily distinguishes it from the Chinese and the American species. It very much resembles, however, the native Western or Giant Arbor-Vitae. The difference will be pointed out when we see the latter.

The Japanese Arbor-Vitae, once common, is now one of the rarest of useful ornamental trees in Japan. In feudal times it constituted with four other conifers the famous five trees of Kiso which were strictly preserved as Tome-Ki (the preserved tree). The other four were the Unbrella Pine, Sawara Cypress, Hinoki Cypress and False or Hiba Arbor-Vitae. These are all in the Garden, the last in the greenhouse. In Japan this Arbor-Vitae may attain a height of 75 feet. Its wood is used to some extent.

Between the last one of these four specimens of Japanese Arbor-Vitae and the outer road stands a narrower

Thuja occidentalis, the American Arbor-Vitae 


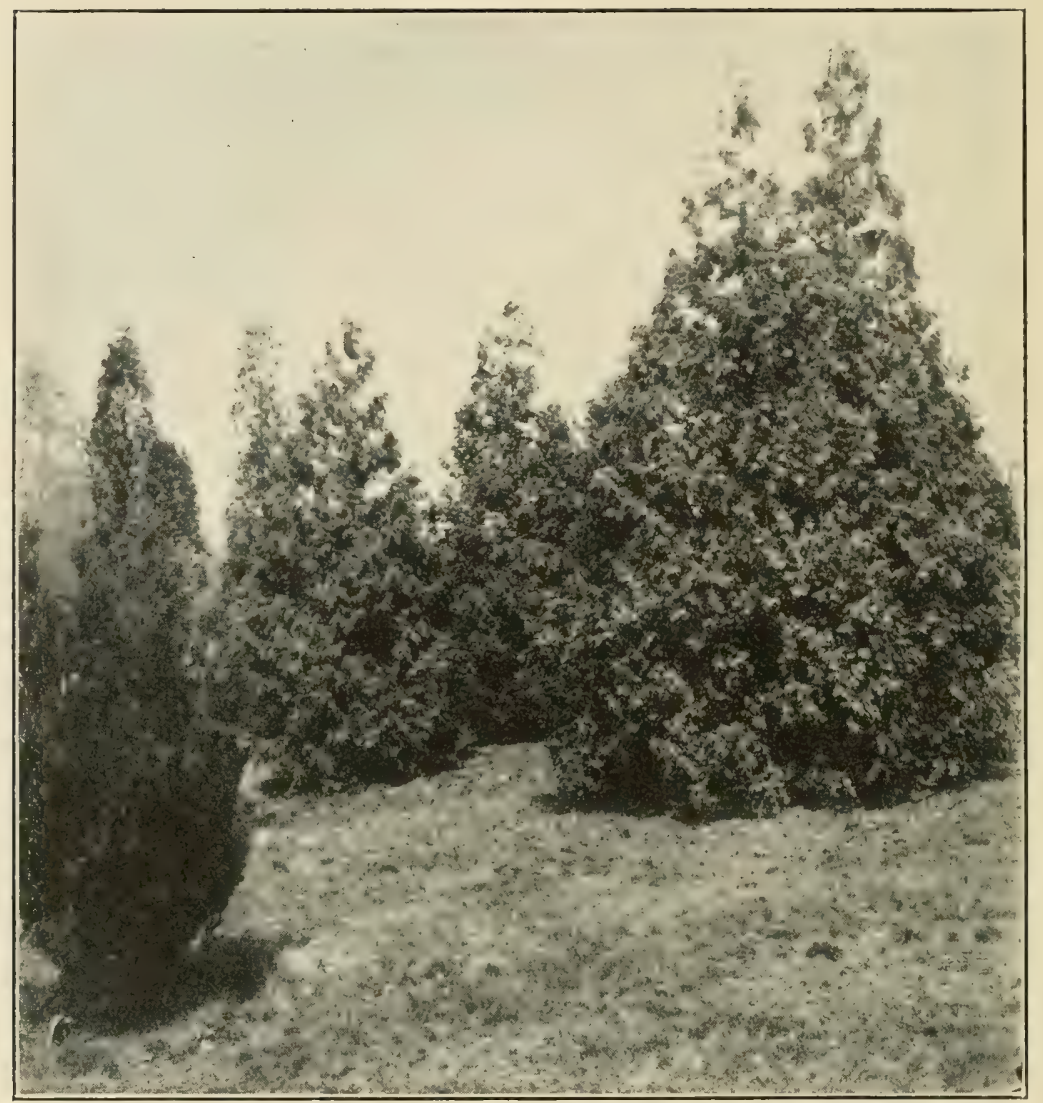

Figure 17. Japanese Arbor-Vitae, Thuja Standishii; Chinese ArborVitae, Thuja oricntalis, in left foreground. 
Another tree of the same kind is next by the inner road and just east of the lamppost. This is the native Arbor-Vitae, whici may be found wild in the eastern United States from Canada south to North Carolina and Tennessee. It is known under several names, among which Northern White-Cedar serves to distinguish it from the Southern White-Cedar which, however, belongs to another genus; the latter is Chamaccyparis thyoides. To the Indians the Arbor-Vitae was known as feather-leaf. It may attain a height of 70 feet and thrives best in low swampy land along the borders of streams.

The wood of this tree is exceedingly tough but a peculiar ten(lency to split along the annual rings limits its usefulness. This feature develops windshake in standing trees and is disliked by the lumberman, for he cannot make thin lumber that will hang together. The Indian, however, valued this feature, for he could easily split the wood for canoe frames.

The early settlers of New Jersey and Pennsylvania made a rheumatism ointment by bruising the leaves and molding them with lard. Drugs are still secured that are used in the manufacture of pulmonary and other medicines.

The Arbor-Vitae is very extensively used as an ornamental evergreen. It lends itself well to trimming and forms very fine dense hedges if properly cared for. Individual trees are the most commonly employed, especially to produce perpendicular effects in foundation planting.

In the center of the strip just beyond the last Japanese ArborVitae are two low sprawly-looking evergreens. They are

\section{Thuja occidentalis var. recurvata}

This pendulous form seems to have little ornamental value. Larger plants may have some merit.

To the left of these two is an American Arbor-Vitae. Near the inner road and just on the west side of the lampost is another Japanese Arbor-Vitae. Then comes a very narrow straight and tall tree in the middle. It is a common American Arbor-Vitae.

The next three broader trees, two by the outer road and one by the inner are 
Thuja occidentalis var. aureo-variegata, the Gollen Variegated or Goldspot Arbor-Vitae

This is a variegated yellowish form of the American ArborVitae.

Next by the inner road is a narrow American Arbor-Titae and then come two low darker-colored globular bushes. Their foliage is quite different from the other kinds of Arbor-Vitae and one might not suspect them to belong here. But they are

Thuja occidentalis var. Spaethii, Spaeth's Arbor-Titae

This is, perhaps, the oddest form of Arbor-Vitae in the Garden. It has two kinds of foliage, the awl-shaped juvenile type predominating. The adult scaly foliage generally found on the lower portions of the plant is very small. It must sometimes be cut out, nowever, for vigorous shoots of it are apt to spoil the shape of the plant. This odd variety is not quite hardy in the Garden, for the foliage generally dies every winter.

The next seven trees of varying sizes are the Imerican ArborVitas. The last of these is nearer the outer road and shows a cut stump near the base. Just beyond it and closer to the outer road is a narrow and taller Pyramidal Arbor-Vitae.

Between the last Imerican - Irbor-Vitae with the cut stump and the inner road is a

Thuja occidentalis var. Wareana, Siberian -Irbor-Titae

This is one of the difficultly distingtished forms. The plants in the collection have been retained under this name from nurseris which supplied thenl. Next nearer the inner road is an American Arbor-Vitae.

Close by in the center of the strip the tree with heavier foliage is

Thuja plicata, the Giant Arbor-Vitae

This is a very fine small specimen of one of our largest native trees in the West. Under cultivation it is quite rapid-growing and tolerant of shade.

In its range from . Maska to northern California and Montana the Giant Arbor-Vitae may attain a height of 150 or 200 feet. It is of value commercially, principally as the chief source of shingles in this country. From eight to twelve million shingles are annu- 
ally produced and seventy to eighty per cent of then come from the Western Arbor-Vitae.

This is the species that is apt to be confused with the Japanese

Arbor-Vitae. Close comparison, however, will show that the foliaged-branching of the latter is not so dense and that the scaly leaves end in short thick triangular points directed outward rather than in long fine free points parallel to the twig.

The next lower tree a bit to the right is

Thuja occidentalis var. spiralis, the Spiral Arbor-Vitae

This is one of the distinct forms in the Garden, characterized by the twisted arrangement of the dense foliage fronds.

The next two bushy evergreens by the inner road and one by the outer road are American Globe Arbor-Vitae.

Scattered over the area before us now are nine small trees which in spring stand out very conspicuously by their bright yellowish foliage. They are

Thuja occidentalis var. lutea, the Golden Peabody Arbor-Vitae

This is one of the finest forms in this Garden. Throughout the summer it is brilliantly yellow.

The next four darker trees with shorter and somewhat twisted foliage are the Spiral Arbor-Vitae. Two are along the outer road and the other two in the center close to the last of the Golden Peabody Arbor-Vitae. A fifth one we have passed by the outer road near the first Golden Peabody Arbor-Vitae.

The next broader tree by the outer road, whose center has been removed, is

Thuja occidentalis var. alba, the White-tipped Arbor-Vitae

This variety has white-tipped foliage during a portion of the summer. Otherwise it is indistinguishable from the common form.

Between it and the inner road is

\section{Thuja occidentalis var. elegantissima}

This is another yellowish form. I second specimen stands next heyond and more in the middle.

To the left of this last is an American Arbor-Vitae and to the right is

Thuja plicata var. atrovirens, the Dark Giant Arbor-Vitae 
This rariety of the Giant Arbor-Vitae has darker foliage than the species itself. A second specimen stands directly ahaad, beyond a lower one which is intervening. The latter is

\section{Thuja occidentalis var. pumila}

This is one of the many small forms, a second specimen of which is straight ahead just beyond the last Dark Giant Arbor-Vitae.

The next narrow evergreen in the center is an American Pyramidal Arbor-Vitae. The next by the outer road is

Thuja occidentalis var. Rosenthalii, Rosenthal's Arbor-Vitae

Another difficultly distinguishable form.

Next to the right is a group of seven American Globe Arbor$V$ itae. Between them and the outer road is a common ArborVitae, beyond which and still closer to the outer road is a

\section{Thuja occidentalis var. sempervirens}

A yellowish form.

The next two trees more in the middle are

Thuja occidentalis var. Douglasii pyramidalis, Douglas Pyramidal Arbor-Vitae

This is quite a fine variety of dense pyramidal form with densely branched fern-like branches.

The next one near the outer road is another Thuja occidcntalis var. sempervirens.

The two rather large trees by the inner road are the American Arbor-Vitae and between them a tiny globular evergreen is

\section{Thuja occidentalis var. Little Gem}

This is considered by some to be identical with Thuja occidentalis var. pumila.

The next two larger trees nearer the outer road are American Arbor-Vitae and in the center in a somewhat diagonal line are three of the very narrow Pyramidal Douglas Arbor-Vitae. To the right of the last of these and to the left of it a pace ahead are two of the common Arbor-Vitae.

Along the inner road we now see fourteen low and for the most part globular plants. These are a mixture of Thuja occidentalis globosa, T. occidentalis globosa noza, T. occidentalis nana and 
T. occidentalis Booth's Da'arf. Here we see a variety of these forms already referred to that are very similar to one another.

The next larger and broader tree in the middle after the last American Arbor-Vitae is a Variegated American Arbor-Vitae. Inother specimen of it is directly ahead, also in the middle, and a third stands to the left by the outer road, and between these two.

The next two larger and broader specimens, one in the middle and the other by the outer road, are the American Arbor-Vitae. Now we come to a group of eight yellow-foliaged evergreens. They are Golden Peabody Arbor-Vitae (p. 129). The next two darker-colored trees, one in the middle and the other with an open center by the other road, are the Spiral Arbor-Vitae. Next in the center the slender-foliaged and thready looking tree is

Thuja occidentalis var. filiformis, Threadtwig Arbor-Vitae

This odd form has very slender branches.

The next ten trees are the Japanese Arbor-Vitae (p. 125).

Beyond them stands a large American elm and on the other side of it are the last specimens of Arbor-Vitae. The first one on the left near the outer road is a Spiral Arbor-Vitae (p. 129). The first in the middle is a Siberian Arbor-Vitae (p. 128). Of the next two, nearer the outer road, the outer one is a George Peabody Arbor-Vitae, and the inner is a common Arbor-Vitae. There remain now six small trees. The three nearest the cross walk are the American Globe Arbor-Vitae and the other two low bushy ones are Siberian Arbor-Vitae. The remaining small slender one by the outer road is the common American Arbor-Vitae.

\section{General Discussion}

The species of Thuja are all evergreen cone-bearing trees. There are six different known kinds. Two are not represented in the Garden, riz.: the Korean Arbor-Vitae, T. koraiensis, found in Korea, and T. setchuensis of western China. The last is not in cultivation. The foliage of these trees resembles that of the cypress, Chamaecyparis, in the flat, scaly divided branchlets and the leaf arrangement. There is apt to be confusion at times in this respect. But the cones are markedly different, though not 
frequently present on ornamental material. Those of Chamaccyparis are globular and the scales composing them are shieldshaped while those of Thuja are egg-shaped or ovoid and their scales are flat.

The forms of Arbor-Vitae are very valuable ornamentally, for they are among the leading evergreens that may be used to secure perpendicular effects. Some of them, as the common native species, are well suited for hedges and lend themselves admirably to trimming.

Commercially, the Giant Arbor-Vitae is the most valuable, as the main source of shingles in this country. The native eastern species has been used to some extent for various minor industries.

These trees thrive best in somewhat moist loamr soil and are easily transplanted. 


\section{PART 10-BALD CYPRESS}

TREES OF UNUSUALLY DURABLE WOOD

The collection of Bald Cypress occupies the eastern end of the long narrow planted area between the two roads in front of Conservatory Range 1. The collection is located on the west side of the main drive after it enters the Garden from Southern Boulevard and opposite the Ginkgos and beginning of Section 1 of the Pines (Map p. 7). Nine trees constitute the group. They are

\section{Taxodium distichum, the Bald Cypress, and}

Taxodium ascendens, the Pond Cypress

These are the only conifers we have encountered so far in our Guide that are not evergreen. They lose their leaves in the winter and secure new ones each spring. Only three other genera of conifers, two of which we shall meet later, do this. They are Larix, the Larch, Pseudolarix, the Golden Larch, and Glyptostrobus. The peculiar feature about this habit in the bald cypress is that not only the delicate leaves are lost, but the slender twigs that bear them fall off, carrying the leaves along.

In the Bald Cypress these delicate leaves stand out in one plane from two sides of the twigs. In the Pond Cypress, however, the leaves are tiny and scale-like, closely pressed against the twigs, which tend to stand erect. The result is a pronounced contrast in the general appearance of the two trees.

The Bald Cypress is not frequently seen in cultivation, though it has proved hardy as far north as Massachusetts and has been known to withstand temperatures twenty degrees below zero. It is one of the best trees for wet situations, though it thrives in ordinary soil. Its fine feathery foliage, particularly the new growth in spring, is very attractive.

The Bald Cypress is a native of the southern United States, where it grows in swampy lands from Delaware to Florida and west to southern Illinois, Oklahoma, and Texas. It is the tree that has given its name to the famous and possibly uncanny Cypress swamps of the South, where it may reach a height of 150 feet. 


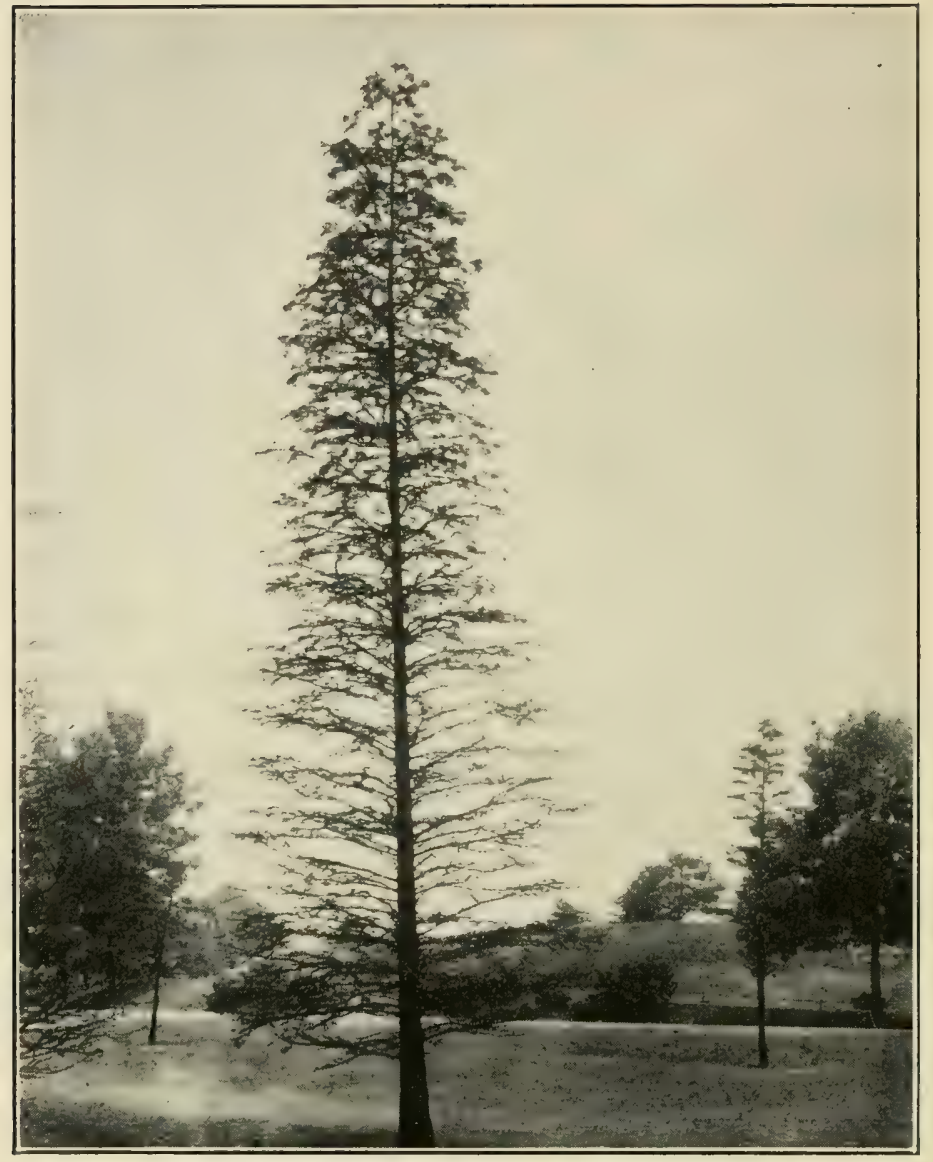

Figure 18. Bald Cypress

Taxodium distichum 
The most interesting feature of the Bald Cypress is the development of the so-called cypress "knees." In situations where the roots of these trees are permanently or periodically under water, soft woody growths up to ten feet in height found on the submerged roots project above the surface of the water. These growths later become hollow. There has long been a question concerning the function of these "knees." It is generally believed that they assist in supplying atmospheric oxygen to the submerged roots. This explanation is based on the observations that these growths form only when the roots are submerged, that their size depends on the depth of the water and that if they too become covered with water the trees die. On the other hand it has been maintained that the hardened surface of these knees could not absorb oxygen, and that if such were the case nature would provide a broaler rather than a narrowing surface of limited area for absorption. Root anchorage has seemed the function from this viewpoint. They serve no reproductive purpose, for they have no buds and die when a tree is cut.

The fact remains, however, that among trees adapted for swamp growth, Bald Cypress is the only one that thrives in soil continuously flooded. Fifty or a hundred of these knees may surround the base of the tree, extending some distance from the trunk. In addition to the "knees," the base of the tree generally has large flutes or buttresses in wet situations. Mature trees are usually hollow at the base.

The wood of the Bald Cypress is very durable, as might be expected, and has been much advertised as the "Wood Eternal." Under wet conditions the trees may attain enormous diameters, whose proportion to their heights may exceed that exhibited by the gigantic Sequoias of California.

Furthermore, the Bald Cypress displays an anomaly among conifers by sending up vigorous sprouts from cut stumps. This departure, as has already been noted, is exhibited in the Pitch Pine and Redwood.

\section{General Discussion}

There are only two or three kinds of Bald Cypress, the number depending, as in all such cases, on the definition of a species. 
They are all confined to North America. The third one, not in the Garden, is the Montezuma Cypress of Mexico, Taxodium mucronatum. The leaves of the last-named tree may be deciduous, semi-evergreen or evergreen according to situation. Evergreenness is induced, naturally, by optimum conditions. This tree was long reverenced by the Indians before the discovery of America by Europeans. It is not hardy, though occasionally planted in California. It is interesting, since it may attain a height of 170 feet with a trunk 40 feet in diameter. A certain very large tree of this kind in Mexico City has been regarded as possibly the oldest living tree in the world, rivaling the Redwoods of California. Our native Bald Cypress may commonly be found 400 to 600 years of age and occasionally from 720 to 1200 years. It is remarkable that trees living in such wet situations should attain such age.

Some botanists regard all these trees as varieties of one species. The differences, it is said, are more geographical than botanical. The Pond Cypress, it is claimed, is the result of less fertile conditions. It is usually confined to the prairies and low pinelands and may even occur on sand dunes. The peculiar appressed nature of the leaves clinging close to the twigs may, consequently, be an adaptation to prevent excessive evaporation of moisture under these drier conditions. The Bald or River Cypress, on the other hand, demands wetter situations. Occasionally both types of leaves, the wide spreading and the closely pressed, are found on the same tree.

One or two very similar trees are found in China and are known as Glyptostrobus heterophyllus. This is little known in cultivation outside of China and is unknown in the wild state. Several specimens have been cultivated at the Garden in the conservatories. Very commonly, however, this relatively rare plant is regarded as a Taxodium. It resembles the Bald Cypress very closely but it loses its cone scales rather than retaining them as in the native trees. This is the principal basis of distinction, similar to that between the Douglas Fir and true firs. Fossil relatives of both Glyptostrobus and Taxodium have been found from widely separated regions. 


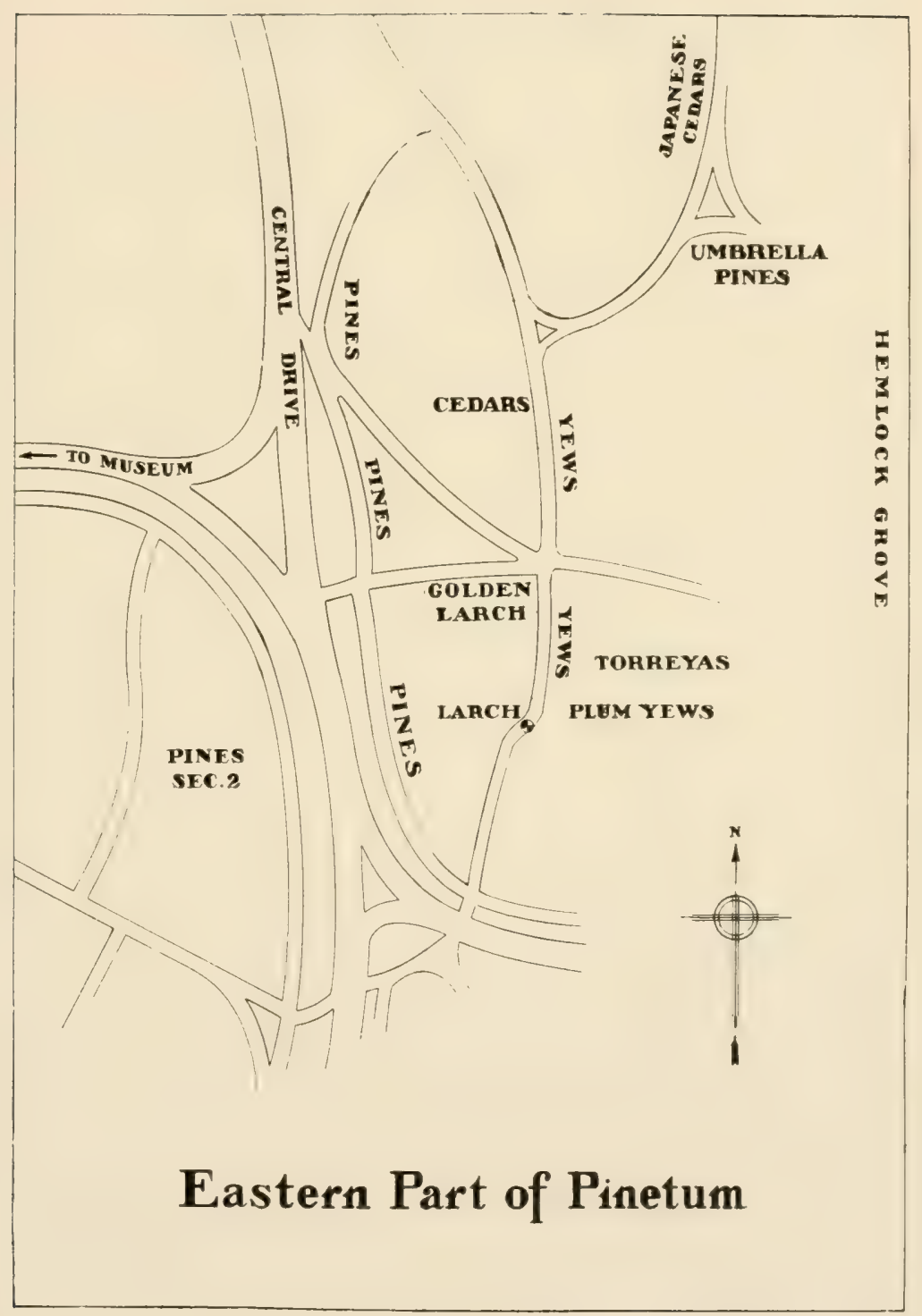




\section{PART 11-LARCHES}

\section{CONIFERS THAT LOSE THEIR LEAVES}

The collection of Larches is located on the ridge between the Central Drive through the Garden and the open meadow to the east of it (Map p. 137). Let us locate ourselves at the curve in the patl, as indicated on the map. Two small larches are located on the south side of this point. They are the only two trees there with flat needle-like leaves in clusters. In winter they are bare, but their branchlets are covered with many regular short spurs.

The nearer of these two trees is a European Larch, and the farther one is a Japanese Larch. The latter may be distinguished by the two white stripes on the lower side of the leaves, which are less conspicuous on the European species. More of these trees stand on the north side of the curve in the path.

In considering the larches we meet the second kind of coniferous trees that lose their leaves in the autumn. The first case was that of the Bald Cypress and the third and last will be the Golden Larch.

As we proceed through the group on the north side of the curve in the path the first two trees are

\section{Larix Larix, the European Larch}

This is a valuable tree of rapid growth for parks and large private estates. It is hardly suitable for small areas because of its tall habit and deciduous nature. It does well in sandy soil.

The Europaan Larch is distinguished from its Japanese relative by its grayish bark and leaves that are green rather than bluish green. The scales of the cones are not curved at their tips. It has a very wide distribution from the Alps of contral Europe to northern Russia and Siberia and attains a height of 140 feet. It is one of the leading timber trees of Europe and its wood is used in a great variety of industries. The trees are extensively used for forestation purposes in Europe, particularly in England.

The bark has astringent and other medicinal properties and has also been used in tanning and dyeing. An oleo-resin known as Venice or Larch Turpentine is obtained by tapping the trees in 
Europe. It is similar to our native balsam (1.79) and possesses medicinal qualities. Its use, however, is more or less confined to veterinary practice. A substance called Briancon Manna or Manna of the Larch exudes from the leaves in summer. It is sweet and was formerly used in medicine. Ethyl alcohol may be obtained by distillation of the wood.

The next trees ahead are

Larix leptolepis, the Japanese Larch

This tree attains a height of 80 feet and more in Japan and is regarded as one of the handsomest and most rapidly growing of the genus. It occurs there on the slopes of high volcanic mountains at elevations of 4000 to 6000 feet. The wood is hard and durable and is used there for general construction purposes. In this country it is perhaps the best of the larches for a lawn specimen.

The Japanese Larch, as already pointed out, is distinguished from the European kind by its more prominent whitish lines on the under side of the leaves which give the foliage a bluish-green tint. Furthermore, the cone scales are broader and bent at their tips.

Just north of these tall Japanese larches are two young trees. They are

Larix eurolepis, the Dunkeld Larch

This is a hybrid that first appeared in England as a cross between the common Europaan and the Japanese Larches. It possesses characters of both its parents and seems to be more vigorous than either of them. It is not well known in this country yet.

The three evergreens on the western edge of this Section are Red Cedars (p. 112).

\section{General Discussion}

There are about a dozen different kinds of larch, all inhabitants of the colder regions and higher altitudes of the Northern Hemisphere. They are all deciduous conifers and only one species, Lari. 
Griffithi, from the Himalayas, is tender. No other tree extends farther north than the larch, which in America reaches $67^{\circ}$ latitude and in Siberia $72^{\circ}$, both within the Arctic circle. The only other conifers approaching this are the Jack Pine and the Common Juniper.

The wood is much used, being hard, heavy, and very durable. That of Larix occidentalis is regarded as the best of all A'merican conifers. From the European Larch turpentine is obtained, though the Maritime Pine is the chief source in Europe. The bark of larch has furnished some tannin extract. The larch is widely tolerant as to soil, growing on both clay and limestone, and preferring a somewhat moist but well-drained soil and an open situation. The American Larch, Larix laricina, thrives even in swamps.

As in the true cedars, Cedrus, the branchlets of the larch are of two kinds. There are elongated slender ones which grow up to two feet a year and bear leaves distributed singly or spirally. The others are the short spurs that bear clusters of leaves. The larches are intolerant of shade and demand full light. Several insect and fungous pests are serious drawbacks to the cultivation of larch. 


\section{PART 12-GOLDEN LARCH}

Three trees constitute the collection of Golden Larch in the Garden. They stand just north of the Larches on the higher ground east of the Central Drive through the Garden (Map 1. 137). These trees are

Pseudolarix Kaempferi, the Golden Larch

This tree is very similar to the true larches. Its long spreading branches are pendulous at the tips, clothed in summer with lightgreen clustered leaves that turn clear yellow in fall. It, too, loses its leaves in autumn, being one of the four genera of conifers that do so. The others are the Larch, the Bald Cypress and Glyptostrobus of China. The Golden Larch is very similar to the true larches but differs by having stalked, pendulous, clustered male flowers and cone-scales which fall from the axis of the cone at maturity as in the true firs. Furthermore, the Golden Larch is distinguished by its longer club-shaped short shoots with distinct annual rings and by its larger and broader leaves.

The Golden Larch is found wild only in a restricted region in eastern China, at altitudes of 3000 to 4000 feet. It attains heights there up to 130 feet. In our country it is quite hardy, though slow growing, and is apparently free from insect pests and fungous diseases. It requires a sunny position, well-drained moderately moist soil, and it dislikes limestone.

To the Chinese this tree is known as chin-lo-sung, i.e., Golden Deciduous Pine, or merely as ching-sung, i.e., Golden Pine. The names, of course, refer to the golden color displayed by the foliage in autumn. It is too scarce to be of much economic value, though the wood is of good quality and easy to work.

This is the only species in the genus Pseudolarix. 


\section{PART. 13-YEWS}

THE WOOD OF ENGLISH YULETIDE AND MEDIAEVAL ARCHERY

VALUABLE ORNAMENTAL EVERGREENS

The collection of Yews is located on the east slope of the ridge between the Central Drive through the Garden and the narrow open mearlow to the east of it (Map p. 137). We shall begin at the southern end of the collection and proceed northward along the path.

The first upright yew on our right close to the exposed rocky formation at the curve in the path is

Taxus cuspidata var. pyramidalis, Pyranidal Japanese- Yew

This is an example of varietal possibilities in horticultural practice. This particular variety is not generally recognized but the tree at hand was received from a nursery under this name. It probably arose from a cutting taken from the terminal growth of a Japanese lew for such cuttings are known to produce upright plants. Side cuttings generally form spreading plants.

Next is a lower, bushier, and broader yew. It is

Taxus baccata var. aurea, the Golden English-Yew

This is a distinct variety of the English lew. Its leaves are golden yellow in early summer, later losing their brilliance. This variety may at first be confused with the somewhat similar Variegated English-Yew which we shall soon meet. Distinctions will then be noted.

The next lower and very dense evergreen that covers the ground beneath it is

Taxus baccata var. repandens, the Spreading English-Yew

This is a very attractive form that lends itself well to many situations. It has graceful drooping foliage and forms a very dense growth close to the ground, only a foot or so in depth. Its leaves seem unusually long for an English Yew and resemble those of the Japanese. But the low weeping habit of the plant betrays it. 
Directly behind this is a small but upright form that does not lie on the ground. It is

Taxus baccata var. fastigiata, the Irish Yew

This is one of the best-known varieties of the English Yew. It is always a female plant, for, unlike the pines, the sexes are diffe:ent individuals in the yews. And the Irish Yew originated over a hundred years ago from a female plant. All Irish Yews since are direct descendants of that original tree. Some very handsome specimens are known in Europe.

The next large and wide-spreading evergreen along the path, as well as all the other similar ones in the background, is

Taxus baccata var. variegata, the Variegated English-Yew

This variety is very apt to be confused with the Golden EnglishYew until one has carefully compared them. The Golden EnglishYew is stiffer, the branches do not arch and project so much and in summer the color of the foliage is deeper yellow. That of the Variegated English-Yew grows pale toward the end of the summer.

The variety before us makes a very dense growth and seems admirable in a protected spot as a border hedge where ample room is given it.

The next lower dense one along the path is another Spreading English-Yew.

The next very wide-spreading plant, with stiffer branches and more stubby foliage, is

Taxus cuspidata var. nana, the Dwarf Japanese-Yew

There are only two or three varieties of the Japanese Yew and this is probably the best known of them. It is a rather stiff lowbranching and wide-spreading form, with shorter and stubbier leaves than we shall find on the Japanese Yew itself. It needs plenty of room to develop properly and is perhaps best used singly because of its individuality. A very similar variety that is difficult to distinguish from the one before us is var. densa. A very handsome example of this latter is located by itself in the center of the driveway in front of Conservatory Range 1. 
Next along the path is another wide-spreading Variegated English-Yew. Behind it the largest tree in the entire group is

Taxus cuspidata, the Japanese Yew

The Japanese Yew has during recent years become one of the favorite ornamental evergreens. It has superseded the more famed English Yew because of its greater hardiness and reliability. It is very commonly used as a hedge plant and in this capacity a lowspreading form is employed that is secured by cuttings from lateral branches of plants. If the upright terminal shoots are rooted upright plants result. The reddish berry-like fruits of the yew are an ornamental asset but to insure their production male and female trees must be planted together. The yews, like the hollies, do not as a rule have both sexes of flowers on the same plant as in the pines and spruces.

The Japanese Yew is native to Japan, where from time immemorial it has been used for ornamental purposes. It attains a height there of 50 feet. The tough, close-grained and beautifully colored wood has been used for cabinet work and indoor decoration. The Ainos, the aboriginal inhabitants of the island of Yeso, made their bows from the Japanese Yew as the archers of Europe did from the tough English Yew.

The Japanese Yew is most readily identified by the two-ranked leaves, which stand up on the twigs forming a $\mathrm{V}$-shaped trough. The leaves of the English Yews do not show this so conspicuously and, furthermore, are not yellowish on the under surface.

Next along the path is another Dwarf Japanese-Yew and behind it a large wide-spreading Variegated English-Yew. Behind this the taller green yew with wide base is a Japanese Yew. The two tall narrow evergreens behind these last yews are Red Cedars (p. 112).

Now we see a few very small yews. The first one to the right close to the bigger Variegated English-Yew is

Taxus baccata var. fastigiata aurea, the Golden Irish-lew

This is a yellow form of the Irish Yew. It may attain a height of six or ten feet. 
To the left of it the small plant nearer the path is a Japanese Yew and the narrower one behind it is an Irish Yew.

Next near the path the tallest of these small forms is

Taxus cuspidata var. Hicksii, Hicks' Yew

This is an upright form of the Japanese Yew developed and sold by the Hicks Nurseries on Long Island. The specimen at hand is rather poor.

The two remaining small plants and the third similar one close by very much resemble English Yews in their foliage and are apt to be confusing. They were raised, however, from seed secured from Japanese Yews in the Garden.

Now we come to larger plants. The broad bushy one with yellowish foliage in the background is a Golden English-Yew.

This specimen shows the features of this variety very well in contrast with the Variegated English-Yews we have passed.

The next larger one along the path is a Japanese Yew and to the left of it is another low spreading stiff Dwarf Japanese-Yew. Directly behind this last one is a tree with drooping branches. It is

Taxus baccata var. Jacksonii, Weeping English-Yew

This is a handsome weeping form of the English Yew.

The last three trees along the path are Japanese Yews.

Let us now turn down the path to the right. Three low dense yews come into view, which are

Taxus baccata var. procumbens or repandens, Prostrate English-Yew

It is difficult to tell which of these two varieties the plants at hand are. This applies as well to previously encountered specimens of the Prostrate English-Yew. The distinction is of little significance.

Behind them the remaining stiff wide-spreading form is another Dwarf Japanese-Yew.

On the north side of the path we are now on are several more yews. The tallest one is a Japanese Yew. The yellowish- or brownish-tinted plants to the right of it with slender projecting branches are Variegated English-Yews. The five lower and stiffer forms remaining before us present some difficulty in an attempt to 
distinguish them. Some of them appear to be Dwarf JapaneseYews and the others probably are

\section{Taxus baccata var. adpressa}

This is a female clonal variety whose leaves are shorter and broader than in the common form.

Let us continue northward along the path on the western side of this group of yews. The corner plant is probably Taxus baccata var. adpressa. Then comes the larger Japanese Yew already pointed out and next to it three Dwarf Japanese-Yews. The Variegated English- Vews already noted are now in the background. The small but upright yew directly beneath the big overshadowing tulip tree as well as the last three low spreading forms with wide projecting branches to the left are Japanese Yews.

The three remaining more upright but poorer-developed plants are

Taxus baccata var. Dovastonii, the Dovaston Yew

These plants have been set out under this name but fail to show much character. It is a variety supposedly marked by an erect stem and horizontal wide-spreading hranches with long weeping branchlets.

In order to see all the yews in the collection, let us retrace our steps a bit and find the extreme southern end of the collection on the eastern side. In other words, we must locate the southeast corner of all the evergreens that are here grouped together. It that point we shall stand in a little protected opening almost completely surrounded by evergreens. I rocky ledge marks the western side outside the trees. (Ince there we should notice the large. low, and wide-spreading evergreen with distinctly weeping effect. It is another Weeping English-Tew. To the left of it, as we regard it from within our little enclosure, are two taller trees. The center one is a Japanese lew and the less rigid one to the left of it probably is

Taxus baccata, the English Yew

The English Yew has long been one of the venerable trees of Europe, particularly in England. The Iule log of olden days 
came from it and its part in English lore has been considerable. Before the advent of Christianity in England the yews were sacred to the pagan Druids, who erected their temples near these trees. In horticultural work it formerly played a greater part than at present and the topiary effects that were secured with the yew were remarkable. We cannot afford to enter into the interesting history of this tree here. The wood has been highly prized for cabinet work and in olden days made the bows of the archers. The foliage of the yew is said to be poisonous to cattle, but the little red berry-like fruits are edible.

In this country the English Yew is not so hardy as the Japanese. A great many garden varieties are cultivated.

The English Yew is found wild over most of Europe and in northern Africa and western Asia.

On the eastern side of our little enclosure are three evergreens. The lower upright bushy one in the center with golden foliage during summer is a Golden English-Yew.

There remain four unmentioned evergreens in this enclosure. They are not yews, though similar to them. They are Plum Yews and Torreyas.

\section{General Discussion}

Six or eight different kinds of yew are known, found only in the Northern Hemisphere. They are all evergreens, so closely related that they are often regarded as geographical varieties of but one species. They do not differ in fruit, only in characters of bud, leaf and habit. Three occur wild in the United States. The Canada Yew, Tarus canadcnsis, is found throughout most of the Northeast, where it is frequently known as Ground Hemlock. It forms bushy masses up to four feet or more in height and is the hardiest of the yews. But it has the habit of turning a sickly brown in autumn and that feature discourages its ornamental use. The Western Yew, T. brevifolia, forms a tree up to 75 feet in height on the Pacific Coast, but is rare in cultivation. In Florida there is the Florida Yew, T. floridana, a small tree of minor value. Others occur in Asia. A few hybrids and several other forms have been produced in cultivation. 


\section{PART 14-PLUM YEWS}

The collection of Plum Yews contains three small plants which stand close to the yews on their eastern side (Map p. 137). See text, last page.)

In the enclosure where we considered the last of the yews there remained unmentioned four evergreens. One of these is the small very low one close to the ground on the western side. Another is next to it and upright. Both are

\section{Cephalotaxus drupacea, the Japanese Plum-Yew}

A third small specimen of this same kind is located about fifty feet farther north on the eastern edge of this entire collection of evergreens.

This evergreen from Japan usually forms under cultivation a shapeless wide-spreading bush. It has an almond-like fruit from the seed of which a resinous oil is pressed by the Japanese for use in lamps. The wood occasionally is employed in cabinetmaking. To the Japanese this bushy tree is known as Inu-gaya, Abura-gaya, and as Anatni. It is not frequently found in cultivation.

\section{General Discussion}

There are six kinds of Plum Yews, all native to Japan, China, or Himalaya. They are ornamental evergreen shrubs and require shelter in cold climates as that of New York. They closely resemble the yews but differ from them in having whitish lines on the under side of the leaves rather than a yellowish-green color. From the Torreyas, which we shall see next and which also are yew-like, they differ by these whitish lines being broader and not narrower than the green lines that accompany them. 


\section{PART 15-TORREYA}

The collection of Torreyas consists of four trees of one kind located on the eastern side of the yews (Map p. 137). See text, last page of yews).

In considering the last of the yews, we noted three trees on the eastern side of the little evergreen enclosure where we were located. The center lower bushy one was a yew. The other two taller ones at the sides of it are

Tumion nuciferum, the Japanese Torreya

The other two trees of this kind are located about thirty-five and forty feet north of these two and on the eastern side of this entire evergreen collection. The very much smaller Plum Yew forms a triangle with these two.

This tree is the largest of its genus, attaining a height of 80 feet in Japan, but more often it is only a shrub 20 feet tall. It is known to the Japanese as Kaya. An oil, kaya-no-abura, is extracted and considerably used for cooking in Japan. The kernels of the seeds, which possess an agreeable and slightly resinous flavor, are used as food. The wood is valued for shipbuilding and cabinet-making.

\section{General Discussion}

There are four different known kinds of Tumion or Torreya. Two of these are native. They are Tumion taxifolium, the Stinking Cedar of Florida, and T. californicum, the California Nutmeg of California. The former, often called Chattahoochee Pine, grows on limestone soil and like the Florida Yew is confined almost wholly to one county. It reaches a height of 50 feet and its wood has some local value. The bruised leaves and branches give off an odor suggesting its common name. This same feature is found in the California Nutmeg, whose seeds resemble nutmegs. The fourth species is Tumion grande of China, where it is usually a shrub but may become a tall tree.

These Torreyas are interesting principally because they represent only a few isolated spots on the earth, Florida, California, China, and Japan. They are remnants of more abundant vegetation in 


\section{(150)}

earlier geological periods. They very closely resemble the yews and are characterized by upposite spreading ranks of firm sharp leaves terminated by a fine hard point. The leaves of the yews, however, are spirally arranged but by a twisting of the stalks appear to be two-ranked. Furthermore, the under surface of the leaves in the yews, especially the Japanese, are yellowish and not whitish. And from the Plum Lews the Torreyas are distinguished by these whitish lines being narrower than the green lines that accompany them. 


\section{PART 16-CEDARS}

THE TREE OF SOLOMON'S TEMPLE

Three genera of evergreens are commonly known as cedars. The common Red Cedar (p. 112) is really a juniper. The White Cedar (p. 106) is a Chamaccyparis. The Arbor-Vitae and the Cedrela are often known as cedar, too. The true cedars are those of the genus Cedrus. The collection of these in the Garden has only three trees, which stand on the higher ground east of the Central Drive through the Garden (Map p. 137). They are north of the yews and on the west side of the path from them.

The three trees here are

Cedrus atlantica var. glauca, the Blue ttlas-Cedar, and Cedrus atlantica var. aurea, the Golclen . Itlas-Cedar

The former, of which there are two trees, has bluish foliage, and the latter, of which there is one tree, has golden foliage. These color features show best on the new growth in spring. The lirst of these is a natural variety that may occur in any batch of seedlings. Consequently, there are gradations in it. The golden form is propagated only by grafting and is not so vigorous as seedling trees.

The Atlas Cedar, of which these are two variations, is native of the Atlas Mountains in Algeria and Morocco of northern Africa. It grows there up to 120 feet in height, forming a very handsome tree, pyramidal when young and flat-topped in age.

These trees prefer well-drained, loamy soil, but will also grow in sandy clay, if there is no stagnant moisture.

\section{General Discussion}

There are three closely related species of true cedar and these are sometimes regarded as geographical varieties of the same tree. Of these the Lebanon Cedar is one of the most famous of trees, because of its interesting historic and religious associations. The Cedars of Lebanon that grew near the eastern shores of the Mediterranean Sea have been famed throughout history as the source of the great timbers which Solomon secured from King 
Hiram for his great temple. Much interesting matter has been written about them which cannot be discussed here.

The third is the beautiful Deodar Cedar of India. Like the Itlas and Lebanon Cedars. this one. too. exhibits a conspicuous flat-spreading top in old age but has a broad pyramidal form when young. Though possibly the most beautiful of the cedars, the Deodar is the tenderest. Consequently efforts to raise it in the (arden have failed. In Pasadena, California, there is a certain arenue that was lined with these trees half a century or so ago. Today they constitute the finest display of these trees in this country, for they have become magnificent specimens fifty or sixty feet high. Every Christmas they are illuminated and are the pride of the land about them.

The cedars are evergreen trees, differing in that respect from the larches, which they closely resemble in foliage. Both have numerous needle-like leaves borne in clusters. Though this applies also to the pines, there is little chance for confusion if one conpares them but once. 


\section{PART 17-UMBRELLA PINE}

\section{A CURIOUS TREE FROM JAPAN}

The collection of Umbrella Pines is located at the extreme northern end of the open meadow that borders the Hemlock Grove on its western side (Map p. 137). These trees are

Sciadopitys verticillata, the Umbrella Pine

This is one of the most distinct of conifers. It is not a pine and has no immediate relatives. It is the sole survivor of a prehistoric group of plants whose other members were exterminated in a remote geological period.

The Umbrella Pine is an evergreen tree, a native of Japan, where it attains heights from 70 to 120 feet and diameters up to 10 feet. It is common in some parts of Japan and the timber is a regular article of commerce. The durable wood is used for boats, bathtubs, etc. The fibrous bark is made into oakum, used for caulking boats and packing steam-pipe joints.

To the Japanese this tree is known as Koya-maki, which means the Podocarpus of Mt. Koya. Podocarpus is another kind of tree found in Japan, specimens of which are growing under glass in the Garden. Like the Ginkgo, Sciadopitys was for a long time known, ornamentally, only in temple gardens near the ancient monastery town of Koya. It is not, however, as popular as the Ginkgo and is not extensively planted in Japan.

Under cultivation the tree is very hardy but slow-growing. It requires some shelter from strong winds and enjoys cool moist situations. Reproduction is accomplished by seeds borne in cones.

The odd feature of the Umbrella Pine is the production of two kinds of leaves. The conspicuous foliage at the tips of the branches resembles the ribs of an umbrella and has given the tree its common name. But these are not true leaves or needles as on other conifers; they are modified stems and have been known to branch. The true leaves are very small and occur at the base of each of these larger rib-like structures known as phyllodes. The possession of these two kinds of leaves makes the Umbrella Pine one of the most curious and interesting of trees. 


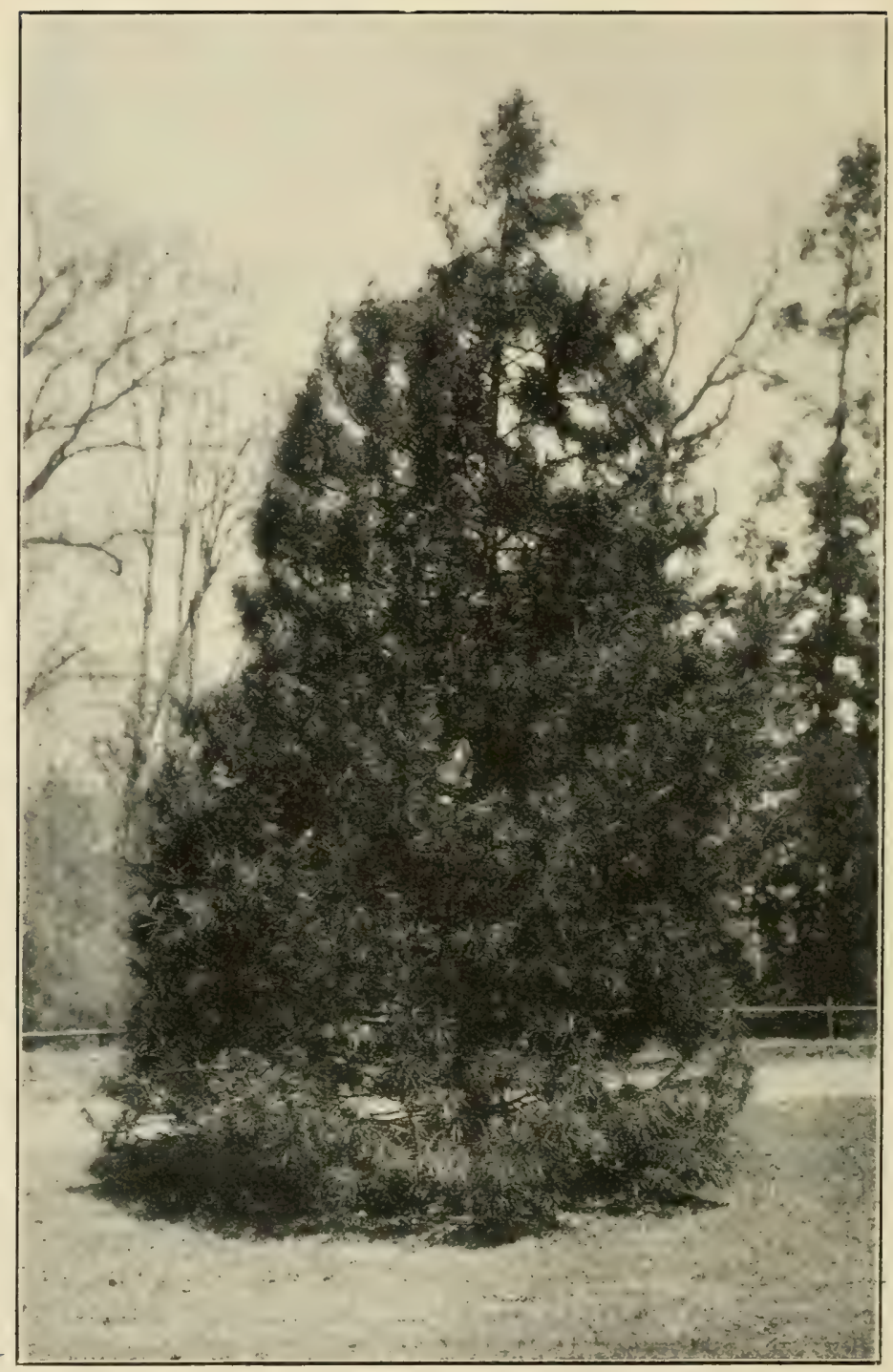

Figure 19. Umbrella Pine Sciadopitys verticillata 


\section{PART 18-JAPANESE CEDARS}

\section{ROYAL TEMPLE TREES OF JAPAN}

The collection of Japanese Cedars is located in a group across the path from the Umbrella P'ines at the north end of the meadow that borders the Hemlock (Grove on its western side (Map p. 137). These trees are

Cryptomeria japonica, the Japanese Cedar

This is one of the handsomest and most distinctive of evergreens. It forms a tall narrow tree of dark foliage and should be planted, preferably, as individual specimens to show its beauty rather than in masses, unless the latter be justified.

Cryptomeria is native to Japan and China, where it attains a height of from 100 to 180 feet, forming a majestic tree that rivals our Redwoods of California in grandeur. In the former country it has for ages been regarded with almost religious esteem and much planted about temples and shrines. There is a story in Japan that when the body of Ieyasu was laid to rest on the Nikko Hills his successor called upon all his followers to send each a stone or bronze lantern to decorate the grounds about the mortuary temples. All complied but one man, who was too poor. He offered to plant trees along the road to the tomb that subsequent pilgrims might be protected from the sweltering sun. His offer was accepted. The trees were planted at the beginning of the seventeenth century and ever since have been maintained or replaced as needed. Today, three hundred years later, that avenue of Cryptomerias is said to present one of the finest sights in the world.

Probably more impressive, according to a contemporary traveler, is another avenue of these trees over a mile long. They are said to have been planted by a priest, Ogo Shonin,- about 650 years ago.

Throughout the Empire. Cryptomeria has been very extensively planted and with the exception of the Japanese Red-Pine, $P$. densiflora (p. 24), it is the most commonly grown conifer in Japan. Two decades ago Cryptomeria was said to constitute thirty per 
cent of the Japanese forests. It consequently is the most used timber tree in Japan and one of the great lumber trees of the world. It has also been extensively used for reforesting denuded lands. It is known to the Japanese as Sugi. The wood is used for all sorts of construction purposes and the bark, carefully stripped from felled trees, is employed as roofing material.

The Cryptomeria thrives best in a climate which approaches that of our Redwood region. Under cultivation it requires deep, welldrained soil, with abundant moisture and protection from sharp wind.

The genus Cryptomeria is represented only by this single species found in Japan. There are, however, a few varieties of it. Approximately in the center of this group along the western side of the path and set back a bit we should find a tree whose leaves are more prickly than those of the others. It is

Cryptomeria japonica var, pungens, the Prickly Japanese-Cedar

At the northern end of the group are two trees with dark-green. short, stout, and stiff leaves. These are

Cryptomeria japonica var. araucarioides, the Araucarian Japanese-Cedar

All the trees in the smaller triangular area between the paths are plain Japanese Cedars.

It seems appropriate, at this point, to make mention of the public spirit of Mr. Lowell M. Palmer, through whose generosity the extensive collection of conifers in the Garden had its inception. Mr. Palmer had assembled a large collection of these trees at his home in Stamford, Connecticut, and in 1903, when the plantings in the Garden were begun, gave 450 trees to the Garden. In 1905, again, he donated 467 more trees. These generous contributions served as an important nucleus around which the present Pinetum has been developed. 


\section{INDEX}

Bold-face type indicates kinds in the Garden; viz., Abies homolepis var. Tomomi.

Names in italics indicate kinds not in the Garden; viz., Abies balsamea.

Reference to other names indicates synonomy; viz., Abies bifida, see $\mathbf{A}$. Momi.

Bold-face numbers refer to pages containing descriptions at points where the plants are first encountered; viz., 68.

Italicized page-numbers refer to pages containing additional information; viz., 68.

Numerals of ordinary font refer to pages on which the plants are incidentally encountered but not described; viz., 68 .

Abies, 72, 78

alba, see $A$. Picea

Alcockiana, see Picea jezoensis amabilis, 79

balsamea, 79

bicolor, see Picea bicolor

bifida, see A. Momi

brachyphylla, see A. homolepis

bracteata, see $A$. venusta

canadensis, see $T$ suga canadensis

cephalonica, 76 .

cilicica, $\mathbf{7 4 ,} 80$

commutata, see Picea Engelmannii

concolor, 76,80

diversifolia, see Tsuga diversifolia

Douglasii, see Pseudotsuga mucronata

excelsa, see Picea excelsa

firma, 73

Fraseri, 79

Gordoniana, see A. grandis

grandis, 78,80

homolepis, 72,80

var. Tomomi, 75

var. umbellata, 72

jezoensis, see Picea jezoensis

lasiocarpa, 77

magnifica, 75, 79, 80

Menziesii, see Picea pungens

Momi, 73

nobilis, 75

Nordmanniana, 74, 80

panachaica, see $A$. cephalonica

pectinata, see A. Picea

Picea, $80^{\circ}$

var. pendula, 78

Reginae-Amaliae, see A. cephalonica

rubra-violacea, see Picea canadensis var. coerulea

subalpina, see A. lasiocarpa

Tomomi, see A. homolepis var. Tomomi
Abies (cont'd)

umbellata, see A. homolepis var. umbellata

umbilicata, see A. homolepis var. umbellata

Veitchii, 73

venusta, 79,80

Abura-gaya, 148

Aka-matsu, 24

Anatini, 148

Arbor-Vitae, 124, 131, 151

American, 125, 127-131

Globe, 124, 125, 129-131

Pyramidal, 125, 128, 130

Variegated, 128, 131

Common, see American ArborVitae

Chinese, 124, 125

Golden, 125

Douglas Pyramidal, 130

False, 125

George Peabody, see Golden Peabody Arbor-Vitae

Giant, $125,128,132$

Dark, 129

Golden Peabody, 129, 131

Goldspot, 128

Hiba, 125

Japanese, 125, 127, 129, 131

Korean, 131

Little Gem, 130

Oriental, see Chinese Arbor-Vitae

Queen Victoria, see White-tipped Arbor-Vitae

Rosenthal, 130

Siberian, 128, 131

Spaeth's, 128

Spiral, 129, 131

Standish, see Japanese ArborVitae

Threadtwig, 131

Variegated

Golden, 128 
Arbor-Vitae (cont'd)

Ware's see Siberian Arbor-Vitae Western, see Giant Arbor-Vitae White-tipped, 129

Bald-Cypress, 133, 135, 141, 144

Balsam, 61

Canada, 76

Carpathian, 14

Bara-momi, 58

Biota, see Chinese Arbor-Vitae

California Nutmeg, 149

Caryopitys edulis, see Pinus edulis

Cedar, 140, 151

Atlas, 151

Blue, 151

Golden, 151

Canoe, see Giant Arbor-Vitae

Deodar, 17, 152

Giant, see Giant Arbor-Vitae

Japanese, see Japanese-Cedar

of Lebanon, 74, 151

Port Orford, 105, 107, 108

Blue Pyramidal, 105

Red, see Red-Cedar

Stinking, 149

White, see American Arbor-Vitae and White-Cedar

Yellow, 107

Cedrela, 151

Cedrus, 140,151

atlantica, 151

var. aurea, 151

var. glauca, 151

Cedrus, see Cedar of Lebanon

Deodara, see Deodar Cedar

effusa, see Cedar of Lebanon

Libani, see Cedar of Lebanon

patula, see Cedar of Lebanon

Cephalotaxus, 148, 150

drupacea, 148

Chamaecyparis, 92, 95, 107, 108, 131, 151

formosensis, 107

Lawsoniana, 105, 107 var. Alumii, 105

leptoclada, see $\mathrm{C}$. thyoides var. andelyensis

nootkatensis, 107

var. glauca, 106

obtusa, 98, 125

var. aurea, 100

Youngii, 101

var. breviramea, see C. obtusa var. pygmea

var. compacta, see C. obtusa var. gracilis compacta
Chamaecyparis obtusa (cont'd)

var. crispata aurea, $\mathbf{9 7}, 102$

var. filicoides, 99

var. filifera, see C. pisifera var. filifera

var, gracilis, 93, 102

aurea, 100

compacta, 98

var. lycopodioides, 100

var. magnifica, 102, 105

var. nana, 92, 103

compacta, 101

var. pygmaea, 103

pisifera, 95, 125

var. aurea, 101

var. filifera, 100

aurea, 94

pendula, 100

aurea, 99

var. plumosa, 93

albospica, 102

aurea, 94, 97

sulphurea, 96

var. pseudo-squarrosa, 92 sulphurea, 94

var. squarrosa, 92, 102, 105

var. sulphurea, 101

sphaeroidea, see $\mathbf{C}$. thyoides

var. andelyensis, see $C$. thyoides

var. andelyensis

thyoides, 106, 107, 108, 127

var. andelyensis, 105

Chin-lo-sung, 141

Ching-sung, 141

Cryptomeria, 30, 107, 155

Common, see Japanese-Cedar

japonica, 155

var. araucarioides, 156

var. pungens, 156

Cupressus, see Chamaecyparis

Cycad, 12

Cypress, 92, 107

Bald, see Bald-Cypress

Common, see Bald-Cypress

Deciduous, see Bald-Cypress

Formosan, see Chamaecyparis formosensis

Hinoki, 98, 101, 125, 108

Dwarf, 92, 93, 99-103, 105

Compact, 101

Golden, 100, 101, 103

Young's, 101, 103

Pygmy, 103

Slender, 93, 94, 99

Compact, 98, 99

Golden, 100, 103 


\section{Cypress (cont'd)}

Lawson, 105, 106

Monte zuma, 136

Nootka, see Yellow Cypress Blue, 106

Pond, 133, 136

Sawara, 93, 95, 97, 99, 100, 111. 103,125

Golden, 101

Plumed, 93; see Plumed Retinospora

Golden, 94; see Golden Plumed-Retinospora

\section{Sulphur, 101}

Veitch's, 93

Scarab, 105, 106, 107

Yellow, 107

Dake-momi, 72

Dantzic, 34

Douglas-Fir, $27,28,59.77, \mathbf{8 8}, 91$

Fir, 72, 78, 90

Alpine, 77, 79

Balsam, 79

Southern, see Fraser Fir

Bristlecone. 79

Cascade, 79

Cephalonian, see Greek Fir

Cilician, 74, 75-78, 79, 80

Douglas, see Douglas-Fir

Fraser, 79

Grand, 78, 79, 80

Great, 78

Greek, 75, 76, 79

Lowland, 78

Momi, 73, 75, 76, 79

Nikko, 72, 73, 75, 76-78, 79, 80

Noble, 75, 79

Nordmann, 74, 75, 78, 79, 80

Red, 79, 90

Silver

Weeping, 78

Tomomi, 75, 78

Veitch, 73, 76, 77, 79, 80

White, 76, 79, 80

Yellow, 90

Ginkgo, 8, 24, 153

biloba, 8, 24

var. fastigiata, see var. pyramidalis

var. pyramidalis, 12

Glyptostrobus, 133, 136, 141

Golden-Larch, 133, 141

Goyo-matsu, 15

Ground Hemlock, 147

Hackmatack, see American Larch

Hara-momi, 58
Hemlock, 81, 86

Canada, 83, 86, 87

Dwarf, 83, 86

Carolina, 86

Common, see Canada Hemlock

Ground, 147

Japanese, 83, 84, 86

Hairy-twigged, $83, \mathbf{8 4}, 86$

Sargent Weeping, 81

Siebo'd's, 83, 84, 86

Weeping, 81

Western, see Tsuga heterophylla

Hime-bara-momi, 63

Hime-komatsu, 15

Inu-gaya, 148

Ira-momi, 65

Japanese-Cedar, 30, 155

Araucarian, 156

Prickly, 156

Jo-bi-sjo, 58

Juniper, 95, 110, 122

Chinese, 110, 111, 112, 115, 117,

$118,120,122$

Conical, 112, 114, 121

Dwarf, 115

Globe, 115 117, 121

Golden, 120

Prostrate, 117

Pyramidal, 118, 120, 121

Variegated, 111, 118, 120, 121

Upright, 117

Weeping, 116, 118

White-leaf, 122

Common, 116, 140

Creeping, 118, 120

Fortune's 111, 112, 118, 122

Greek, 114, 115, 116

Horizontal, see Creeping Juniper

Meyer's, 120

Pfitzer's, 110, 112, 120

Prostrate, 120, 121

Needle-leaved, 115, 117, 118, 120

Reeves', 112

Savin, 111, 112, 115, 117, 118, 121 . 122

Tamarix, 118, 120

Waukegan, see Juniperus horizontalis

Western, 122

Juniperus, 95, 110, 122

canadensis, see $\mathbf{J}$. communis var. depressa

chinensis, 110

var. albo-variegata, see var. argenteo-variegata 
Juniperus chinensis (cont'd)

var. argenteo-variegata, 122

var. aurea, 120

var. aurea-variegata, 121

var. fastigiata, 117

var. foemina, see var.

Reevesiana

var. globosa, 115

var. nana, 115

var. neaboriensis, 121

var. pendula, 116

var. Pfitzeriana, 110

var. procumbens, 117

var. pyramidalis, 118

variegata, 118

var. Reevesiana, 112

communis, 116

var. canadensis, see $\mathbf{J}$. communis var. depressa

var. depressa, 120

excelsa, 114

var. structa, 114

horizontalis, 118, 120

var. prostrata, 118

Keteleeri, see J. virginiana var.

Keteleeri

neaboriensis, see $\mathbf{J}$. chinensis var. neaboriensis

occidentalis, 122

prostrata, see $\mathbf{J}$. horizontalis

Reevesiana, see J. chinensis var. Reevesiana

Sabina, 111

var. prostrata, 120

var, tamariscifolia, 118

sinensis, see $\mathbf{J}$. chinensis

sphaerica, 111

squamata, 115

var. Meyeri, 120

virginiana, 112

var. albospica, 116, 144

var. Cannartii, 111

var. glauca, 111

pendula, 121

var. globosa, 117

var. Keteleeri, 117

var. nana pendula, 121

var. pendula

glauca, 121

var. plumosa argentea, 115

var. pyramidalis, 120

var. Schottii, 116

var. tripartita, 114

Kaya, 149

Komi-tsuga, 84
Koya-maki, 153

Kuro-matsu, 30

Kuro-tsuga, 84

Larch, 133, 138, 139, 141

American, 140

Chinese Golden, see Golden-Larch

Dunkeld, 139

European, 138, 139

Golden, see Golden-Larch

Japanese, 138, 139

Larix, 133, 138, 139

americana, see $L$. laricina

decidua, see L. Larix

eurolepis, 139

europaea, see L. Larix

Griffithii, 140

Henryana, see L. eurolepis hybrida, see L. eurolepis japonica, see L. leptolepis Kaempferi, 138

laricina, 140

Larix, 138, 139

leptolepis, 139

microcarpa, see L. laricina

occidentalis, 140

Maidenhair-Tree, 8, 24

Columnar, 12

Pai-koo-sung, 24

$P a-K w o, 11$

Picea, 58, 68

Abies, 66, 68

var. aurea, 68

var. Barryi, 67

var. columnaris, see var. pyramidalis

var. compacta, 65

var. Cranstonii, 67

var. finedonensis, 66

var. Gregoryana, 65,68

var. inversa, 67

var. Maxwellii, see P. Maxwellii

var. pendula, 67

var. pyramidalis, 67

var. ruba, 67

ajanensis, see $\mathbf{P}$. jezoensis

alba, see $\mathbf{P}$. canadensis

Alcockiana, see $\mathbf{P}$. bicolor

australis, see $P$. rubra

bicolor, 65

breifolia, see $P$. mariana

Brezeriana, 68

canadensis, 65,68

var. coerulea, 66

columbiana, see P. Engelmannii

Engelmannii, 62, 68

var. glauca, 62 
Picea (cont'd)

excelsa, 66

glauca, see $\mathbf{P}$. canadensis

Gregoryana, see P. Abies var

Gregoryana

jezoensis, 64

laxa, see $\mathbf{P}$. canadensis

mariana, 68

var. Doumetii, 64

Maxwellii, 68

Maximowiczii, 63

nigra, see $P$. mariana

obovata

var. Schrenkiana, see

P. Schrenkiana

Omorika, 60

orientalis, 63

Parryana, see $\mathbf{P}$. pungens

Picea, see P. Abies

polita, 58

pseudo-pungens, see P. Engelmannii

pungens, 61, 68

var. argentea, see $\mathbf{P}$. pungens var. glauca

var. coerulea, see $\mathbf{P}$. pungens var. glauca

var. glauca, 59

compacta, 62

Kosteri, see $\mathbf{P}$. pungens var.

Kosteri

pendula, 61

var. Kosteri, 59

var. Kosteriana, see $\mathbf{P}$. pungens var. Kosteri

var. viridis, see $\mathbf{P}$. pungens

rubens, see $P$. rubra

rubra, 68

Schrenkiana, 66

sitchensis, 68

Thunbergii, see $\mathbf{P}$. polita

Torana, see $\mathbf{P}$. polita

Tschonoskii, see P. Maximowiczii

Pine, 13, 51, 90

Alpine, 13

Arizona, 52

Arolla, 13

Austrian, 27, 31, 32, 33, 39, 40, 41, $44,47,50,53,55,56$

Banks', see Jack Pine

Banksian, see Jack Pine

Bhotan, see Himalayan WhitePine

Bhutan, see Himalayan WhitePine
Pine (cont'd)

Black, see Austrian Pine; 28, 32, 36,38

Blackbark, 32

Bristle-cone, 47, 52

Bull, 28, 32, 35

Canary, 54

Chattahoochee, 149

Chihuahua, 52

China, 30, 53

Coulter, 52

Crimean, 27, 31, 34, 44

Cuban, 52, 55, 56

Digger, 35, 53

Foxtail, 47, 52

Golden, 141

Gray, see Jack Pine; 35, 52

Gray-leaf, 35

Hard, 38, 41, 52

Heavy, 28

Hickory, 42

Jack, 24, 36, 39, 40, 41, 43, 52, 53, 140

Japanese

Black, 16, 28, 34, 39, 43, 53, 56, 63

Red, 24, 30, 31, 34, 53, 56, 63, 155

Umbrella, 23, 30; see Umbrella. Pine

White, 15, 26, 39, 48, 53, 63

Jeffrey, 27, 32, 35, 53

Jersey, 32, 39, 52, 53

Khasia, 56

Knee, 44

Knobcone, 52

Korean, 14, 41, 42, 43, 44, 46, 47, 50,53

Lace-Bark, 23

Limber, 46, 48, 52, 53

Loblolly, 52, 54, 56

Lodgepole, 35, 52

Longleaf, $38,52,54,56$

Long-leaved Indian, 56

Longschat, 38

Macedonian, 14, 16, 48, 50, 53

Maritime, 31, 140

Monterey, 52

Montezuma, 56

Mugho, 44, 54, 55

Murray, 36

Nozway, 40, 52

Black, 38

Nut, 35, 50

Old-Field, see Loblolly Pine

Oregon, 90 


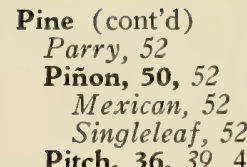

Pitch, 36, 39, 40, 43, 52, 53, $55,135,155$

Pond, 38, 52, 55

Poverty, 42

Prickly, 36, 42

Puget Sound, 90

Red, 36, 40, 52, 53, 54, 155

Canadian, 41

Japanese, 24

Redbark, 32

Sabines', 35

Sand, 52

Sapwood, 32

Scotch, 24, 31, 33, 39-41, 43, 44, $46,53,54,55,56$

Pyramidal, 48

Silvery, 41, 48

Scots, 33

Scrub, 36, 38, 39, 52, 53, 55

Shortleaf, 52, 56

Sierra Brownbark, 28

Singleleaf, 52

Slash, see Cuban Pine

Soft, 52

Southern Mountain, 42

Spruce, 36, 52

Stone,

Italian, 54

Swiss, 13, 15, 16, 42, 47, 48, 50, 53,55

Sugar, 28, 52, 55, 56

Swamp, see Cuban Pine California, 52

Table-Mountain, 42, 52, 53

Tamarack, 36

Tamrac, 36

Thunberg, 28

Truckee, 32

Torch, 38

Torrey, 52

Umbrella, 153

Japanese, 23

Waterer, 47

Weymouth, see Eastern WhitePine, 19

White

California, 28

Columnar, 21

Eastern, 15, 17, 26, 38, 41, 46, $48,52,53,54,55,56$

Himalayan, 16, $48,50,53,56$
Pine, White (cont'd)

Japanese, 15, 26

Mexican, 52,56

Western, 52, 56

Whitebark, 23, 52, 53

Yellow, 38

Southern, 27, 28, 56, 88

Western, 27, 32, 35, 39, 52, 53, 55,56

Pinus, 13, 51

Abies, see Picea Abies

albicaulis, 23, 47, 52

aristata, 47,52

arisonica, 52, 56

attenuata, 52

austriaca, see $\mathbf{P}$. nigra

Ayacahuite, 56

Balfouriana, 47, 52

Banksiana, 24, 52, 140

Benthamiana, see $\mathbf{P}$. ponderosa

Boursieri, see P. Murrayana

Bungeana, 23

canariensis, 54

caribaea, 52, 55

Cembra, 13, 47

var. pumila, 13

cembroides, 52

var. edulis, see $\mathbf{P}$. edulis

var. monophylla, see $P$. monophylla

chinensis, see $\mathbf{P}$. sinensis

clausa, 52

contorta, 36, 52, 55

var. Murrayana, seeP. Murrayana

Coulteri, 52

densiflora, 24, 155

var. umbraculifera, 23

divaricata, see P. Banksiana

echinata, 52

edulis, 50,52

Elliottii, see $P$. caribaea

excelsa, 16

var. Peuce, see P. Peuce

flexilis, 46,52

funebris, see P. sinensis

glabra, 52

Griffithii, see $\mathbf{P}$. excelsa

Henryi, see $\mathbf{P}$. sinensis

heterophylla, see $P$. caribaea

inops, see $\mathbf{P}$. virginiana

var. clausa, see $P$. clausa insularis, 56

Jeff reyi, 32

Kaempferi, see Pseudolarix Kaempferi 


\section{Pinus (cont'd)}

koraiensis, 42, 47

Lambertiana, 28, 52

Laricio, see P. nigra

leucosperma, see $\mathbf{P}$. sinensis longifolia, 56

mandshurica, see $\mathbf{P}$. koraiensis maritima, see $P$. Pinaster

mitis, see $P$. echinata

monophylla, 52

montana

var. Mughus, 44

Montezumae, 56

monticola, 52

Mughus, see P. montana var. Mughus

Mugo, see P. montana var. Mughus

muricata, 52

Murrayana, 35

nepalensis, 16

nigra, 31

var. Pallasiana, 27

Omorika, see Picea Omorika

Pallasiana, see $\mathbf{P}$. nigra var. Pallasiana

palustris, 38,52

parviflora, 16, 26 var. pentaphylla, 15, 16, 26 pentaphylla, see $\mathbf{P}$. parviflora var. pentaphylla

Peuce, 14

Pinaster. 31

Pinea, 54

ponderosa, 27,52

var. Jeffreyi, see P. Jeffreyi pumila, 47

pungens, 42, 52

quadrifolia, 52

radiata, 52

resinosa, 40, 52

rigida, 36, 52, 135

Sabiniana, 35, 52

serotina, $38,52,55$

sinensis, 30

strobiformis, 52

Strobus, 17, 52

var. fastigiata, 21

var. pyramidalis, 21

sylvestris, 33

var. argentea, 41

var. fastigiata, 48

var. pyramidalis, see var.

fastigiata

var. Watereri, 47

Taeda, 52
Pinus (cont'd)

tabuliformis, see $\mathbf{P}$. sinensis

Thunbergii, 28

Torrevana, 52

Virginiana, 38, 39, 52

Wateriana, see $\mathbf{P}$. sylvestris var. Watereri

Wilsonii, see $\mathbf{P}$. sinensis

Plum-Yew, 147, 148, 150

Japanese, 148, 149

Pseudolarix, 133

amabilis, see P. Kaempferi

Fortunei, see P. Kaempferi

Kaempferi, 141

Pseudotsuga, 88, 91

Douglasii, see P. mucronata

macrocarpa, 91

mucronata, 88

taxifolia, 88

Red-Cedar, 27, 28, 32, 112, 117, 121, $122,139,144,151$

Cannart's, 111, 112

Fountain, 114

Globe, 117

Keteleer's, 117

Pyramidal, 120

Schott's, 116, 117, 121

Silver, 111, 112, 114, 115, 121, 122 Weeping, 121

Silver-spotted, 115, 117

White-tipped, 116

Redrwood, 38, 135, 136

Retinospora, 92, 95

Andely, see Andelyan White-

Cedar

Clubmoss, 100

Fernspray, 99, 101, 103

leptoclada, see Moss Retinospora \& Andely Retinospora

Moss, 92, 94, 97, 101, 102

Sulphur-colored, 94, 103

Plumed, 93, 95-97, 101-103, 105 Golden, 94, 96, 97, 99, 100, 103

Sulphur-colored, 96, 98-103

White-tipped, 102

Thread, 100-105

Golden, 94, 97, 99-103, 105

Golden Weeping, 99

Weeping, 100, 102, 105

Riga, 34

Sabina, see Juniperus Sabina

Salisburia adiantifolia, see Ginkgo biloba

Savin, 112

Sciadopitys, 125, 153

verticillata, 153 
Shira-tsuga, 73

Shirabe-momi, 73

Shirabiso, 73

Siro-momi, 58

Spruce, 58, 68, 90

Alcock's, 65, 70

Barry, 67

Black, 64, 68

Blue

Colorado, 59, 61, 62

Compact, 62

Weeping, 61

Koster's, 59, 62

Bog, 65

Brewer's Weeping, 71

Cat, 65

Colorado, 61, 62, 68, 70, 71, 88

Double, 65

Douglas, see Douglas-Fir

Doumet's, 64

Engelmann, 62, 68, 70

Blue, 62

Finedon, 66

Gregory, 68

Hemlock, see Hemlock

Hondo, 64

Iramomi, see Alcock Spruce

Japanese-Bush, 63, 70

Maximowicz's, 63, 70

Maxwell's, 68

Norway, 64, 66, 70, 90

Golden, 68

Pyramidal, 67

Red, 67

Weeping, 67

Oriental, 63, 64, 70, 71

Parry's, 61

Prickly, 61

Red, 68

Schrenk's, 66, 70

Serbian, 60, 64, 70

Silver, 61

Single, 65

Sitka, 68

Skunk, 65

Tigertail, 58, 63, 70

Weeping, 68, 71

White, 61, 65, 68, 70

Blue, 66,68

Yezo, 64, 70

Sugi, 156

Tamarack, see American Larch

Tanyosho, 23

Taxodium, 133

adscendens, see $T$. ascendens ascendens, 133
Taxodium (cont'd)

distichum, 133

var. erectifrons, see $\mathbf{T}$. ascendens

var. imbricarium see $\mathbf{T}$. ascendens

var. mexicanum see $T$. mexicanum

var. microphyllum see $\mathbf{T}$. ascendens

var. mucronatum, see $T$. mucronatum

imbricarium, see $T$. ascendens

mexicanum, see $T$. mucronatum

microphyllum, see $T$. ascendens

mucronatum, 136

Taxus, 142, 147, 150

baccata, 144, 146

var. adpressa, 146

var. argentea, see

var. variegata

var. aurea, 142, 145, 147

var. canadensis, see $T$. canadensis

var. cuspidata, see $\mathbf{T}$. cuspidata

var. Dovastoni, 146

var. fastigiata, 143, 145 aurea, 144

var. hibernica, see $\mathbf{T}$. baccata var. fastigiata

var. Jacksonii, 145

var. minor, see $T$. canadensis

var. procumbens, 145

var. repandens, 142, 143, 145

var. tardiva, see $\mathbf{T}$. baccata var. adpressa

var. variegata, $143,144,145,146$

brevifolia, 147; see T. cuspidata

var, nana

canadensis, 147

cuspidata, 144, 145, 146, 147

var. brevifolia, see $\mathbf{T}$. cuspidata var. nana

var. compacta, see $\mathbf{T}$. cuspidata var. nana

var, densa, 143

var. Hicksii, 145

var. nana, 143, 144, 145, 146

var. pyramidalis, 142

floridana, 147

Hicksii, see T. cuspidata var. Hicksii

minor, see $T$. canadensis

parvifolia, see $T$. baccata, var. adpressa 
Taxus (cont'd)

tardiva, see $\mathbf{T}$. baccata var. adpressa

Thuja, 95, 124, 108, 131

caucasica, see $\mathbf{T}$. occidentalis var. Wareana

gigantea, see $\mathbf{T}$. plicata var. atrovirens, see $T$. plicata var. atrovirens

japonica, see T. Standishii

koraiensis, 131

Lobbi, see T. plicata

Menziesii, see $\mathbf{T}$. plicata

occidentalis, 125

var. alba, 129

var. albo-spica, see var. alba

var. aureo-variegata, 128

var. Booth's Dwarf, 131

var. columnaris, see var. pyramidalis

var. Douglasii, see var. filiformis pyramidalis, 130

var. elegantissima, 129

var. fastigiata, see var. pyramidalis

var. filif ormis, 131

var. George Peabody, see var. Golden Peabody

var. globosa, 124, 130 nova, 130

var. Golden Peabody, 129

var. Little Gem, 130

var. lutea, 129

var. nana, 130

var. Ohlendorffi, see $\mathbf{T}$. occidentalis var. Spaethii

var. pumila, 130

var. pyramidalis, 125

var. Queen Victoria, see

T. occidentalis var. alba

var. recurvata, 127

var. Rosenthali, 130

var. sempervirens, 130

var. Spaethii, 128

var. spiralis, 129

var. Wareana, 128

orientalis, 124

var. aurea, 125

plicata, 128

var. atrovirens, 129

setchuensis, 131

sibirica, see $T$. occidentalis var.

Wareana

Standishii, 125

Wareana, see $\mathbf{T}$. occidentalis var. Wareana
Tome-Ki, 125

Toranoo-momi, 58

Torreya, 147, 148, 149

californica, see Tumion californicum

Japanese, 149

nucifera, see Tumion nuciferum, 149

taxifolia, see Tumion taxifolium

Tsuga, 81, 86

americana, see $\mathbf{T}$. canadensis

canadensis, $\mathbf{8 3}, 86$

var. compacta, 83

var. pendula, 81

var. Sargentiana, see $\mathbf{T}$. canadensis var. pendula

caroliniana, 86

diversif olia, 84, 86

heterophylla, 86

Mertensiana, 86

Sieboldii, 83

Tsuga, 83, 84, 86

Tumion, 149

californicum, 149

grande, 149

nuciferum, 149

taxifolium, 149

Umbrella Pine, 125, 153

White Cedar, 106, 107, 151

Andelyan, 105

Coast, 106, 107

Northern, 106, 127, see American Arbor-Vitae

Southern, 106, 127, see Coast White-Cedar

Yew, 142, 147, 150

American, see Canada Yew

Canada, 147

Common, see English Yew

Dovaston, 146

English, 144, 146

Golden, 142, 143, 145, 147

Prostrate, 145

Spreading, 142, 143

Variegated, 142, 143, 144-146

Weeping, 145, 146

Florida, 147

Hicks', 145

Irish, 143, 145

Golden, 144

Jackson, see Weeping English- Yew

Japanese, 144, 145, 146, 147

Dwarf, 143, 144-146

Pyramidal, 142

Plum, 148

Western, 147 

THE WILSON PRESS, INC. NEW YORK CITY 



